\title{
La mousson, pluie des agriculteurs et vent des marins
}

The monsoon, rains for the small farmers, winds for the sailors

\section{Françoise Aubaile-Sallenave}

\section{(2) OpenEdition}

1 Journals

\section{Édition électronique}

URL : http://journals.openedition.org/ethnoecologie/1834

DOI : 10.4000/ethnoecologie.1834

ISSN : 2267-2419

\section{Éditeur}

Laboratoire Eco-anthropologie et Ethnobiologie

\section{Référence électronique}

Françoise Aubaile-Sallenave, « La mousson, pluie des agriculteurs et vent des marins », Revue d'ethnoécologie [En ligne], 5 | 2014, mis en ligne le 30 juin 2014, consulté le 21 décembre 2020. URL http://journals.openedition.org/ethnoecologie/1834; DOI : https://doi.org/10.4000/ethnoecologie. 1834

Ce document a été généré automatiquement le 21 décembre 2020.

\section{(c) $(1) \Theta \Theta$}

Revue d'ethnoécologie est mis à disposition selon les termes de la licence Creative Commons Attribution - Pas d'Utilisation Commerciale - Pas de Modification 4.0 International. 


\title{
La mousson, pluie des agriculteurs et vent des marins
}

The monsoon, rains for the small farmers, winds for the sailors

\author{
Françoise Aubaile-Sallenave
}

1 Parler de la mousson, c'est parler d'un vent saisonnier revenant régulièrement chaque année, c'est parler de pays heureux de recevoir la pluie bienfaisante qui s'y déverse parfois en trombe, c'est parler d'une saison, c'est parler de bateaux et de voyages, de courants marins allant de la côte orientale de l'Afrique aux mers de Chine et du Japon et entraînant les hommes vers des contrées lointaines et nouvelles, c'est parler d'Orient et d'Extrême-Orient, d'aventures et de découvertes.

2 La mousson, pour nous, ce sont d'abord les pluies torrentielles s'abattant sur l'Inde évoquées par le roman de l'anglais Bloomfield La mousson, mais ce mot a son histoire propre qui nous mène vers l'Arabie.

3 Dans l'océan Indien, la mousson se confond, pour les Européens, avec la découverte du monde. Cette zone, liée à la quête des épices, connaît, depuis plus de deux mille ans, des mouvements intenses mettant en contact des populations très diverses aux activités variées et échangeant des produits de commerce et des vivres.

4 Enfin cette route des Moussons a été l'alternative à la route intérieure dite de la Soie, de beaucoup plus ancienne, qui traverse l'Asie centrale.

\section{Histoire du mot}

5 Le français mousson est emprunté au portugais ancien moução, qui est lui-même un emprunt à l'arabe maûsim ${ }^{1}$. C'est ce qu'il ressort de la relation al-mohit de l'amiral turc Sidi 'Alî çelebi (1554) (Hammer 1834: 548), qui nous enseigne comment les pilotes de l'océan Indien, ses contemporains, [c'est à dire arabes, turcs, persans et vraisemblablement portugais] connaissaient précisément les époques de la mousson qui déterminent les dates de départ dans chaque port. Au Yémen, c'est la saison de la 
navigation. Pour les marins de l'océan Indien, c'est l'époque où l'on navigue d'un port à l'autre. Il ne s'agit donc pas d'une période ou d'un vent particuliers, comme pour nous, mais c'est la date de navigation donnée d'après le port de départ, par exemple mâusim alZafâri, mousson du Dhofâr. Dans cette optique, la mousson du sud-ouest qui empêche la navigation est appelée ghalq « fermeture ».

L'arabe mûsim $^{2}$ désigne également la saison principale et par extension une périodicité annuelle ; c'est celle du pèlerinage à La Mekke, la saison de la foire ; en Afrique du nord, ce sont les fêtes religieuses moussem (pluriel mawâsim), et sur les côtes de l'Arabie, la saison des vents favorables à la navigation vers l'Afrique ou l'Inde. Le terme appartient au vocabulaire des Bédouins d'Arabie où wasmî désigne « les premières pluies de printemps, les premiers germes après les pluies printanières "; le verbe à la cinquième forme signifie «chercher les premiers pâturages du printemps, paître sur un sol qui commence à se couvrir de végétation ». À Beirût, mausim est utilisé pour tout ce qui revient une fois par an, comme les fêtes. Au Liban, jusqu'au début du xx siècle, mausim désigne la saison la plus importante, celle pendant laquelle on travaille la soie.

\section{Qu'est-ce que la mousson et où souffle-t-elle?}

\section{Carte 1 : Les lieux cités}

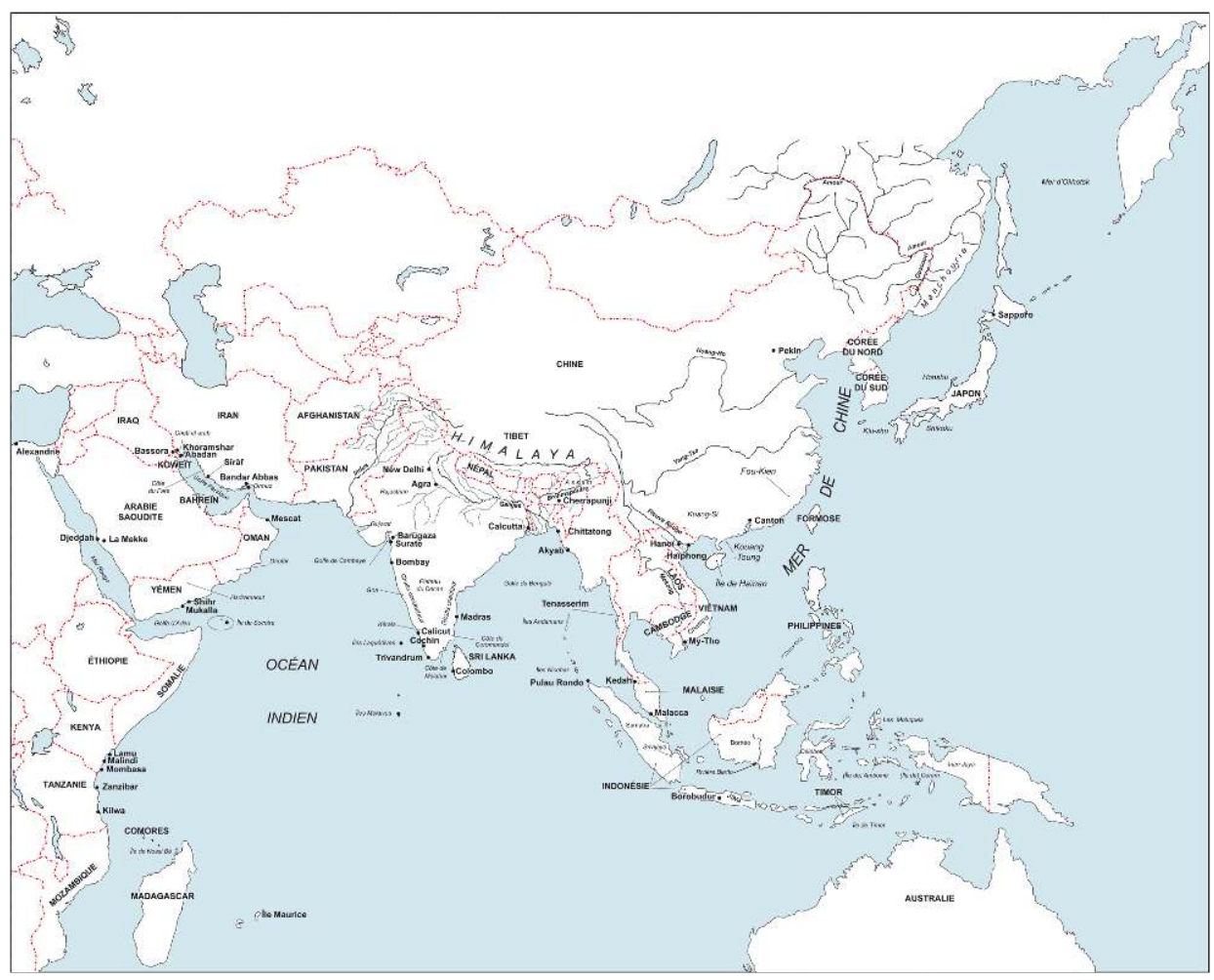

Carte établie et réalisée par F. Aubaile et L. Venot

Ce terme désigne des vents soufflant alternativement dans l'année, en été, d'avril à octobre, du sud-ouest et venant de la mer, ils sont alors chauds et humides; en hiver, de novembre à mars, ils soufflent du nord-est depuis l'intérieur des terres, ils sont alors froids et secs. Ils provoquent donc, dans les zones tropicales et équatoriales du continent asiatique, deux principales saisons de climat contrasté. La mousson d'été apporte la pluie 
et c'est elle qu'attendent les paysans d'Asie du sud-est, qui leur permettra de bonnes récoltes. Sur les côtes orientales de l'Inde, de l'Asie du sud-est et jusqu'en mer de Chine, la mousson d'été se transforme souvent en vents très violents et tourbillonnants, les typhons (terme chinois), occasionnant des pluies considérables et des inondations catastrophiques dans les terres basses comme celles du delta du Gange au Pakistan Oriental, du fleuve Rouge au Nord-Viêtnam et des fleuves de Chine.

Ces vents résultent des pressions créées par les différences entre la température de la mer et celle de la terre. Au dessus des continents, l'air voisin du sol est relativement froid en hiver et chaud en été. Dans le premier cas, l'excès de densité de cet air tend à créer un anticyclone froid. C'est ainsi qu'en hiver un puissant anticyclone thermique existe à peu près en permanence sur le nord-est de l'Asie, d'où résultent sur les côtes méridionales et orientales de ce continent des vents très froids et très secs soufflant d'entre nord et nordest et constituant la mousson d'hiver. En été, c'est au contraire une vaste dépression thermique qui s'établit sur l'Asie et alors la mousson froide est remplacée par des vents chauds et humides du sud à sud-ouest soufflant vers cette dépression et constituant la mousson d'été (Queney 1959 : 290-291).

La mousson d'été qui souffle du sud-ouest atteint même l'Asie centrale chinoise en étendant l'influence de la mer loin dans l'intérieur jusqu'aux régions de l'Oussouri, de l'Amour, de la Mandchourie, d'une partie du Japon et de la Corée, faisant monter jusqu'au $43^{\circ}$ de latitude nord les masses d'air chaud et humide. Si, dans ces régions, les hivers sont, sous l'influence de la mousson, rigoureux, froids et secs, les étés, par contre, sont imprégnés d'une moiteur tropicale, à l'arrivée des pluies. «La végétation, latente depuis des mois, est saisie d'une frénésie de croissance", selon Pfeiffer ([s.d.] : 52). Chine, Corée et Japon possèdent une végétation très riche et variée où les espèces tempérées se mêlent aux espèces tropicales.

En outre, le fait que l'été tropical, normal dans les régions situées de part et d'autres de l'équateur jusqu'aux $13^{\circ}-15^{\circ}$, agisse jusqu'au $40^{\circ}$ (Pékin) ou même $43^{\circ}$ de latitude nord (Sapporo), est un phénomène d'une exceptionnelle importance; sa principale conséquence est la disparition, dans cette partie de l'Asie, de la barrière de déserts qui, ailleurs, sépare pays tropicaux et pays tempérés (Delvert $1968: 563$ )... Calcutta et Hanoï sont sous le Tropique à la latitude du Sahara central et reçoivent respectivement 1600 $\mathrm{mm}$ et $1700 \mathrm{~mm}$ de pluie. Ceci est également la conséquence de la mousson.

11 Toutefois les reliefs, chaînes montagneuses et hauts plateaux, nuancent l'influence des moussons et leur font obstacle, ce qui donne à chaque région son caractère. Une moitié du sous-continent indien, toute la Chine du sud reçoivent $1000 \mathrm{~mm}$. L'Asie du sud-est et les trois îles du Japon, Kiu-shu, Shikoku et Honshu, reçoivent plus de $1400 \mathrm{~mm}$ (Delvert 1968 : 559). Dans la péninsule indochinoise, lorsqu'en novembre le Centre-Viêtnam est submergé par les pluies, le centre Laos, de l'autre coté de la haute Chaîne annamitique, reste sec (Condominas $1953: 514$ ).

12 L'Indonésie prise entre l'Australie et le continent asiatique subit différemment les moussons ; à l'ouest, à Sumatra, Java, Bornéo, Célèbes, les pluies tombent d'octobrenovembre à avril avec des vents du sud-est alors que de décembre à mars soufflent des vents du nord-ouest provoquant la sécheresse. À l'est, aux Moluques et en Irian Jaya (moitié occidentale de la Nouvelle Guinée), la situation est totalement inverse, les pluies tombent de mai à octobre-décembre venant du nord-est alors que de décembre à avril souffle un vent sec du sud-est venant d'Australie. 
13 L'énorme masse de l'Inde insulaire est moins touchée par la mousson d'été chaude et humide favorable à la végétation et l'agriculture. En effet, bien que soumis à deux régimes de vents réguliers, ce pays se trouve dans une situation particulière avec le haut massif de l'Himalaya qui commande une orographie et un régime spécial des pluies. Celles-ci sont très inégalement réparties sur la péninsule ; au nord-est, les collines de l'Assam sont très abondamment arrosées, $12 \mathrm{~m}$ à Tcherrapoundji, $16 \mathrm{~m}$ dans la haute vallée du Brahmapoutre ce qui provoque parfois des inondations catastrophiques dans les terres basses du delta du Gange au Pakistan Oriental. Alors que, dans la province de Madras, en pays tamoul, les monts des Ghats à l'ouest empêche l'action bénéfique de la mousson d'été et que le pays souffre de la sécheresse (Dumont 1957 : 84), à l'ouest, les chutes d'eau dépassent $5 \mathrm{~m}$ à Mahabaleswar (Ghats occidentaux) ou à Akyab (Arakan Yoma); cette côte reçoit de plein fouet le choc de la mousson du sud-ouest de juin à septembre faisant bénéficier l'agriculture de ces régions des pluies qui l'accompagnent. Ces pluies commencent brutalement et il y a le plus souvent un contraste pluviométrique énorme entre mai et juin. C'est le burst of the monsoon. Cet éclatement se produit à date assez fixe avec peu de variations : vers le 1er juin, sur la côte orientale (à Cochin et Trivandrum), vers le 5 juin à Bombay, vers le 15 juin au Rajasthan, vers le 25 juin à Agra et vers le 2 juillet à Delhi. À l'inverse, «sur la côte de Coromandel, l'été est assez sec et les pluies n'arrivent qu'en octobre ou novembre avant la mousson d'hiver », le nord-ouest est quasiment désertique et le cœur du Deccan reçoit moins de $1000 \mathrm{~mm}$ (Delvert 1968 : 573).

Ajoutons que la mousson diffère des alizés qui sont des vents soufflant toute l'année dans la même direction, dans la zone comprise entre les tropiques et l'équateur; ainsi dans l'océan Atlantique nord, ils soufflent dans le sens est-ouest et, dans la zone sud, ils soufflent dans le sens contraire ouest-est.

\section{Les pays soumis à la mousson. Son influence sur la végétation et les sociétés}

15 Ces vents soufflent dans une zone très large, principalement comprise dans l'hémisphère nord et qui concerne pratiquement toutes les côtes que borde l'océan Indien, depuis l'Afrique orientale jusqu'à l'Insulinde et l'ouest de l'océan Pacifique, des Célèbes jusqu'à la mer d'Okhotsk. Ces régions qui vont de l'Inde à l'Extrême-Orient forment ce que le géographe Jules Sion a nommé en 1928 « l'Asie des Moussons ».

\section{L'Asie des moussons}

16 C'est là, dans cette Asie des Moussons, que se sont développées anciennement de grandes civilisations basées sur la culture du riz, céréale dont on fait souvent deux récoltes par an et parfois trois récoltes, ce qui permet de fortes concentrations de population en plaine. Dans ces contrées purement rurales, des densités égales à celles des régions industrielles de l'Europe sont fréquemment atteintes. L'Asie des moussons nourrit plus de la moitié de l'humanité.

17 En effet, les vents de la mousson provoquent deux principales saisons de climat contrasté et la durée de la saison sèche est un élément essentiel pour la végétation, dans ces pays tropicaux, du fait de l'accumulation de réserves dans les graines ou tubercules. La biologie du riz inondé est adaptée à la mousson chaude et humide d'été ; pour Georges 
Condominas (1953: 537), la rizière irriguée est «la technique la plus perfectionnée d'exploitation du sol en climat de mousson ». Dans la presqu'île indochinoise et la Chine du sud, les rizières s'étalent dans les plaines. Mais dans l'Asie insulindienne, les zones d'influence de la mousson coïncident souvent avec des terres volcaniques, où « l'altération des roches éruptives jointe à l'humidité produit des sols très fertiles. C'est le cas des traps basaltiques du Dekkan transformés en un sol noir qui est une excellente terre à coton" (Termier 1959: 1484-5). C'est aussi le cas des îles de l'Insulinde, Philippines, Java, Sumatra, où l'homme a aménagé les pentes parfois très fortes de ces régions montagneuses, étageant ses rizières en de multiples terrasses parfois très étroites et créant des paysages somptueux de miroirs vert et bleu.

18 Toute cette Asie du sud-est, de climat tropical, était, jusqu'à il y a peu, couverte de forêts très riches en essences variées mêlant les espèces tropicales et les espèces tempérées.

\section{La mousson règle la vie du paysan}

19 Chez les Santals du delta du Gange, le calendrier de la riziculture est étroitement lié aux pluies de la mousson d'été. Dès le début des pluies, dans le courant du mois de mai, commence la réfection des diguettes des rizières qui avaient été détériorées pendant la saison sèche; cette tâche conditionne la bonne culture du riz inondé. C'est le travail des hommes de réparer les brèches pour que l'eau reste dans le champ et de surveiller son niveau jusqu'à la fin septembre où a lieu la fête de la déesse Durga et la moisson.

20 Après la réfection des diguettes, les hommes accomplissent plusieurs labours dont le dernier se passe en juillet début août, dans une terre saturée d'eau par les pluies de la mousson. Un peu avant, à la mi-juin, au cours des pluies qui précèdent la mousson, les femmes ont mis en terre les semences dans un sol humide mais non submergé. Un mois et demi à deux mois plus tard, le sol est recouvert d'eau et les plants y baignent ; c'est alors qu'on les arrache pour les repiquer. Les travailleuses pataugent dans la boue mais l'on accepte joyeusement ce désagrément car l'on sait que de lui dépend la nourriture des mois suivants. Tout de suite après a lieu le repiquage dans le champ inondé. Le travail se fait souvent sous de fortes averses et avec un grand vent qui incline les feuilles. Pendant plusieurs jours, les femmes accomplissent ce dur labeur qui débute à 6 heures du matin et se termine à 6 heures du soir, interrompu par deux repas pris au bord de la rizière. Le signal d'arrêt est le chant des grenouilles qui, à la chute du jour, s'élève sur les rizières. C'est alors une immense clameur de joie de la part des femmes.

21 À la fin de septembre, le riz est en épis et on laisse se résorber l'eau des rizières. Cela correspond aussi à la fin de la saison des pluies. C'est alors que l'on moissonne généralement en terrain sec et qu'ont lieu les travaux de dépiquage et d'engrangement des grains (Martel 1965). Alors débute également la saison des fêtes et des mariages.

\section{Croyances et fêtes liées à la mousson d'été chaude et humide}

22 Les croyances montrent une image négative de la mousson. L'arrivée de la mousson d'été, chaude et humide, au $5^{\text {ème }}$ mois (juillet), signale souvent l'arrivée des maladies liées à l'eau, malaria, typhus, choléra et d'inondations souvent désastreuses. Aussi, dans les pays de l'Asie du sud-est, Viêtnam, Chine, Japon et Corée, pratique-t-on au $5^{\text {ème }}$ jour du $5^{\text {ème }}$ mois toute une série de rituels destinés à se protéger contre ces divers maux : on suspend, dans la maison, des bouquets d'armoise dont l'odeur fera fuir les microbes, on fait claquer 
des pétards qui effrayeront les mauvais génies ; au Viêtnam, on brûle des papiers votifs et des mannequins qui se substituent à la personne sur laquelle les génies de la mort avaient déjà mis leur marque ; partout, on achète et on prépare des médicaments et des amulettes .... Cette fête correspond à l'ancienne célébration du solstice d'été.

En Inde, cette mousson d'été est «conçue, à l'échelle cosmique, comme une désintégration $\mathrm{du}$ monde où les démons l'emportent sur les dieux » qui s'absentent pendant cette période (Gaborieau 1982: 16). Ces pluies marquent une coupure dans le cycle annuel : c'est celle des quatre mois (de juillet à octobre). Ce sont des mois néfastes et de mauvais augure. Les filles mariées se doivent de visiter leurs parents avant la mousson qui pourrait leur être fatale. Durant les deux premiers mois, on ne doit pas se baigner dans les rivières considérées comme impures et dangereuses. Durant cette période, ne peut avoir lieu aucune cérémonie de bon augure, initiation, mariage, cultes de prospérité et de protection du village et du lignage. La période est au contraire obscure et dangereuse, affectée par des bouleversements profonds dans la vie des dieux et des hommes, où se manifestent une rupture des activités ordinaires, des désordres et renversements sociaux; au Népal, les basses castes se font arrogantes, les femmes contestent l'autorité du mari et de la belle-mère, l'autorité royale est remise en question au cours des fêtes de Dasai et Divali à la suite de quoi reviennent progressivement une remise en ordre de la société et un retour des dieux. C'est cependant une période où hommes et dieux communiquent par de nombreuses fêtes, les plus nombreuses de l'année. "Ces quatre mois qui couvrent la saison des pluies et de l'automne sont positivement sous le signe de Shiva, dieu de la création et de la destruction; mais négativement, ils sont endeuillés par l'absence de Vishnu qui s'en est allé dormir aux enfers » (Gaborieau 1982 : 19).

Ils débutent par la fête de nâga pañcamî, le $5^{\text {ème }}$ jour de Shrâvana [juillet] ${ }^{3}$ qui est dédiée aux serpents maîtres du sol et de la pluie ; le $15^{\text {ème }}$ jour, à la pleine lune Shrâvana purninâ, voit un retour partiel des dieux sur la terre et une purification des hommes initiés des trois classes supérieures, Brahmanes prêtres et savants, Kshatrya rois et guerriers et Vaisya marchands et agriculteurs. Cette fête est aussi particulière aux Brahmanes. Dasai est la fête des Kshatrya en Asvina [septembre] et Devali est la fête des Vaisya en Kartika [octobre]. Au Népal, cette dernière fête marque la victoire des dieux sur les démons et la réinstauration de l'ordre social. Elle écarte définitivement le spectre des démons et de la mort, assure la prospérité de la famille, de l'entreprise commerciale ou de l'exploitation agricole. C'est aussi la fin des pluies de mousson et le début de la longue période de huit mois où reprennent les activités ordinaires et les fêtes collectives de prospérité et de protection (Gaborieau 1982).

\section{L'Asie occidentale semi-désertique}

25 À cette Asie des moussons, riche en forêts et cultures irriguées, surpeuplée dans les deltas, s'oppose la partie occidentale du continent asiatique, semi-désertique et souvent désertique et très peu peuplée. Ce n'est pas que la mousson d'été n'intervienne pas, mais ces vents sont chauds et secs car ils arrivent du continent africain tout proche. Le relief, cependant, nuance leur influence. Ainsi dans les montagnes du sud-est de l'Afghanistan, sur les versants exposés à la mousson de sud-ouest, croît une forêt de type tropical où s'associent chênes et conifères de l'Himalaya, pins, sapins et cèdres déodar (Delvert 1968 : 563-5). De même, les vents qui atteignent l'Oman, sont chauds et humides parce qu'ils 
viennent de traverser l'océan Indien. C'est ainsi qu'au Dhofâr, de juin à mi-septembre, pendant le kharîf ou mousson de sud-ouest, les versants exposés au sud sont recouverts de nuages chargés d'humidité, ce qui explique la végétation arborée dense contrastant avec les régions avoisinantes de l'Hadramaout semi-désertique (Monod 1979: 144-5; Miller \& Morris 1988 : XI). Formant une enclave tropicale tout à fait inattendue le long de cette côte aride, cette région de l'Oman est une aire privilégiée pour les arbres à encens Boswellia carterii qui y croissent en abondance et développent une biologie s'accordant avec la mousson. Au Koweït, en début d'été, souffle le kaus, vent chaud et humide du sudest, favorisant une certaine végétation dite ghâbât istwâiiyat (Kabarity $1988: 231)^{4}$ qui est une sorte de forêt de mousson; mais ces vents provoquent aussi des rafales qui arrachent au désert son sable et l'entraine tourbillonnant dans la baie de Koweït.

Par contre, dans le sud-ouest de la péninsule arabe, les vents d'été sont chauds et totalement secs car ils n'ont fait que traverser le golfe d'Aden, très étroit et n'ont pas eu le temps de s'humidifier ; ainsi la côte reste déserte de végétation tout comme le sud-est de l'Iran et le nord-ouest de l'Inde.

\section{La mousson, vent de mer, vent des navigateurs} Japon.

\section{Influence de la mousson sur la navigation}

31 «Il faut prendre la Monsons à point nommé pour le voyage, le retardement d'un mois ou de vingt jours seulement, entraîne la perte d'une année » écrivait Chardin ([1711] 1811, III : 60) à la fin du XVII e siècle à propos des voyages en Chine au départ du golfe Persique. En effet, la connaissance de la mousson, qui est le changement produit à une date précise de la direction des vents, est fondamentale pour la navigation qui est à voile jusqu'au début du $\mathrm{xx}^{\mathrm{e}}$ siècle.

Elle contraint les marins à s'accommoder de son calendrier très particulier car elle pousse les vaisseaux alternativement d'ouest en est puis d'est en ouest. Si, à une époque de l'année, elle favorise la navigation, à l'autre époque, elle empêche, au contraire, tout déplacement en maintenant bateaux au port et équipage à terre.

La navigation et la pêche sont fortement affectées par ces vents qui sont souvent très forts et soulèvent une grosse mer ; c'est ce qu'il ressort de tous les récits de navigateurs. Mais on s'en accommode. Dans l'océan Indien, la mousson du sud-ouest permet le retour vers le nord depuis l'Inde du sud et l'Afrique orientale, elle empêche par contre les bateaux des côtes occidentales de l'Inde et de l'Arabie de prendre la mer.

Revue d'ethnoécologie, 5 | 2014 
Ces vents qui soufflent vers le nord-est se forment loin au sud aux alentours de l'équateur et atteignent progressivement les côtes de l'Inde. Ainsi chaque port a son calendrier. « La mousson qui se manifeste d'abord à Colombo (Photographies 1 et 2), à la fin de la troisième semaine de mai, atteint Bombay dans la première ou la deuxième semaine de juin. Les propriétaires de boutres de la côte de Malabar sont donc contraints de faire rentrer leurs bateaux avant la mi-mai à mesure que la mousson gagne vers le nord; les boutres du Gujerat devront à leur tour, chercher refuge à la fin de la première semaine de Juin. Ceux qui se trouvent en Arabie, pour leur part, rallient leurs ports d'attache en juin afin de regagner l'Inde avant la mousson. Pour la même raison, c'est à la fin du mois d'avril que les boutres arabes se trouvant sur la côte ouest de l'Inde mettront le cap sur la péninsule arabique. Pendant la durée de la mousson du sud-ouest, autrement dit de la mimai à la mi-septembre, les ports du littoral occidental indien sont fermés à la navigation qui est totalement interrompue » (Hawkins $1981: 32$ ).

Photographie 1 : Boutre indien dans le port de Colombo

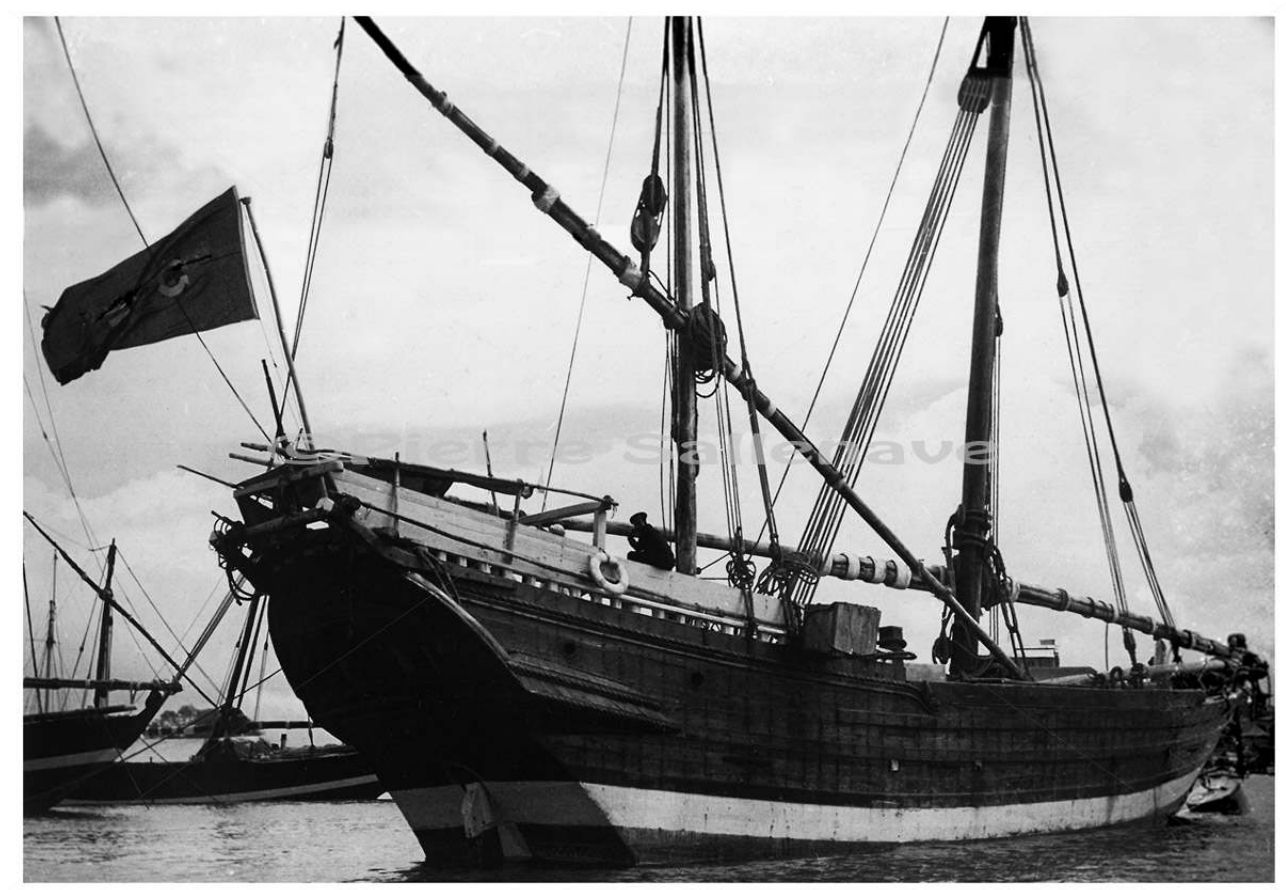

(c) P Sallenave 1934 
Photographie 2 : Boutre indien dans le port de Colombo. La poupe

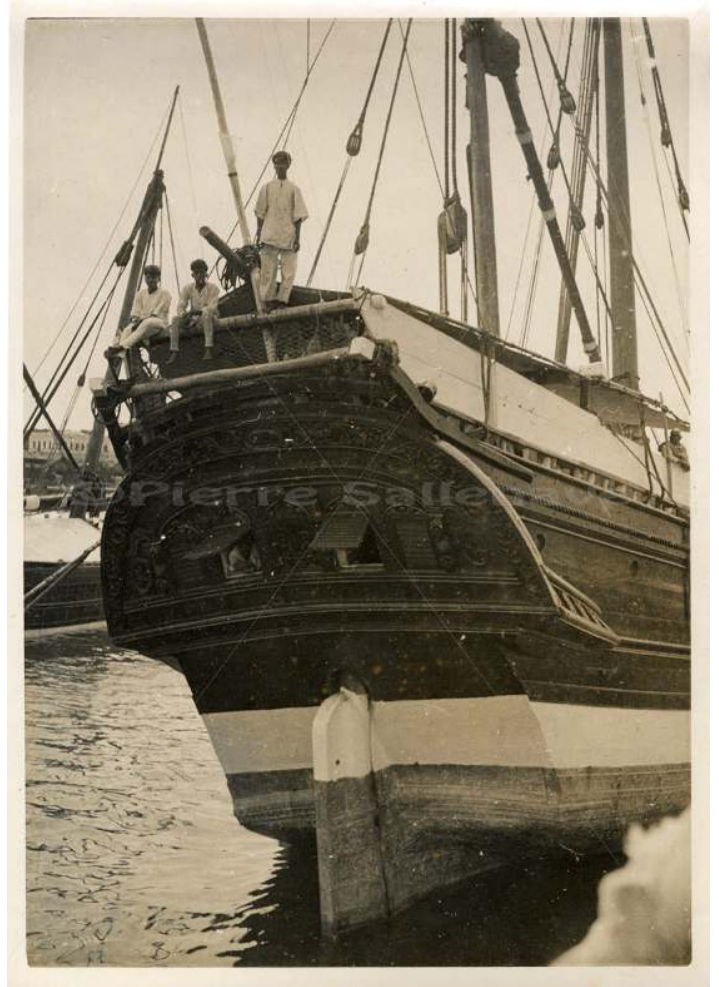

(c) P Sallenave 1934

La mousson d'été du sud-ouest, dans la partie orientale de l'océan Indien et les parages de la Cochinchine, celle d'hiver du nord-est du Centre-Viêtnam au Japon sont assez violentes pour arrêter la pêche et la circulation des bateaux (Photographies 3 et 4). Elles retardent même les puissants vapeurs : on risque une mauvaise traversée, si l'on va pendant l'été de Marseille à Colombo et Ho Chi Minh ville (Saïgon), pendant l'hiver d'Hanoï à Shangaï et Yokohama. 
Photographie 3 : Petite jonque

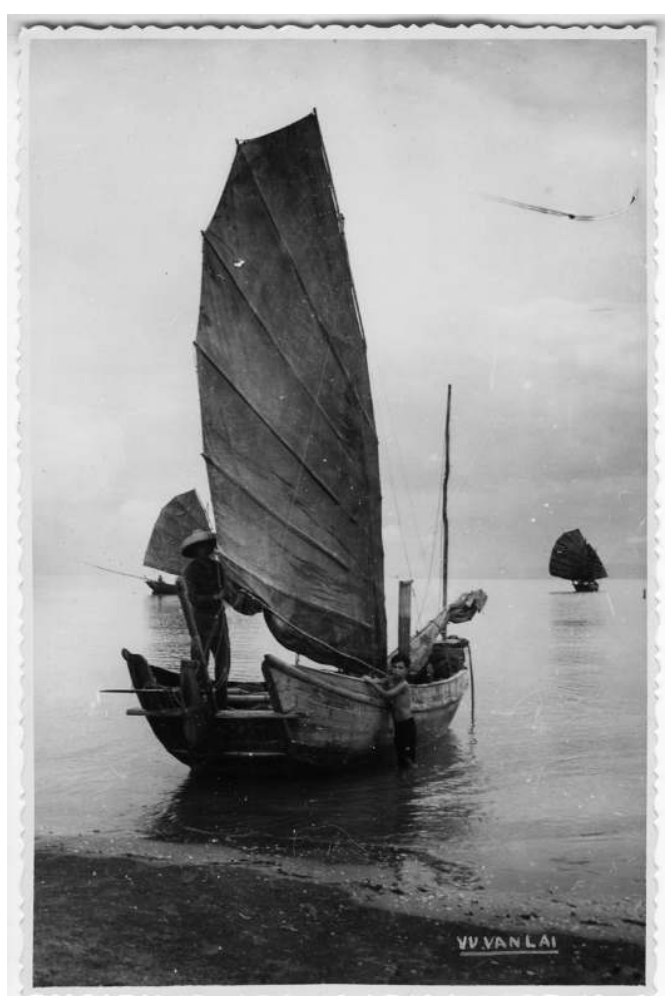

Photographie 4 : Patron de jonque à Phu Lang Thuong, nord Vietnam

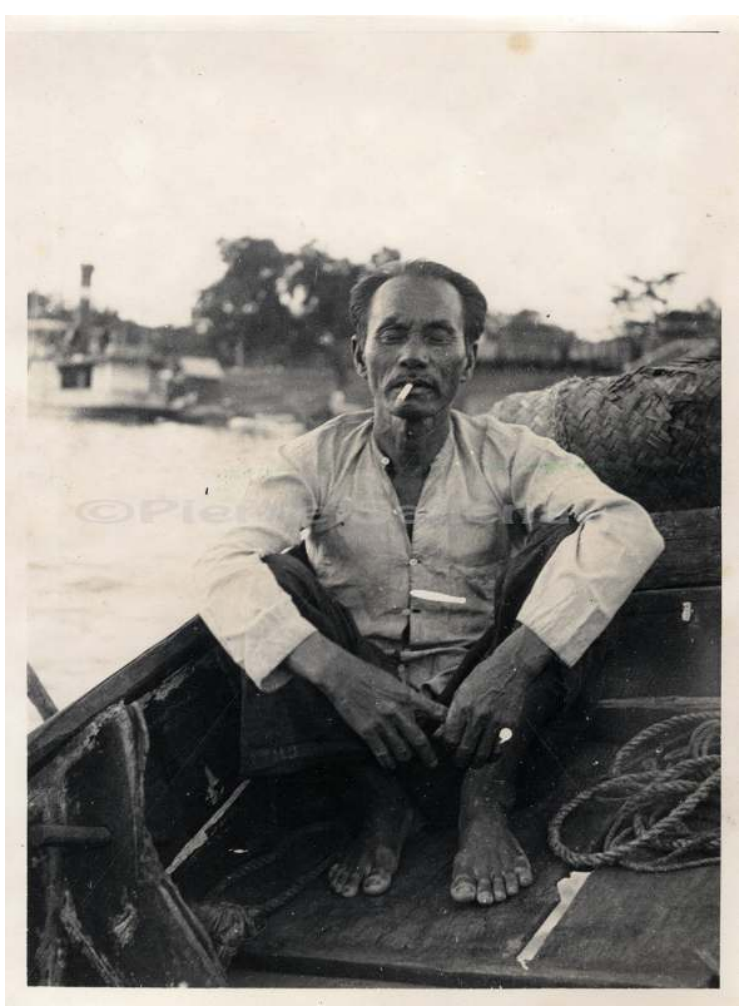

(C) P. Sallenave 1935 
les côtes du Makran et de l'Arabie du sud, la mousson du sud-ouest provoque une forte houle au large et le ressac qui en résulte rend extrêmement hasardeux tout essai d'abordage ou au contraire le départ en mer. De même, tout au long de la côte occidentale de l'Inde, la flotte entière des boutres est immobilisée pendant quatre mois. Durant cette période, aujourd'hui encore, certains ports de cette région sont même fermés à tout trafic quel qu'il soit. C'est la période où l'on se repose, où l'on vit en famille, où l'on répare les bateaux. Cette situation est connue depuis longtemps; le Périple de la mer Érythrée disait la même chose, au II ${ }^{\mathrm{e}}$ siècle de notre ère, quand il évoquait les dangers de la navigation sur les côtes occidentales de l'Inde où la barre et les fortes marées, au moment de la mousson du sud-ouest, occasionnaient de nombreux naufrages (Huntingford 1980 : chap. 46).

Par contre, la mousson d'hiver, qui souffle du nord nord-est, porte les bateaux de l'océan Indien, boutres, sambûq, boom, ganja, kotia, dhangi, thoni, ${ }^{5}$ et les voiliers des côtes arabes vers les ports de l'Afrique orientale, Mombasa, Lamu, Zanzibar etc.; cette période est annoncée lorsqu'apparaît Suhail, l'étoile Canopus, notre Chien. Là encore nous avons des témoignages anciens ; ce sont ces mêmes informations que donne déjà Pline (v. plus bas).

Dans le golfe Persique, la situation est particulière car les vents changent peu de sens. Le Golfe, tout comme l'Iran, sont soumis, durant toute l'année, aux hautes pressions qui prévalent dans le nord du pays avec un centre au nord-est en hiver et nord-ouest en été. Les vents du nord-ouest shamal («nord» en persan) soufflent de février à octobre ; dans les mois les plus chauds, de mai à septembre, ils s'accompagnent d'une forte humidité qui rend l'atmosphère du Golfe très inconfortable. Toutefois, la direction de ces vents est constante et bien que soufflant fort, ils n'excèdent jamais 65 à 70 miles à l'heure (environ $100 \mathrm{~km} / \mathrm{h}$ ) (Ganji $1968: 217-220$ ) poussant les bateaux aux allures portantes, du Chott elArab, au fond du golfe Persique, vers le sud ; par vent arrière, toutes voiles déployées, ils rallient en moins de trois semaines les côtes du sud de l'Inde, et par vent de travers, longeant les côtes méridionales de l'Arabie, ils vont vers l'ouest, le Yémen et l'Afrique de l'est.

À l'ouest de la Péninsule arabique, «à Aden, la saison du négoce s'étend de septembre à juin; en dehors de cette période, la mousson du sud-ouest rend précaire les mouillages. Sans mettre un terme aux échanges, elle les réduit considérablement. Les statistiques portuaires d'Aden sont à cet égard, révélatrices; chaque année, aux mois de juillet et d'août, les boutres qui entrent et qui sortent sont moitié moins nombreux que ceux qui y jettent l'ancre le reste de l'année » (Hawkins 1981 : 27) (Photographie 5). 
Photographie 5 : Djibouti les quais de la douane vers 1930

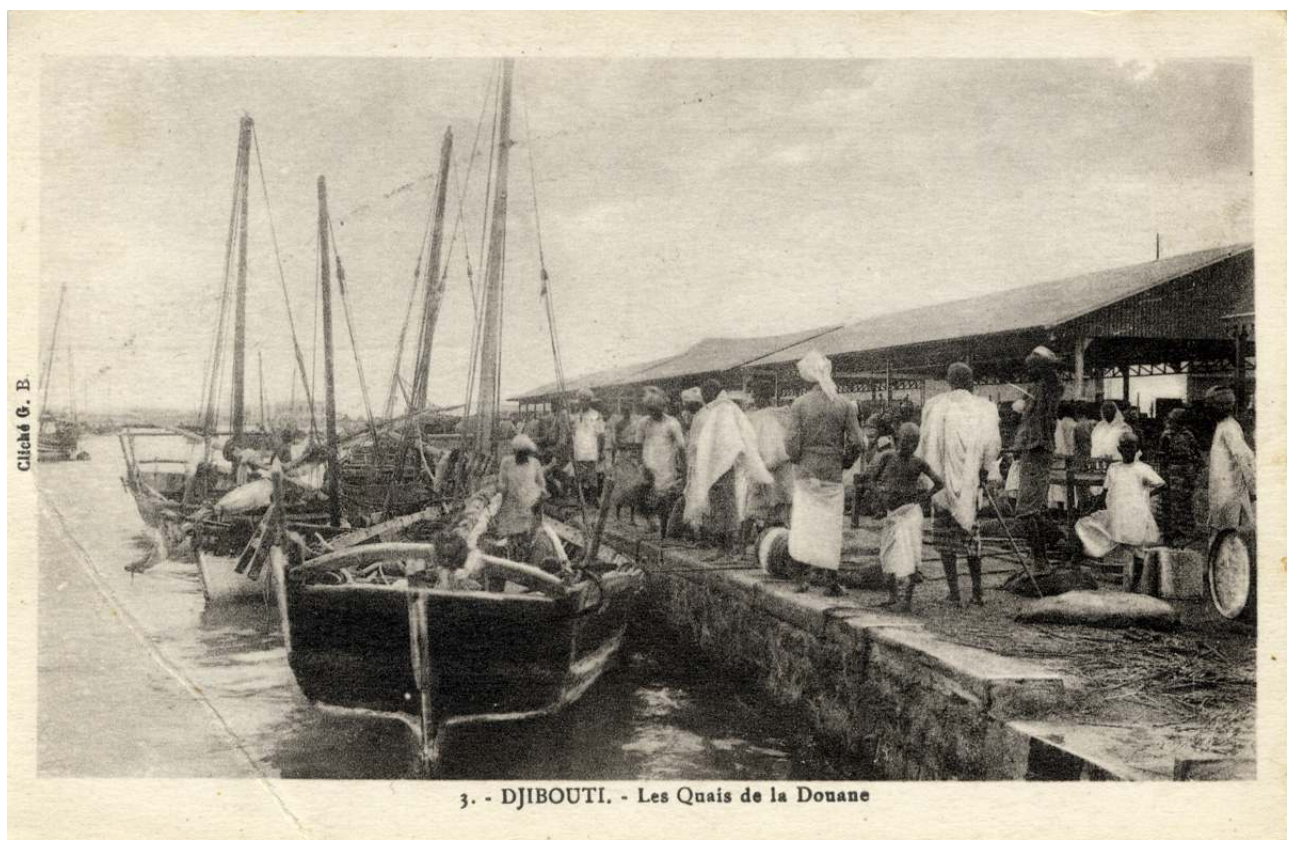

Cependant une bonne connaissance de la mousson et un bon bateau permettent des navigations rapides. Les marins de l'océan Indien utilisaient la régularité de la mousson pour des trajets triangulaires ; une Kotia de Bombay de cinquante tonneaux (petite taille) pouvait ainsi charger à Mandvi, dans le golfe de Kuch au Gujerat, une cargaison de riz, d'huile et de poix à destination de Nossi Bé, petite île au nord ouest de Madagascar, à plus de 2000 milles de distance ; le bateau traversait ainsi presque tout l'océan Indien. Pendant cinq ans de suite, ce boutre effectua la même traversée partant en décembre avec la mousson d'hiver soufflant du nord-est, il accomplissait ce voyage en trente ou quarante jours (Photographies 6 et 7). De là, il remontait jusqu'aux Comores et revenait en juin à Bombay porté par la mousson d'été, soufflant du sud-ouest (Hawkins 1981: 96). Il avait toujours navigué aux allures portantes, les plus confortables. 
Photographie 6 : Anjouan, port de Mutsamudu, les djahazi ( boutres) à quai

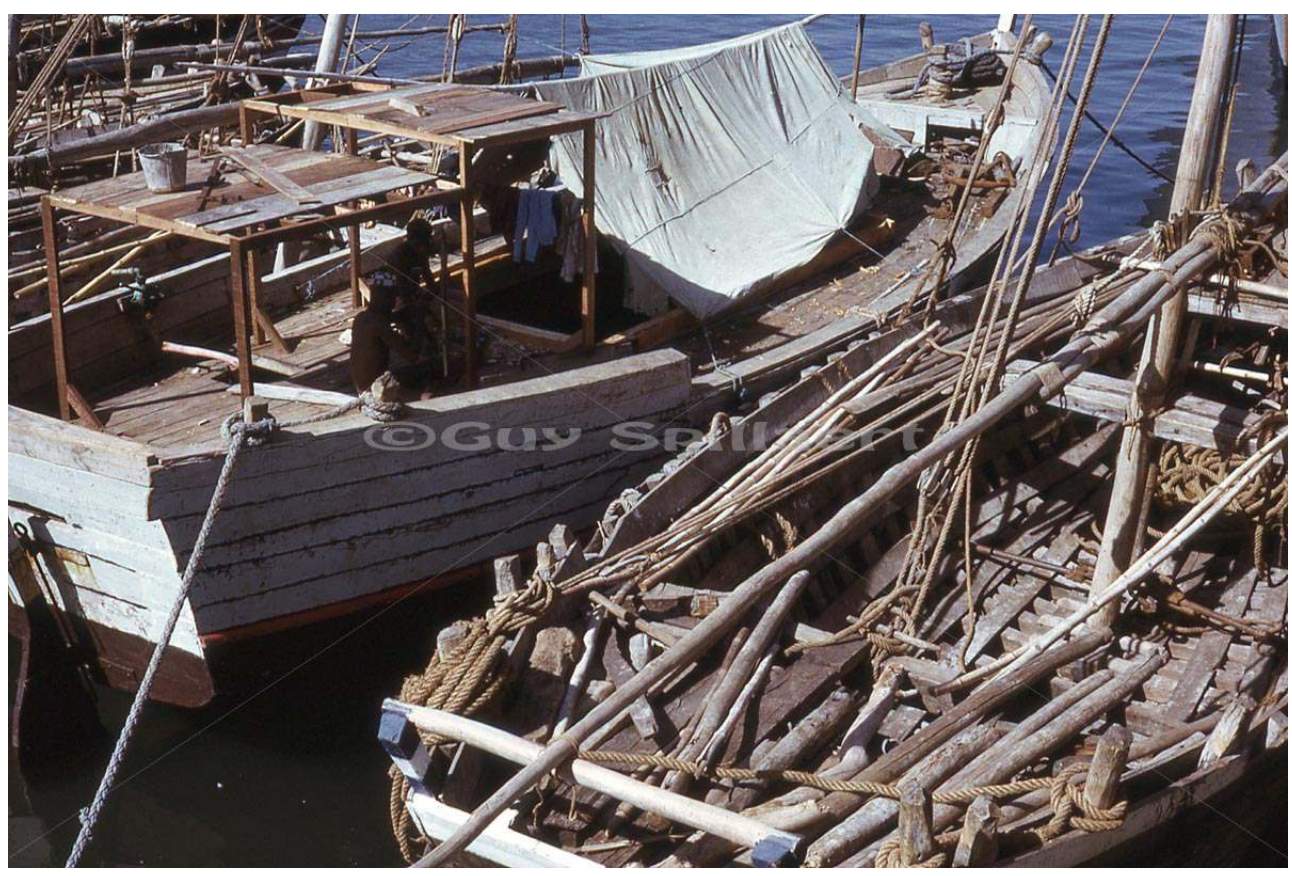

(c) G. Spillaert 1974-3

Photographie 7 : Anjouan, port de Mutsamudu, djahazi le long du quai

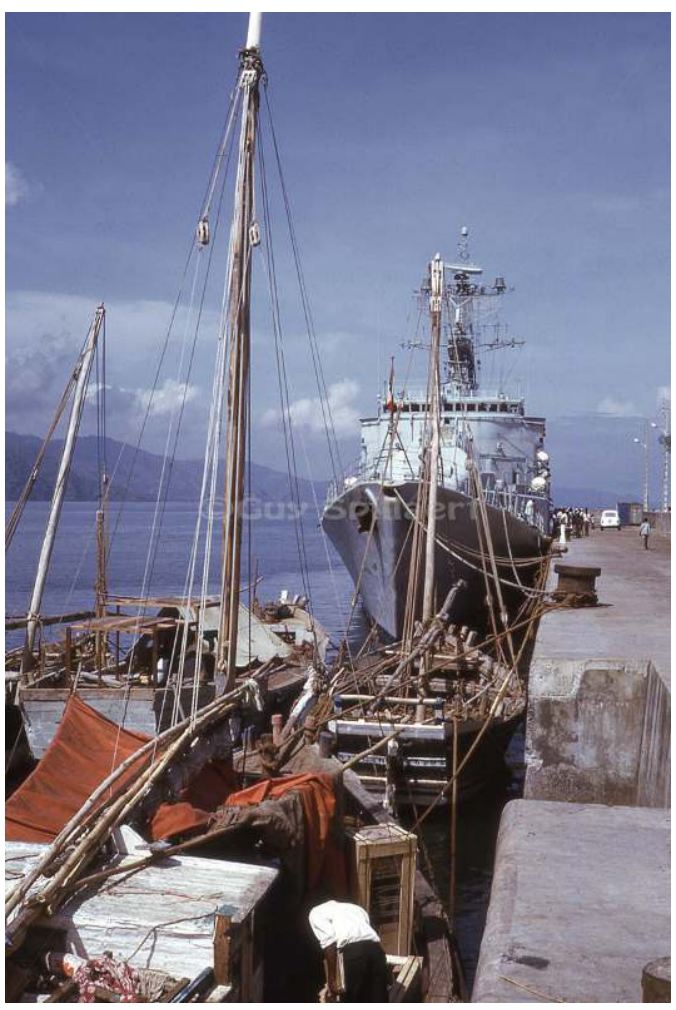

(c) Guy Spillaert 1974-2 


\section{Les courants marins et les marées}

41 Ces grands vents réguliers affectent fortement les eaux et créent de violents courants qui jouent un rôle au moins aussi important que le vent dans la navigation des bateaux à voile et à moteur, car eux aussi varient selon les saisons. Ils se conjuguent souvent avec les marées.

Depuis des siècles, les patrons des boutres mettent à profit ces variations saisonnières qui leur permettent d'atteindre à la voile en moins de trois semaines l'Afrique orientale, en partant en février ou en mars, époque de l'année où le courant nord-équatorial est le plus fort, dans le sens sud-ouest sur les côtes arabes et somalies (Photographie 8). Le voyage de retour s'effectuera grâce au vent de la mousson du sud-ouest qui souffle à partir d'avril ; telle est l'origine du courant de la Somalie qui renforce encore le courant sud-équatorial.

Photographie 8 : Boutre à Mayotte, le vent est tombé avant l'orage

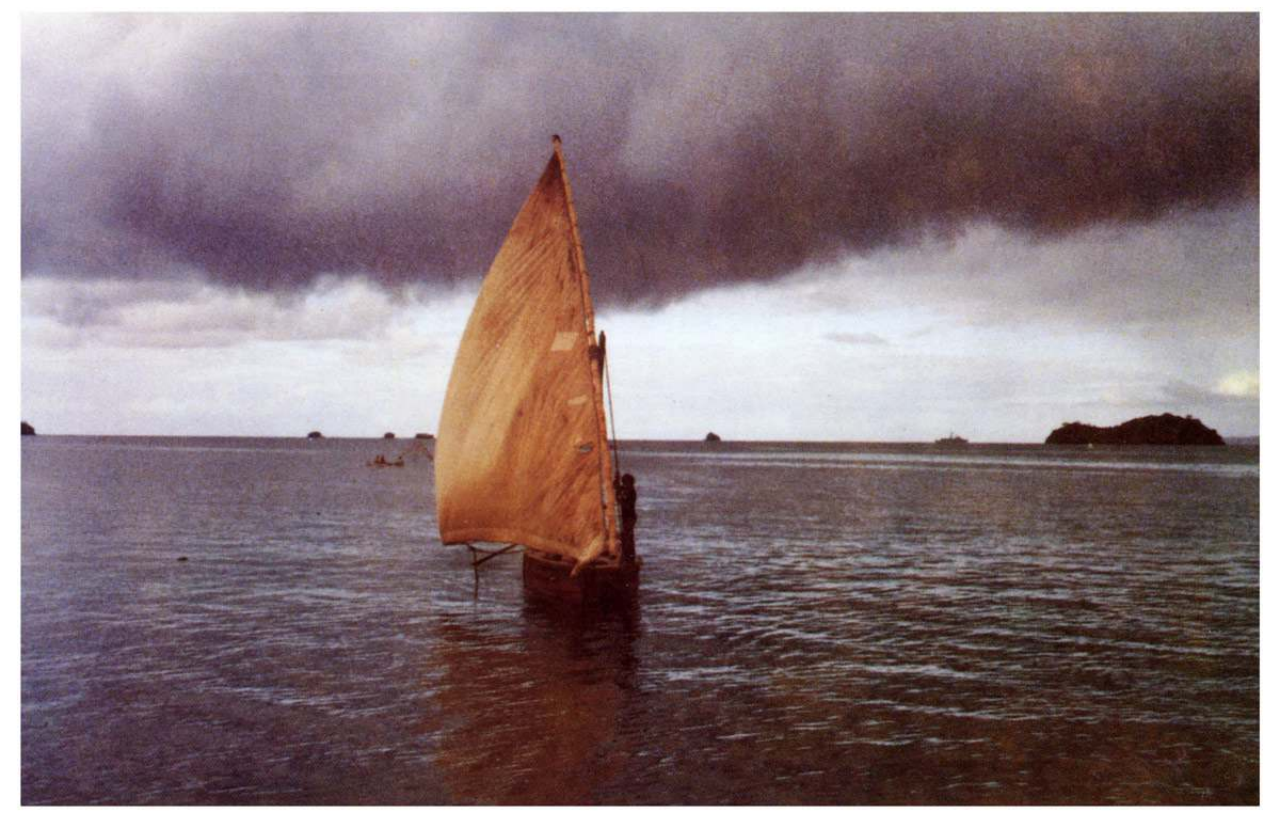

(c) P. Alexandre ca1975

Mais si la mousson permet les voyages à certaines époques, elle les interdit à d'autres. Bien avant le début de la mousson du sud-ouest, ses effets se font sentir sur la côte du sud de l'Arabie, provoquant un fort ressac qui empêche, après le 15 Avril, de prendre la mer, depuis Muscat ou Matrah, en direction du sud, que l'on soit à voile ou à moteur; de même, sur la côte occidentale de l'Inde, la barre interdit toute navigation.

Dans le golfe Persique, pendant les mois d'été, les vents du nord poussent les eaux du Chott el-arab plus avant dans le Golfe provoquant un fort courant.

Dans le sud de la mer Rouge, marées et vents de mousson conjugués occasionnent autour des nombreuses îles de violents courants dont il faut connaître parfaitement la localisation, le sens et le calendrier et même l'horaire si l'on ne veut être drossé sur les rochers qui affleurent, comme le raconte si bien Monfreid dans Les secrets de la mer Rouge. Sur les côtes orientales de l'Asie, les vents de mousson peuvent faire varier le niveau moyen de la mer de $0,50 \mathrm{~m}$ à 1,50 $\mathrm{m}$ selon les saisons. Dans le nord de l'océan Indien et 
dans la mer de Chine, le courant se renverse de l'été à l'hiver, tout en conservant une vitesse qui atteint dans le sud-ouest du golfe de Bengale 150 ou même 180 kilomètres par jour. En effet, cette côte orientale de l'Inde ne connaît que peu de mouvements de bateaux, et encore au nord de Madras seulement. Elle est, en outre, arrosée par des fleuves qui ont des variations considérables; le rapport des hautes eaux aux basses eaux dépasse 100 pour les affluents méridionaux du Gange, créant ainsi de violents contrecourants capables d'entraîner les bateaux au large et de prolonger considérablement leur voyage.

\section{Les savoirs de la navigation}

Naviguer en pays de mousson nécessite donc un savoir particulier : connaître les vents dominants, les courants et... les étoiles. Il s'est formé une classe de marins spécialistes. Ceux du golfe Persique et d'Inde, appelés nawâkhid (sing. nakhoda), ou ma'allim "patrons" de bateaux, n'avaient pas de cartes mais un calendrier basé sur l'apparition des étoiles. Henri de Monfreid, dans ses récits sur la mer Rouge, nous a laissé des descriptions très vivantes de ceux qu'il appelle « nacoudas » (Photographies 9 et 10).

Photographie 9 : Pilote à la barre d'un boutre indien, port de Colombo et en partance aux îles Laquédives

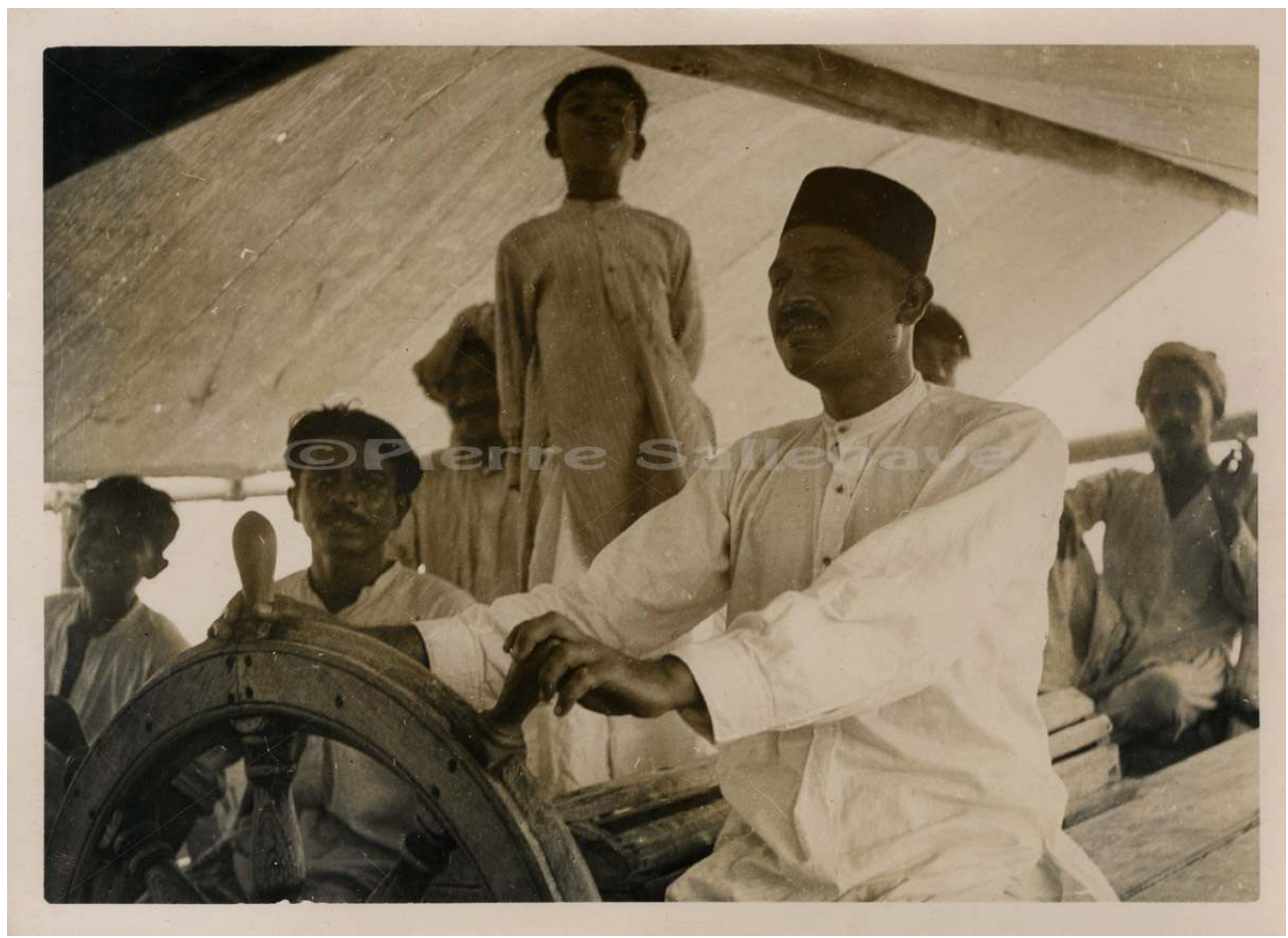

(C) P. Sallenave 1934 


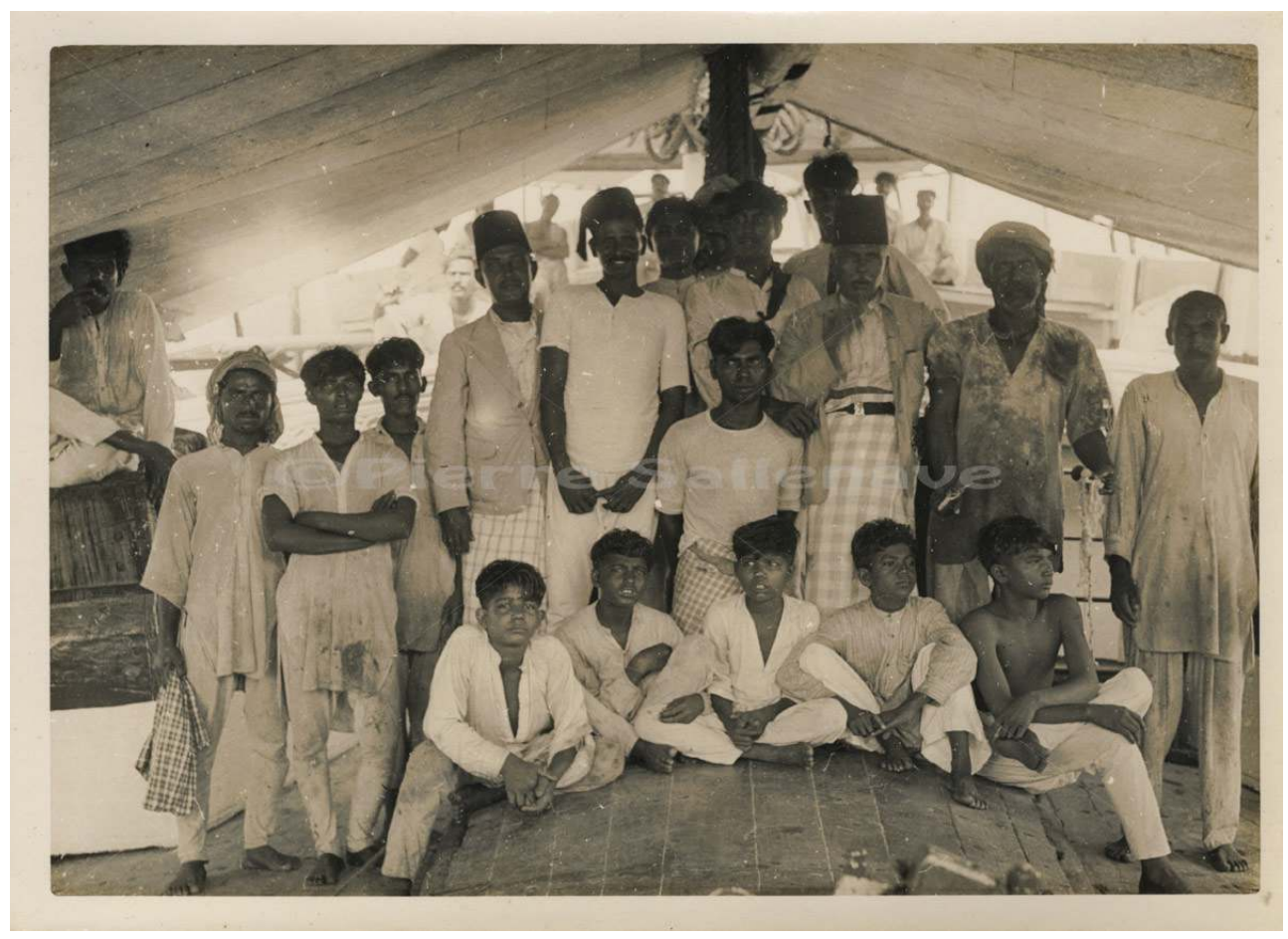

(C) P. Sallenave 1934

Excellents marins, ces derniers " parvinrent à imposer leur suprématie et à monopoliser le commerce maritime avant l'arrivée des Portugais dans l'Océan Indien. Un grand nombre de patrons de boutres arabes pratiquaient la navigation astronomique et se servaient d'astrolabes. Ceux qui l'ignoraient encore, connaissaient d'expérience, la manière de naviguer en mer, récifs et mouillages sûrs n'avaient plus de secrets pour eux. Les connaissances, transmises de père en fils, perpétuaient aussi la tradition. Leurs instructions nautiques décrivaient les particularités des côtes et indiquaient la direction des courants et des vents aux différentes saisons " (Hawkins 1981: 20). Les contacts anciens avec les Chinois, dont les jonques de commerce abordaient au Kerala et dans le golfe Persique aux X-XI ${ }^{e}$ siècles, familiarisèrent les Arabes et les Persans avec la boussole ; à la fin $\mathrm{du} \mathrm{XI}^{\mathrm{e}}$ siècle, ils l'avaient adaptée à leurs besoins, inventant même le da'yra ou compas sur cardan.

\section{Les Malais et le peuplement de Madagascar}

La connaissance des vents alternatifs de la mousson et des courants, de bonnes embarcations, fut-ce des pirogues à balancier, expliquent vraisemblablement un phénomène qui nous semble étonnant: celui de migrations anciennes de Malais à Madagascar qu'ils ont en partie peuplée.

En effet, « tout le nord de l'île est soumis au rythme des moussons. Ce double régime des vents a permis et permet toujours des relations entre l'île et l'Inde éloignée de $4000 \mathrm{~km}$ » (Leroi-Gourhan et al. 1953 : 683). Par ailleurs, Madagascar est le centre vers où convergent toute une série de courants marins, aujourd'hui cartographiés et qui prennent leur source à l'est. L'histoire nous offre plusieurs exemples de la force et de la direction de ces courants. En 1762, alors que Pondichéry était aux mains des Anglais, le colonel 
Coutenceau, chargé d'un message pour l'île de France, aujourd'hui île Maurice, s'embarqua hardiment sur une chaloupe et, se laissant emporter par les courants, arriva en deux mois à Port-Louis. On a vu d'autre part des jonques malaises emportées par la tempête, aborder les côtes malgaches (Leroi-Gourhan et al. 1953: 686-7) C'est vraisemblablement pourquoi les Malgaches appellent quelquefois leur pays ny anivun' ny riaka « la terre située au milieu des courants » (Leroi-Gourhan et al. 1953 : 686-7).

À ce caractère particulier des courants, s'ajoute une parenté linguistique évidente qui a permis de déterminer l'origine malaise du malgache. Cette langue qui comporte de nombreux dialectes (dont le sakalave et le menara sont les plus importants), possède à $93 \%$ un vocabulaire d'origine austronésienne. Le malgache s'apparente au lawangan, au dusun deyah et au ma'anyan de Bornéo, langues de populations qui vivent au sud de Kalimantan, sur les côtes et à l'intérieur, occupant le moyen cours de la rivière Barito. Ces langues appartiennent à la famille austronésienne occidentale (Dahl 1951, Ruhlen 1987 : 343).

Plusieurs migrations indo-malaises semblent avoir profité de ces courants; elles trouvèrent l'île habitée par des hommes qui n'étaient cependant pas des noirs. Les historiens s'accordent aujourd'hui à en trouver l'origine à la fois en Mélanésie et en Afrique tout en divergeant considérablement sur les périodes de peuplement; les uns pensent à une invasion autour de 2500 ans av. J.-C. venant d'Inde et de Malacca, tandis que d'autres situent autour du IIIe ou IVe siècles de notre ère des migrations venant de Sumatra, allant même jusqu'à dire « que la plus importante invasion est celle des Javanais en $1555 »$ ! De façon certaine, l'élément négroïde africain ne remonte qu'à une époque récente, au cours du second millénaire de notre ère (Leroi-Gourhan et al. 1953 : 684-5). Ces populations de pasteurs devaient avoir des bateaux assez robustes et grands pour transporter les vaches qu'ils ont introduites du continent africain.

Des questions se posent encore sur les modalités du déplacement des Malais. Sont-ils venus en traversant la mer ou bien ont-ils longé les côtes? Seule certitude: des populations d'Océanie sont venues avec leurs pirogues à balancier qu'elles ont « laissées » au sud de l'Inde, sur les côtes de l'Afrique orientale et à Madagascar (Photographie 11). 


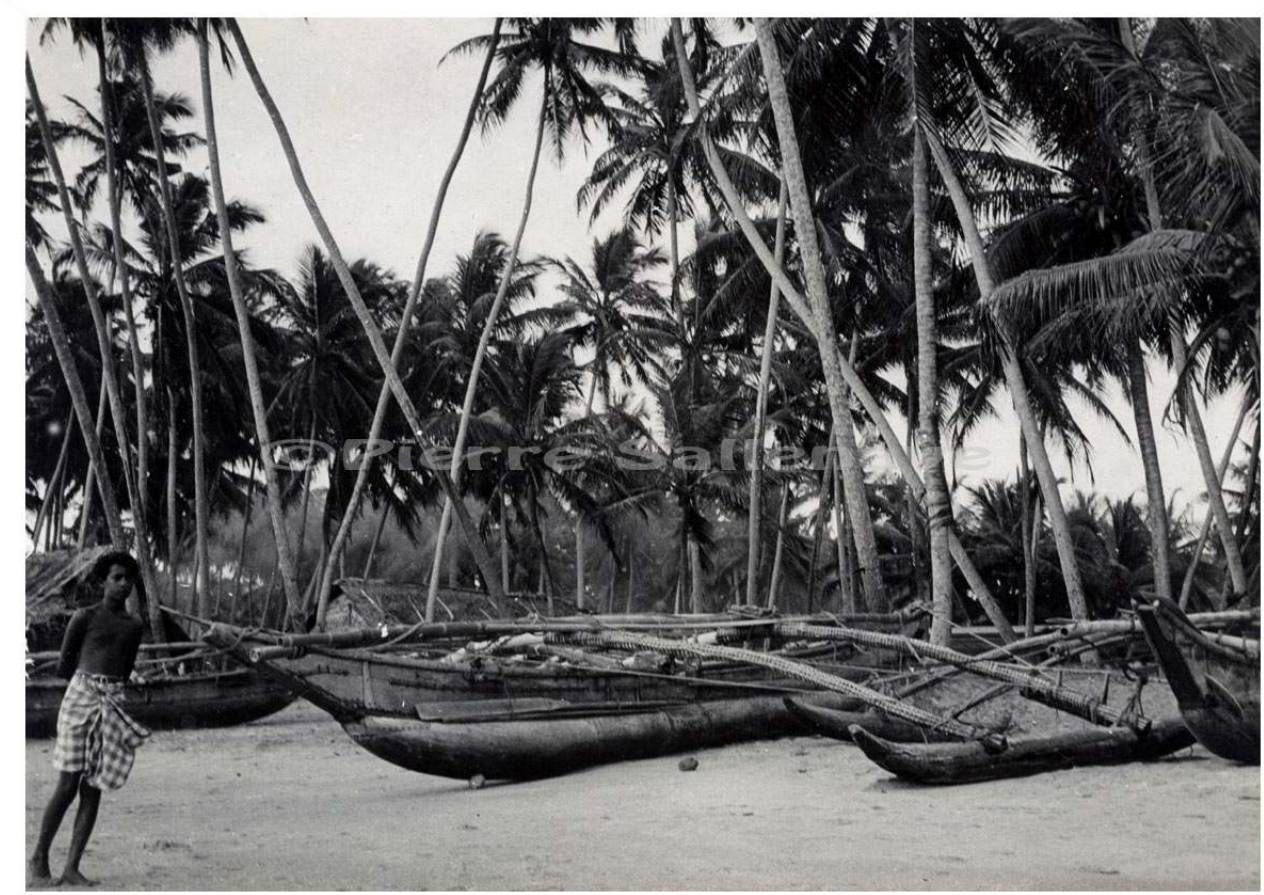

(C) P. Sallenave 1934

\section{Les navigateurs et les bateaux}

54 Ces connaissances du rythme des vents et des courants ont donc une grande profondeur historique. Une pièce romaine de cuivre de l'empereur Maximin (235-238) trouvée dans la province de My-Tho au Sud-Viêtnam ${ }^{6}$ - même si l'on sait que les Romains n'ont jamais mis les pieds en Indochine -, de nombreuses perles indiennes récoltées sur la côte africaine et dont les plus anciennes datent de 200 av. J.-C. (Van der sleen) attestent l'ancienneté et l'ampleur des relations commerciales dans l'océan Indien.

\section{Qui navigue?}

55 À travers les âges, et depuis les témoignages les plus anciens, l'on voit que la navigation a des objectifs presque essentiellement marchands que ce soit dans l'Antiquité, au MoyenÂge, à la Renaissance et jusqu'à aujourd'hui, toutes nations confondues. Ce sont les commerçants qui, les premiers, se sont lancés dans des voyages, affrontant l'inconnu, et même si les découvertes ont été progressives, il y avait une grande curiosité telle celle du marchand Ibn Vahab. Fuyant Basrah dévastée par la révolte des Zandjs (870-871 ap. J.-C. / AD), il arrive au port de Sirâf dans le golfe Persique. Là, saisissant une occasion, il s'embarque pour la Chine, atterrit au port de Khanfou ${ }^{7} \mathrm{~d}^{\prime}$ où il part pour Khomdan, la capitale, dans le seul but de voir l'empereur de Chine; il y arrive après un trajet de deux mois (Reinaud [1846] 1982 : 79). Ces marchands étaient riches et s'associaient entre eux comme ils le faisaient pour les caravanes terrestres, car il fallait un budget important pour armer un bateau, le remplir de marchandises et mobiliser un capital pendant la durée de ces longs voyages. Marco Polo, Sindbad le marin ont laissé ces images et plus proche de nous les Compagnies des Indes hollandaise, anglaise et française. 

commerciaux, telle celle qu'envoya au VII ${ }^{\mathrm{e}}$ siècle en Inde l'empereur T'ai-tsong des T'ang, pour ramener un roi de l'Inde (Pelliot $1904: 449$ ). Elles mobilisaient d'immenses flottes pour se rendre, au cours de longs voyages, dans les pays du sud de l'Asie, en Inde ; c'est encore une importante ambassade chinoise qu'accompagna, à la fin du XIII ${ }^{\mathrm{e}}$ siècle, Tcheou Ta Kouan qui passa près d'un an dans l'empire khmer.

Il y avait aussi une autre classe de voyageurs qui jusqu'à l'ère coloniale est toujours allée de paire avec les marchands, c'est celle des missionnaires. Ce furent les Bouddhistes d'Inde qui, dans les premiers siècles de l'ère chrétienne, vont sur la côte du CentreViêtnam pour convertir l'empire de Cham, à Java où ils construisent le temple de Borobudur, et mettent en place l'empire de Srivijaya, à Sumatra et au Cambodge dans le royaume khmer. Plus tard, les Musulmans propagèrent le Coran en Malaisie et en Indonésie dès qu'ils abordèrent durablement dans ces régions aux $\mathrm{VIII}^{\mathrm{e}}$ et $\mathrm{IX}^{\mathrm{e}}$ siècles mais c'est surtout à partir de la fin du $\mathrm{Xv}^{\mathrm{e}}$ siècle que leur influence se ressent. Les Chrétiens suivirent de peu, dès l'ouverture de la route par Vasco de Gama en 1498, avec les Jésuites portugais, puis les Capucins, Franciscains ....

Enfin, il y avait les curieux tels le géographe-historien irakien al-Mas'ûdî, au x ${ }^{e}$ siècle qui, sa vie durant, a beaucoup voyagé mais surtout a interrogé les marins à leur retour ce qui fait qu'il semblait avoir parcouru le monde musulman; ou bien le tangérois Ibn Battûta qui, en 1325 à l'âge de 21 ans, entreprend un long voyage qui l'a peut-être mené jusqu'en Chine ; il ne revient qu'en 1349. Son expérience est remarquable, car ce savant juriste n'a pas de but vraiment religieux, il n'est pas un marchand, mais très désireux de connaître le monde des Musulmans; sans être un aventurier au sens où nous l'entendons, il est un homme vivant bien ses aventures.

\section{Les bateaux}

Dans cette immense mosaïque de cultures touchées par les moussons, celles de l'océan Indien, celles des îles de la Sonde, celles de la Mer de Chine, les embarcations étaient des plus variées dans leurs formes, leurs tailles, leurs voilures.

Toutefois, il existe une parenté certaine entre les bateaux d'Asie du sud-est, chinois ou viêtnamiens, et ceux de l'océan Indien, persans, sud-arabiques et indiens, en ce qui concerne la coque, mais non la voilure. En effet tous ces bateaux ont des coques souples, sans armature interne rigide (comme elle l'est, par contre, dans la construction traditionnelle européenne) ; les bordés sont assemblés de chant soit par couture végétale (Inde, Arabie du sud, golfe Persique), soit par des clous-carvelles ${ }^{8}$ (Chine, Viêtnam); les constructions sont en bois sans qu'aucun élément de fer n'y entre. C'est ce type de construction à bordés cousus qui a prévalu jusqu'au XIX ${ }^{\mathrm{e}}$ siècle et survit encore au $\mathrm{XXI}^{\mathrm{e}}$ siècle, en Oman.

61 Toutefois, le recul historique que fournissent les documents archéologiques et les textes met en évidence une évolution des coques et des voilures. C'est la voile latine qui prévaut encore sur les boutres djahazi des Comores, d'Afrique de l'est et Madagascar. (Photographie 12) 
Photographie 12 : Lamu 2 boutre à voile latine sortant du port, bon vent de travers

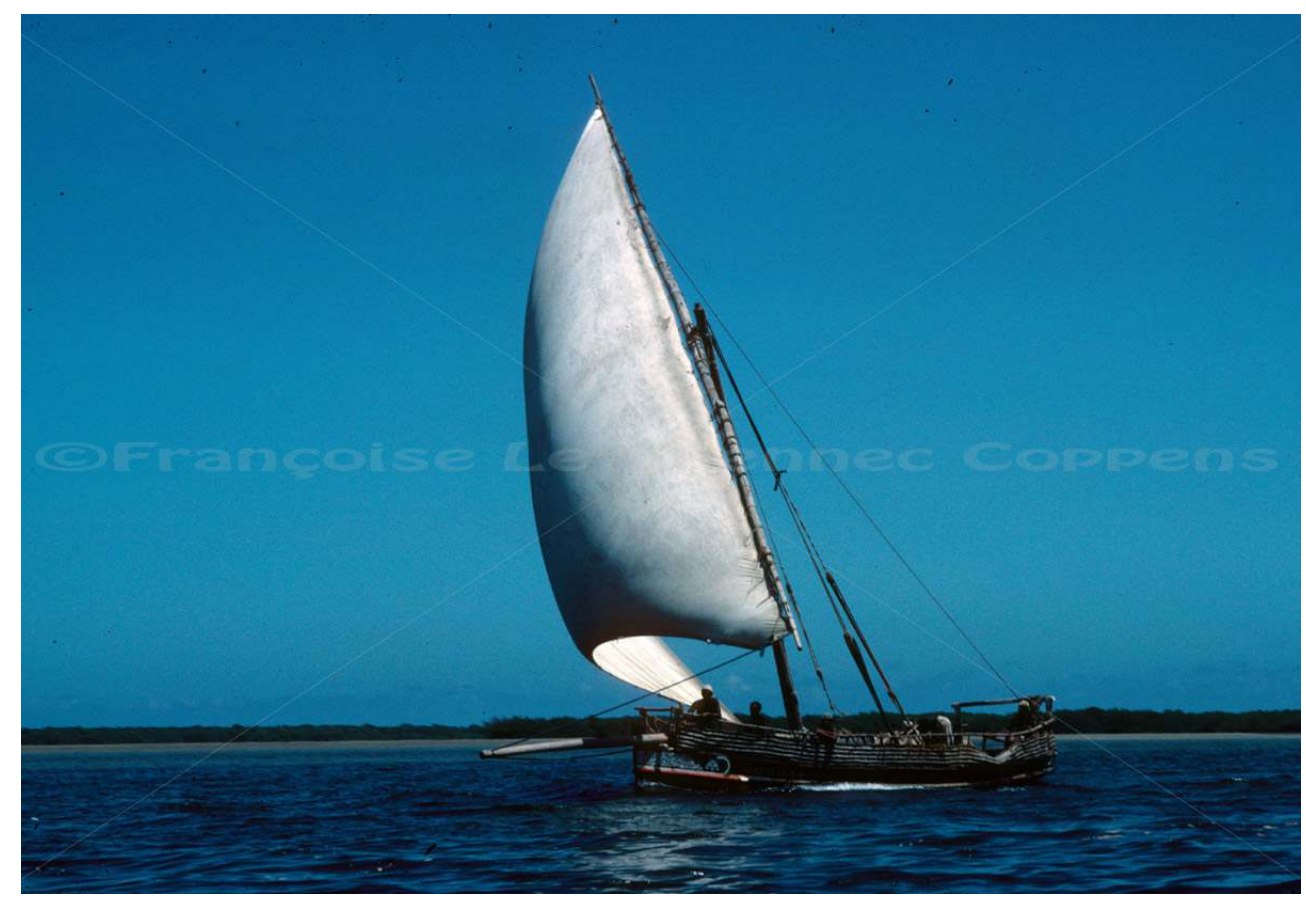

(C) F. le Guennec Coppens

Dans le golfe Persique, à la fin du XvII ${ }^{e}$ siècle, le cocotier fournissait toute la construction locale des sambouqs de Bandar Abbas, coque, voiles, cordages et le fret, comme le souligne Chardin. Cependant, pour les embarcations de construction plus soignée et durable, on utilisait des bois indiens dont le meilleur est le teck, Tectona grandis, qui a la particularité de ne pas attaquer le fer (Aubaile-Sallenave 1987 : 133-135).

« Les bateaux qu'ils [les Persans] nomment chambouc sont hauts, longs et étroits; ce que les Persans disent qu'ils font ainsi, pour empêcher l'eau d'y entrer, quand la mer est plus agitée. Ils sont faits de cet arbre qui porte la noix de cocos, et duquel l'on dit que l'on peut faire et charger un navire tout ensemble, le corps du vaisseau se faisant du corps de l'arbre, les voiles et les cordages avec ses feuilles et avec son écorce, et le fruit de l'arbre fournissant la charge du vaisseau. Il est vrai que tous les cordages du golfe Persique sont faits de cette écorce ; mais je n'y ai pas vu d'autres voiles que de toile de coton. Ce qui est remarquable, c'est que les planches des barques sont cousues avec ces sortes de cordes, et enduites de chaux au défaut de poix, sans un morceau de fer en aucun endroit; ce qui fait que ces bâtiments ne résistent guère à la mer (Chardin (1711) 1811, VIII : 510-511).

Aujourd'hui encore, la plupart des bateaux de l'océan Indien sont à bordages cousus et en matériau purement végétal, tels le pattamar de haute mer des Laquédives, les masula de Madras et padangu de la côte de Coromandel, les yathra oruwa etc. (Aubaile-Sallenave 1987 : 6). Les padava de la côte du Bengale, grands bateaux à rames qui servent à la pêche à la senne, sont recousus avant la saison de pêche, qui a lieu pendant la mousson d'hiver, d'octobre à avril-mai. Sur cette même côte, les teppa sont des catamarans, c'est à dire des radeaux (tamoul kattu maram, «troncs attachés ») faits de troncs équarris, que l'on délie, chaque soir, pour monter sur la plage au retour de la pêche à la grosse crevette et que l'on lie chaque matin, pendant la saison de pêche ${ }^{9}$.

Longtemps avant l'apparition des bateaux européens, les bateaux au long cours indiens, chinois et arabes sont des bâtiments de haut-bord capables d'affronter les tempêtes, 
même s'ils n'avaient jamais beaucoup de fond ni de quille, puisqu'ils devaient s'échouer sans encombre sur les plages sous l'effet des marées et aussi, plusieurs fois par an, pour être radoubés, nettoyés de leurs tarets.

Aux yeux des Arabes, les bateaux chinois devaient être grands, car al-Mas'ûdî au xe siècle, note qu'en un lieu du golfe Persique nommé al-Dardour, resserré entre deux montagnes, seuls passent les petits navires alors que les navires chinois ne peuvent s'y engager (Reinaud 1982 :14-15) (Photographie 13). Ces embarcations, souvent de plusieurs dizaines de mètres de long, bénéficiaient, depuis le début de notre ère, de techniques permettant la navigation au long cours: le gouvernail axial et le compas magnétique ${ }^{10}$ (Soutif 1992 :148), dont l'usage correct suppose la connaissance de la déclinaison magnétique. En outre, les cloisons intérieures étanches assurent la bonne conservation des marchandises et, en période de tempêtes, minimisent les dégâts de l'eau. Quant à la voile aurique, rendue rigide par les lattes, permet de bien remonter au vent et par sa forme haute et étroite, de gréer plusieurs mâts sans risque de déventer une partie de la voilure (Poujade 1946 :160). En décembre 1409, une flotte chinoise descend du Foukien au Champa (centre Viêtnam) en 10 jours et nuits, hissant 12 voiles [par bateau] et par vent favorable (mousson d'hiver) (Pelliot $1933: 282$ ).

Photographie 13 : Grandes jonques bœuf pêchant au chalut, Fai Tsi Long, Nord-Vietnam

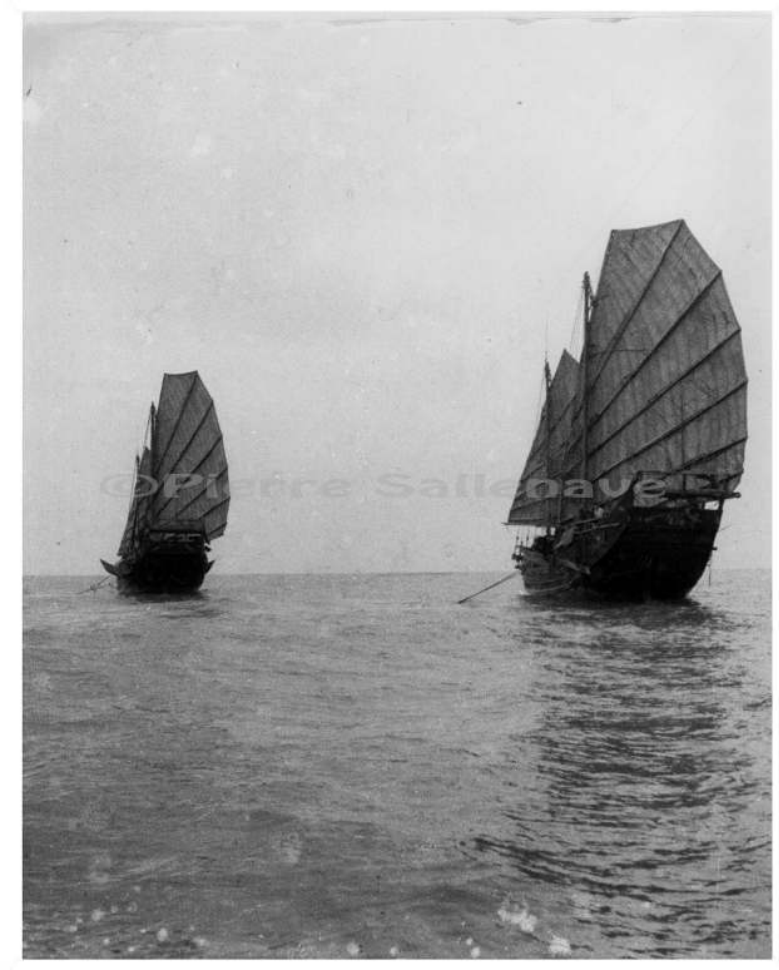

(C) P. Sallenave1938

66 Les embarcations de l'océan Indien portent la voile arabe, appelée settee sur les boutres ; sa forme trapézoïdale permet de remonter au vent à l'opposé des voiles carrées de la marine occidentale qui remontaient mal au vent et ne permettaient qu'une navigation aux allures portantes, vent de travers et vent arrière. Depuis longtemps, les bateaux portent souvent deux mâts ${ }^{11}:$ ibn Mâgid, patron de navire et poète omanais du XVI ${ }^{\mathrm{e}}$ siècle, écrit dans un poème dont l'extrait fait penser à un haïku : 
« je parle et le bateau passe devant moi avec deux voiles ${ }^{12}$

Mais quelle était la vie à bord ? Hawkins (1981 : 32-33), qui la connaît bien, nous décrit ce qu'elle était à bord d'un boutre vers les années 1950, description qui vaut probablement pour les siècles antérieurs. «Il est impossible de s'isoler et la cuisine consiste en une boîte à feu située à l'avant du bateau. Chacun mange comme il peut et où il peut. Frugal il y a une cinquantaine d'années, le régime n'a pas varié. Les aliments de base sont ce qu'ils ont toujours été : riz, poisson séché, dattes, graisse, café si le boutre est arabe, thé, s'il est indien. Lorsque le voyage dure plus longtemps que prévu, on remplace, dit-on, par de l'eau de mer ce qui manque dans le réservoir d'eau douce. Il arrive fréquemment que les marins arabes soient atteints de calculs rénaux, conséquence de la déshydratation » (Photographies 14 et 15).

\section{Photographie 14 : Cuisinier d'un boutre indien port de Colombo}

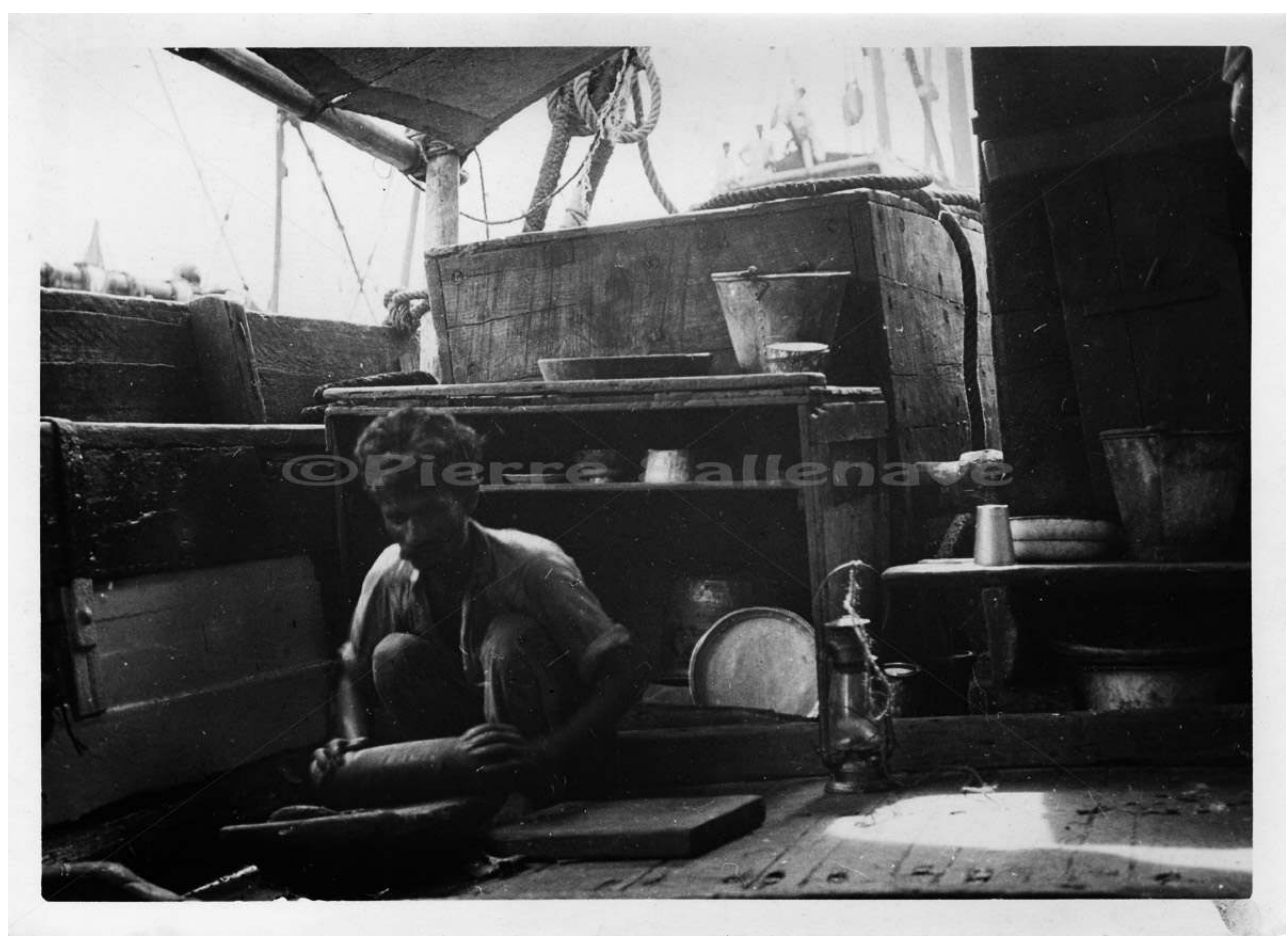

(C) P. Sallenave1934 


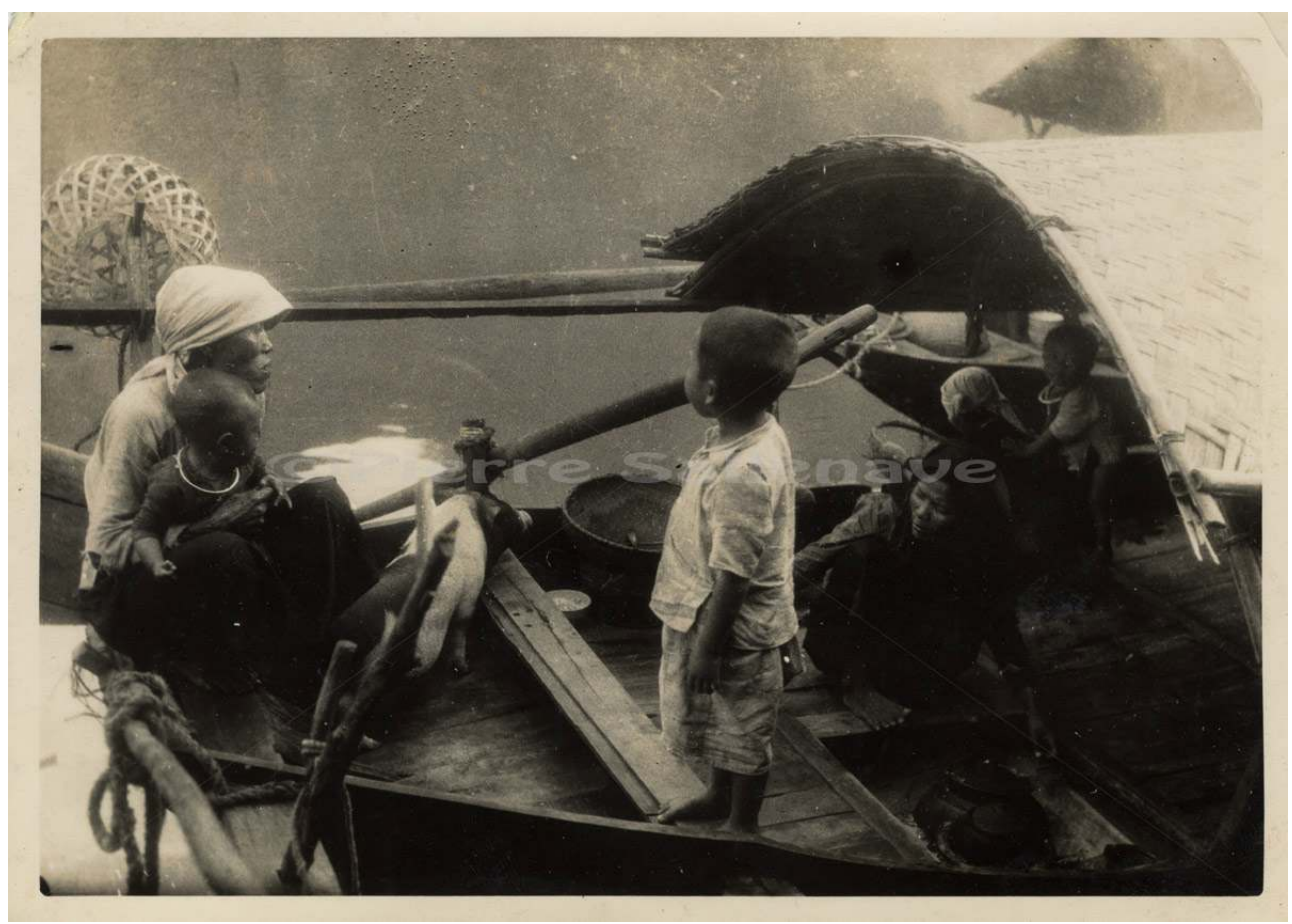

C P. Sallenave 1935

68 Par ailleurs il était nécessaire, dans les eaux chaudes de ces mers, de réviser les bateaux plusieurs fois par an : Mombasa est aujourd'hui l'un des ports préférés des bateaux arabes et indiens pour leur remise en état avant la fin de la saison et le retour au port d'attache en Arabie, dans le Golfe ou en Inde - avec la mousson d'été (Photographies, 16, 17 et 18). On profite de la marée de printemps, celle de Pâques, qui permet de hâler les bateaux sur la plage et de mettre les coques à sec, en carénage. C'est alors qu'on les gratte pour enlever les algues, les bernacles parasites et l'ancienne couche de graisse et de chaux, puis on passe un enduit anti-fooling ${ }^{13}$ contre les tarets, le shahamu (en arabe " graisse ») à base de chaux et de graisse animale (de chameau ou de bœuf) ou végétale. Chardin, à la fin du XVII ${ }^{\mathrm{e}}$ siècle, s'étonne de voir les samboucs cousus de Bandar Abbas couverts d'un enduit à base de chaux et non de poix comme en Occident. La composition de cet enduit à base de chaux est identique à celle pratiquée par les Chinois qui pourraient bien avoir influencé les bateaux de l'océan Indien. 
Photographie 16 : À Mombasa

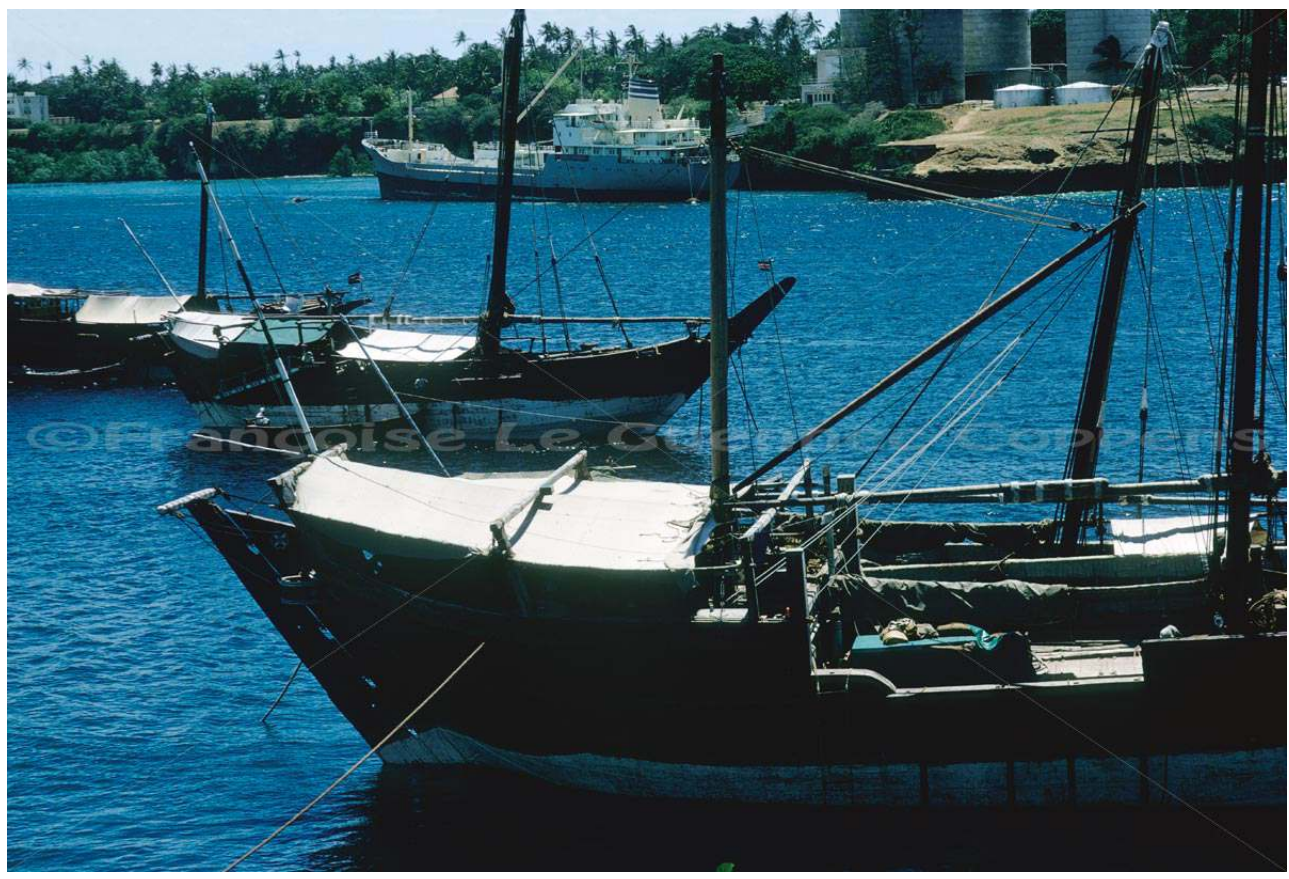

(c) F. Le Guennec Coppens mai 1972

Photographie 17 : À Mombasa

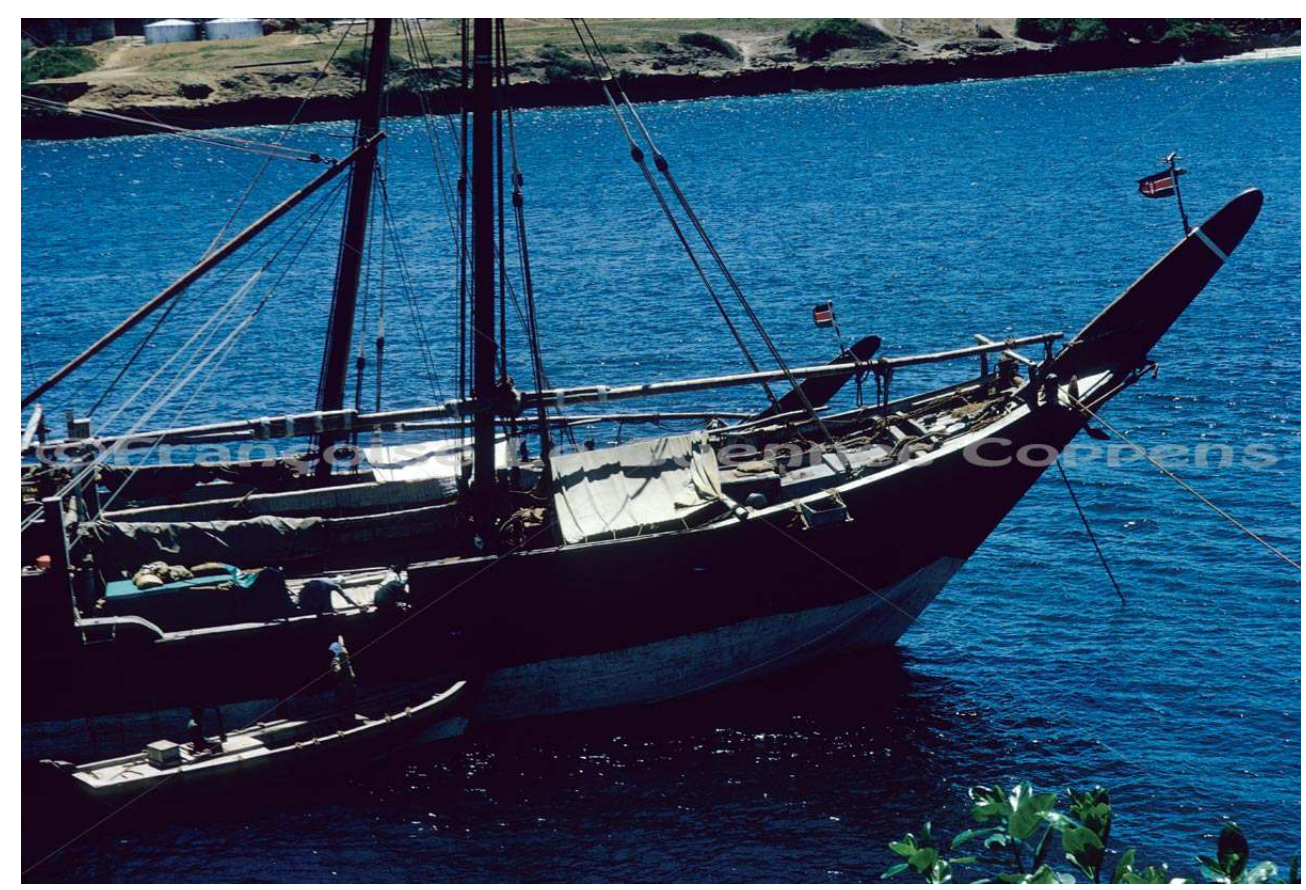

(c) F. Le Guennec Coppens mai 1972 
Photographie 18 : Mombasa, boutre, pied du mât

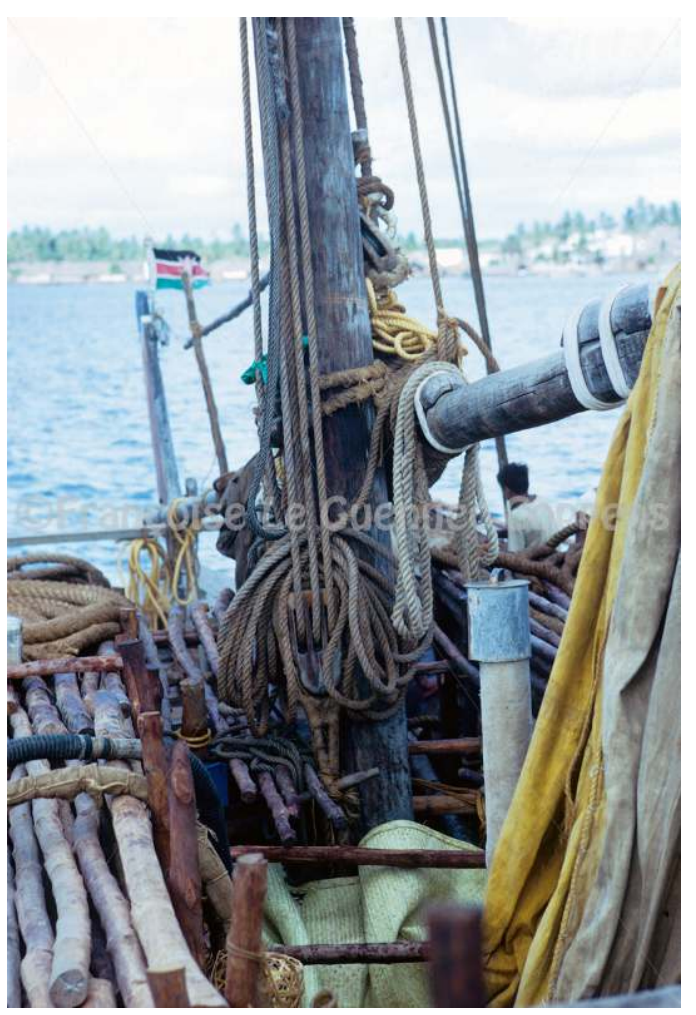

(c) F. Le Guennec Coppens avril 1972

Aujourd'hui cette marine traditionnelle garde toute son importance. En 1945, 5000 boutres environ croisaient encore au large de la côte occidentale de l'Inde (Hawkins 1981 : 109), ce nombre n'a guère diminué aujourd'hui puisque certains bateaux se sont adaptés au moteur qui est loin d'affranchir totalement de la mousson. En effet, le moteur n'est qu'un ajout au bateau qui conserve toujours ses voiles et les utilisent aux allures portantes.

\section{La quête des épices dans l'océan Indien avant les Portugais}

Principale productrice d'épices, l'Asie en est depuis toujours une forte consommatrice. D'après les Pen t'sao, ouvrages de matière médicale chinoise et les Ayurveda, ouvrages sanscrits de l'Inde, rédigés aux alentours de l'ère chrétienne, on utilisait largement le poivre, le gingembre, la cannelle, le curcuma, le santal. Si l'Inde produisait tous ces produits, la Chine devait, quant à elle, en importer quelques uns.

Les relations entre les diverses populations bordant l'océan Indien et le Pacifique remontent loin dans le passé. Indiens, Chinois et Malais, grâce à leurs techniques évoluées de la navigation et la connaissance des vents de mousson et des courants, pratiquent la navigation hauturière dès avant l'ère chrétienne. Soit ils allaient chercher, soit ils exportaient, soit ils acclimataient épices, parfums et bois précieux. 


\section{Les épices de l'Asie des Moussons} C'est avec le poivre, Piper nigrum, que l'on peut se faire une idée de l'ancienneté et de l'étendue des routes commerciales maritimes. Cette épice prestigieuse a été jusqu'à la Renaissance le produit de base du commerce entre l'Inde et l'Europe. Indigène sur la côte des Malabar au sud de l'Inde, cette liane a, très tôt, été importée par les missionnaires bouddhistes dans l'archipel malais et au Cambodge. Notre monde méditerranéen antique connaît le poivre, mais avec des éclipses ; n'en a-t-on pas trouvé dans la momie de Ramsès II, mort en 1235 av.J.-C. ? Théophraste (370-285 av. J.-C.), sans la connaître, décrit dans son Livre des Plantes le fruit rouge du peperi frais, d'après les récits que lui en ont fait les scientifiques qui l'ont vu sur pied lors de l'expédition d'Alexandre en Inde. Ce ne fut, en fait, que peu de temps avant l'ère chrétienne qu'elle fut diffusée dans le monde romain ; on en connaissait aussi une autre espèce, le poivre long, Piper longum, le poivre des apothicaires, originaire d'Inde également, mais plus rare. ${ }^{14}$

Autres épices très anciennement connues, les cannelles Cinnamomum spp. sont des écorces d'épaisseurs variées, enroulées sur elles-mêmes comme de petits roseaux (canna, dimin. canella), que l'on récolte sur plusieurs espèces de grands arbres du sud-est asiatique. Deux espèces, produisant des écorces aux parfums assez semblables, sont utilisées. L'une, la Cannelle de Ceylan, $C$. verum J. Presl., est un petit arbre indigène dans la moitié sud-ouest de l'Inde où il croît jusqu'à $2.000 \mathrm{~m}$ d'altitude. Il vient sur les pentes occidentales des collines du Tenasserim et sur le versant occidental humide de Sri Lanka. C'est une des raisons pour lesquelles les Portugais occupent cette île en 1536. L'écorce, très fine, est détachée de l'arbre en un tube qui peut avoir un mètre de long. L'autre, la Cannelle de Chine, $C$. aromaticum Nees. est un grand arbre du sud de la Chine et de la péninsule indochinoise. L'écorce est épaisse et vient en morceaux. La première description chinoise en a été faite au $\mathrm{III}^{\mathrm{e}}$ siècle et au $\mathrm{v}^{\mathrm{e}}$ siècle. La Chine exporte encore de grandes quantités d'écorces vers la Malaisie pour des usages médicaux. On utilise aussi comme aromates, et depuis fort longtemps, ses fruits non mûrs et séchés. Ils sont une épice importée en Europe dès le XIII ${ }^{e}$ siècle. piquante, à l'arôme caractéristique, et l'employait de façons variées, dans les cuisines des divers pays de l'Occident médiéval. Venise et Gênes l'importèrent en grandes quantités d'Alexandrie et des ports de Syrie et Palestine où les caravanes l'amenaient de Basra à la suite des bateaux persans et arabes qui s'en chargeaient dans les pays d'origine, Inde du sud, Ceylan. Dans son pays d'origine, cette plante est connue depuis les temps très anciens sous le nom sanscrit de sringavera. Une autre espèce assez connue au Moyen Âge mais aujourd'hui quasiment disparue de nos cuisines occidentales est le zérumbet ( $Z$. zerumbet), du persan zurunbâd, plante native du Chittatong et que la médecine utilisait comme stimulant et sudorifique. Toutes les plantes de cette famille des Zingibéracées ont une nature forte et très aromatique; nous en connaissons quelques autres, curcuma, galanga, zédoaire. Toutes sont originaires de l'Inde et d'Asie du sud-est.

Les Cardamomes Elettaria cardamomum (L.) Maton, sont des herbes poussant naturellement dans les forêts humides des montagnes du sud-ouest de l'Inde et de celles de Ceylan. On en connaît deux variétés dont la principale est la petite cardamome, très appréciée et qui fournit le gros des exportations. On la cultive traditionnellement en Inde du sud, dans les états du Kérala et de Nilgiri et à Ceylan. C'est l'une des épices les plus

Revue d'ethnoécologie, 5 | 2014 
anciennement connues en Inde et que mentionne l'Ayurveda de Susrut. Elle apparaît au I ${ }^{\text {er }}$ siècle en Méditerranée ; Plutarque, note dans son traité d'Isis et d'Osiris, qu'elle entre dans les parfums de sacrifices égyptiens. Elle devint plus courante aux $\mathrm{III}^{\mathrm{e}}$ et $\mathrm{IV}^{\mathrm{e}}$ siècles, période où se déploie à Rome un grand luxe venu de l'occupation des provinces moyen-orientales, où l'on commence à connaître également le clou de girofle et la noix muscade importés des Moluques via la Malaisie.

Dès le début de l'ère chrétienne, les navires chinois sillonnaient le Pacifique à la recherche d'épices et de parfums qui occupaient une place importante dans les rituels religieux, la cosmétique et la pharmacopée. Le santal et le bois d'aloès étaient les plus prestigieux.

77 Les Santals Santalum spp. sont de petits arbres, inégalement répartis depuis l'Inde centrale jusqu'au nord de l'Australie et les îles du Pacifique. Le bois parfumé des espèces du Pacifique faisait l'objet, bien avant l'arrivée des Européens, d'un commerce au long cours à bord de grandes pirogues à balancier; l'on connaît les voyages extraordinaires des Hawaïens à la recherche du bois de santal qu'ils avaient épuisé chez eux. Son importance s'explique par son usage comme encens privilégié dans les rituels religieux d'Extrême-Orient, en petits copeaux ou en poudre. Le santal blanc, Santalum album L., petit arbre, vit en parasite sur les racines d'autres arbres. Indigène en Indonésie orientale, de l'est Java à Timor, il est très anciennement introduit en Inde dont c'est un des parfums les plus anciennement mentionnés. Il est aussi le premier connu au Moyen-Orient peut-être dès avant notre ère, mais avec certitude au $\mathrm{VI}^{\mathrm{e}}$ siècle quand le voyageur grec Cosmas Indicopleustes, en signale le commerce depuis Ceylan (Liv. XI, 15). À cette même époque, le santal arrivait en Chine par l'intermédiaire du Cambodge avec lequel les Chinois entretenaient des relations commerciales par mer (Laufer 1919 : 318).

Les Bois d'Aloès ou bois d'aigle, Aquilaria spp., sont récoltés dans les forêts du sud-est asiatique par des populations de chasseurs-collecteurs. Ils sont depuis au moins deux millénaires l'objet d'un commerce actif avec l'Extrême-Orient, principalement la Chine ; Hui-Lin Li (1979 : 105-107) cite au début du IV siècle le papier parfumé fabriqué à partir de l'écorce de gharu-wood. Dans les forêts du Centre-Viêtnam et du Cambodge, Chinois et Arabes vinrent très tôt le chercher. On le trouve également dans les forêts de l'Assam, dans la Péninsule de Malacca, et dans toute la Malaisie.

80 Ces deux bois sont les parfums les plus estimés pour les cérémonies religieuses d'Asie du sud-est, Chine et Japon, tant chez les Bouddhistes, que chez les Mahométans. Mais la Chine elle-même possède des épices et des parfums qu'elle utilise dans les rituels religieux, la cosmétique et la cuisine. Ce sont des graines et des résines.

81 La badiane ou anis étoilé, Illicium verum Hook., est la graine du fruit en forme d'étoile d'un grand arbre, indigène au sud de la Chine dans les provinces du Kouang-Si, du KouangToung, dans l'île de Haïnan et au nord du Viêtnam. Très tôt introduite au Japon, elle ne fut que tardivement connue en Europe. C'est vers 1588 que l'anglais Cavendish en aurait rapporté à Londres quelques graines des îles Philippines ; ou bien, c'est Charles de l'Ecluse qui en apporta à Londres en 1601, et en donna la première description. Toujours est-il que le terme badiane vient du persan bâdyân qui désigne le fenouil. Il fut introduit par Thévenot en 1681.

82 Exploité en Chine dès le $\mathrm{VII}^{\mathrm{e}}$ siècle au moins, le camphrier de Chine, Cinnamomum camphora (L.) J. Presl., vient dans les provinces du sud et de Formose, et fournit le 
camphre naturel du commerce, connu sous le nom de camphre de Chine, du Japon, de Formose. Les Arabes utilisent très tôt cette résine et l'exportent vers l'Occident musulman. Le Coran le mentionne le camphre dont on peut penser que c'est le camphre de Chine arrivant par la route dite de la soie.

Autre source de camphre, celui que fournit le camphrier, Dryobalanops aromatica Gaertn., arbre de haute taille de Bornéo, Sumatra et de la péninsule malaise. Il atteint couramment $80 \mathrm{~m}$ et fournit le camphre de meilleure qualité ; mais surexploité, pour les Bouddhistes et les Musulmans, il est devenu très rare et pour cela très coûteux. ${ }^{15} \mathrm{Il} a$ aujourd'hui pratiquement disparu.

Également très recherché par les Arabes et les Chinois, l'Elémi de Manille Canarium spp., est une oléo-résine fournie par diverses espèces de Canarium. On disait aussi « animé ». Il est fourni en Malaisie par Canarium luzonicum ; qui est également présent au nord des îles Philippines, et par C. commune L., en Indochine. Dans les pays d'Asie du sud-est, on s'en sert comme encens, sans parler des usages médicaux.

L'archipel malais et plus particulièrement les îles Moluques sont la source de la muscade et du girofle, les épices les plus orientales utilisées par notre monde européen. Mais, bien avant l'arrivée des Portugais, en 1512, les Malais fournissaient les armateurs chinois et arabes en clous de girofle, noix muscade et macis qui sont tout à la fois parfum et épice (Photographie 19).

\section{Photographie 19 : Prao de transport, Kolek,Nord-Java}

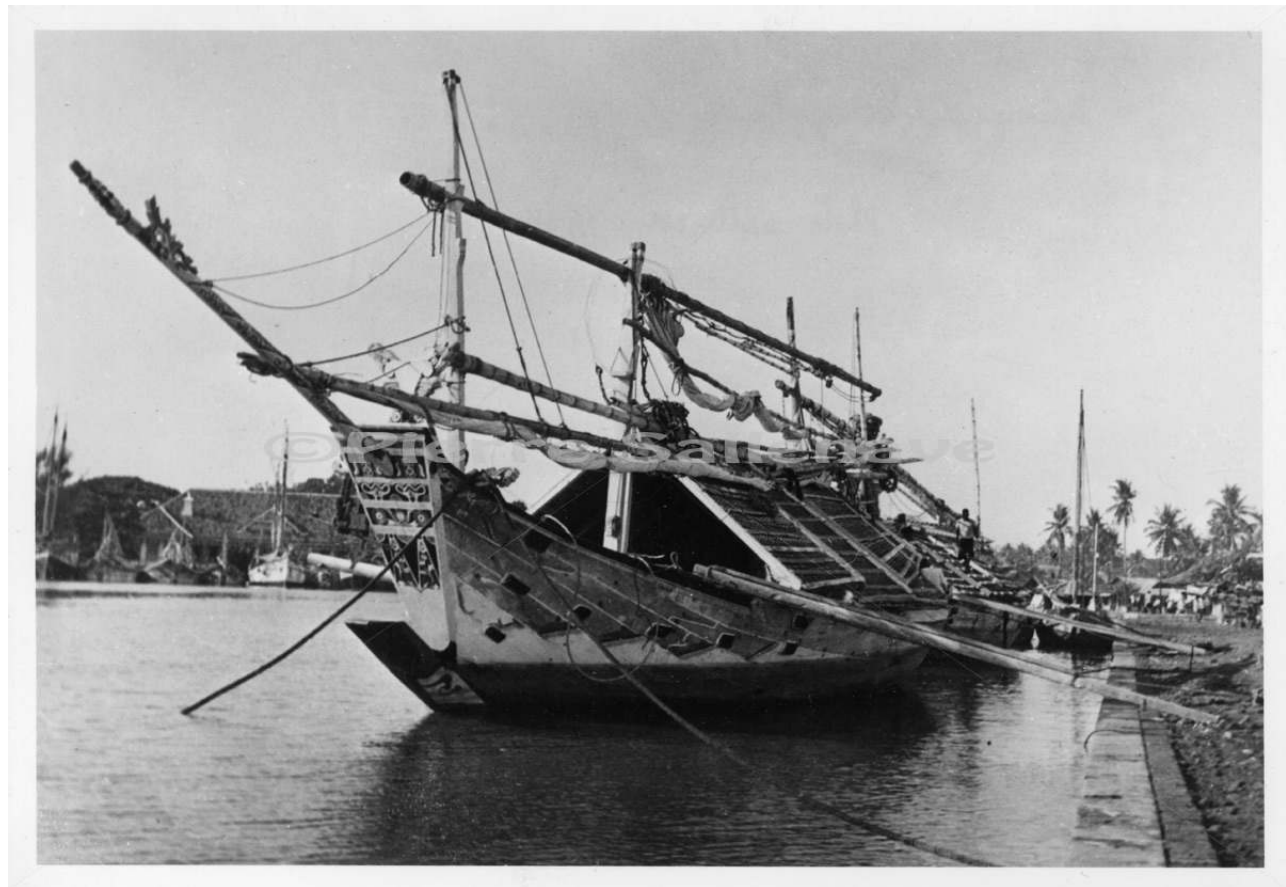

(C) P. Sallenave 1934

Natif des Moluques, sauvage à Céram et dans les îles du sud et est de l'archipel malais, indigène à Banda, Amboine et l'ouest de la Nouvelle Guinée, le muscadier Myristica fragrans Houttuyn., fournit la graine et le macis qui l'entoure; celui-ci en est la pulpe séchée. Inconnu de l'antiquité, ce sont les Arabes qui l'introduisent en Occident. alMas'ûdî qui va en Inde en 916-920 note que muscade, clou de girofle et santal viennent 
«des mers qui bordent l'Inde et la Chine» que l'on pourrait interpréter comme étant celles qui bordent les îles Moluques. des îles heureuses (peut-être Socotra), que les marchands de l'Inde et de la Perse y font escale $^{17}$. Cette île se trouve sur la route de l'Afrique de l'est où la présence indienne est celle qui est la plus anciennement attestée, dès 200 ans av. J.-C. Cette présence indienne a perduré et, aujourd'hui encore, les Banyans du Gujerat y vivent très nombreux ${ }^{18}$.

91 L'activité maritime indienne est, aux $\mathrm{I}^{\mathrm{e}}$-II ${ }^{\mathrm{e}}$ siècles, développée en un large réseau comme le montre l'organisation du port de Barugaza (ancienne Bharukaccha, aujourd'hui Broach) dont les pilotes, montés sur des trappaga et korumba, longs bateaux avec un équipage important ${ }^{19}$, font entrer les navires étrangers, dans la ville, située au fond d'un estuaire qui en rend l'accès difficile (Huntingford 1980 : chap. 43-44).

L'ancienneté de la présence des missionnaires bouddhistes indiens dans l'archipel malais donne une idée de cette marine et de la maîtrise indienne de la mer et des vents de mousson. Ils convertissent et colonisent les populations de Java et de la presqu'île de Malacca, aux premiers siècles de l'ère chrétienne et y introduisent, avec leurs noms sanscrits, quelques plantes alimentaires comme l'oignon, la pastèque, le sésame, des arbres fruitiers tels la pomme-cannelle Eugenia jambolana, des Citrus, le jujube Zizyphus jujuba ; ils introduisent également des plantes et arbres rituels utilisés par les prêtres et pour les pompes royales tel Michelia Champaka aux fleurs délicieusement parfumées (Haudricourt 1953 : 540-541). 

développement de leur marine qui devait aller avec la connaissance de la mousson. Ce sont les splendides bas-reliefs du temple de Borobudur, datés du début $\mathrm{VII}^{\mathrm{e}}$ siècle, et qui mettent en scène des navires. Deux types de bateaux sont représentés : l'un est un gros navire avec un balancier, l'autre type ne comporte pas de balancier. Ce serait, selon les chroniques javanaises, des navires du Gujerat sur lesquels, vers 603, un roi du Gujerat, devançant la destruction de son royaume par les Scythes (Perses), partit avec son fils et 5000 personnes parmi lesquelles des paysans, des artisans, des guerriers, des médecins, et des écrivains. Ils s'embarquèrent sur six grands navires et cent petits bateaux pour Java où ils fondèrent une civilisation qui a donné Borobudur aux innombrables bas-reliefs (Mookerji 1957: 34; n. 1; 103-105²0. Cette marine de la côte occidentale indienne est restée très active. En témoignent les nombreux types de voiliers qui sont indiens : kotia, dhoni, ganja, pattamar etc.

L'Inde est un pays producteur d'épices -le poivre, la cannelle, le gingembre poussent dans les régions du sud, Malabar et Kerala-, de plantes à parfums -le costus et le santal-, de produits parfumés -le musc du chevrotin du Tibet et de l'Himalaya-, de bois de construction navale comme le teck et de bois de teinture comme le bois rouge « Brésil » ( Caesalpinia Sappan) qui donnera son nom au Brésil. C'est aussi le pays par lequel transitent les produits venant de Malaisie, des îles de la Sonde ; ce sont d'autres épices (cardamome, galanga, zédoaire), des bois de senteur (bois d'aloès, santal), des résines parfumées (camphre, benjoin). Les Indiens seront autant marchands de leurs propres produits qu'intermédiaires de produits qu'ils vont chercher plus à l'est, de même que les Persans et les Arabes seront les intermédiaires entre l'Orient et la Méditerranée avant les Portugais. À partir de 1865, l'Inde anglaise devient producteur d'une plante qu'elle ignorait jusque là, le thé, qui donnera lieu à un commerce intense.

La côte occidentale, bien que recevant de plein fouet la mousson d'été qui empêche les mouvements des bateaux pendant quatre à cinq mois, est cependant la côte la plus active. C'est là que sont produites la plupart des épices indiennes que viennent chercher Persans, Arabes et Chinois. Elle abrite de nombreux ports très sûrs. Calicut, sur la côte des Malabar, est l'un des meilleurs et des plus importants. Pour Ibn Battuta (c. 1343), il est l'un des plus grands ports du monde où se rencontrent les gens de Chîn, de Java, de Sailân, de Lahal (Maldives), du Yémen, et du Fars qui y commercent le poivre, le teck, le curcuma, et l'ambre gris. Cent ans plus tard, l'italien Conti (1430) admire cette grande ville, le plus important des emporia de l'Inde, où l'on trouve en abondance le poivre, la laque, le gingembre, la cannelle la plus riche, le myrobolan chebul, le zédoaire. Sa renommée en fait le terme du voyage de Vasco de Gama. Proche de Calicut, Cochin est une ville fameuse où l'on négocie beaucoup de poivre, selon Birdwood en 1606. Un peu au nord, Goa devient au XVI ${ }^{\mathrm{e}}$ siècle l'emporium des Portugais; il est l'aboutissement du voyage en Inde et le départ vers l'Extrême Orient, Chine, Japon et vers l'Éthiopie et l'Afrique de l'est. Autre port très ancien, Surate sur le golfe de Cambaye, dans le Gujerat. Les Musulmans l'appellent la Porte de la Mekke parce qu'on s'y embarque en foule pour le pèlerinage. Elle prend son essor avec les Européens. $\mathrm{Au} \mathrm{XVII}{ }^{\mathrm{e}}$ siècle, elle est "l'un des grands relais de l'océan Indien entre la mer Rouge, la Perse et l'Insulinde ; c'est la porte de sortie et d'entrée de l'empire moghol,... le rendez-vous préféré d'armateurs et de prêteurs à la grosse aventure. Les lettres de change y affluent; qui vient s'y embarquer est sûr d'y trouver de l'argent affirme Tavernier (1925, 2 : 21). Autre signe de grand négoce : un parfait cosmopolitisme ethnique et religieux. À côté des Banians (qui tiennent 
la première place en tant qu'intermédiaires) et du vaste artisanat «gentil » de la ville et de ses environs, il faut situer, à égalité ou presque avec les Hindous, une société marchande musulmane qui étend elle aussi ses affaires de la mer Rouge à Sumatra et au reste de l'Insulinde, plus une colonie active d'Arméniens » (Braudel 1979 : II, 520).

\section{Les Chinois à la recherche des épices et du savoir bouddhique}

Du côté des Chinois, l'on a également très tôt des informations sur l'activité maritime, qui était nécessairement lié à la connaissance des moussons. Depuis longtemps déjà, ils possèdent une batellerie extraordinairement diversifiée et efficace, et, dès avant notre ère, pratiquent la navigation hauturière. Sous les Han (202 av. J.-C.-220 ap. J.-C.), les ports de Canton et de Haïphong (qui appartenait alors à la Chine) accueillaient les marchands de Chine, des Indes et du monde arabo-persan. Là s'échangeaient les soies, les pierres précieuses, les aromates (Bray 1987 : 194). Avec l'avènement du Bouddhisme au vi siècle avant notre ère, les relations avec l'Inde se sont multipliées, par la route intérieure d'abord, puis également par mer. Des bouddhistes allaient en Inde parfaire leurs connaissances ; c'est ainsi qu'un groupe de Chinois part en 399 pour revenir en 414. Fahsien relate ce voyage qui le mène à Tamluk, à l'embouchure du Hoogli, dans le golfe du Bengale, région riche en monastères bouddhiques, où il passe deux ans à copier des sutras avant de s'embarquer pour Ceylan qu'il atteint quatorze jours plus tard grâce à la mousson d'hiver qui souffle du nord (Giles $1923: 66$ ).

Une route maritime menant de Chine à Ceylan était ouverte vers 317-32021. Elle s'est rapidement prolongée à l'Inde occidentale et plus tard à la Perse, où selon al-Mas'ûdî (943), dès la première moitié $d u v^{e}$ siècle, les bateaux chinois et indiens remontaient jusqu'à an-Nedjef qui, autrefois, était à l'embouchure de l'Euphrate et dépendait de la royauté de Hira (al-Mas'ûdî , trad. I : 88).

C'est du monde entier que leur viennent, sous les T'ang (618-907), les produits pour leurs encens; les plus employés sont le bois d'aloès du Viêtnam, l'encens d'Inde et d'Arabie, le patchouli de Malaisie, les girofles des Moluques, le liquidambar d'Indochine ${ }^{22}$. À cette époque, les bateaux atteignaient régulièrement l'Inde. Les Chinois y connurent de nombreuses plantes qu'ils introduisirent dans leurs Géographie et Histoire naturelle avec leur nom indien (Bretschneider 1870-1871: 93-94) et qu'ils acclimatèrent, comme le jasmin d'Inde dont ils parfument aujourd'hui leur thé. Ils entretenaient également de fréquents rapports aussi bien par voie de terre que par voie de mer avec la Perse et aux VIII ${ }^{\mathrm{e}}$-IX ${ }^{\mathrm{e}}$ siècles avec les Califes Abbassides (Bretschneider 1870-1871 : 93-94).

9 Les Annales des T'ang décrivent, aux $\mathrm{VII}^{\mathrm{e}}$ et $\mathrm{VIII}^{\mathrm{e}}$ siècles, la route suivie par leurs jonques depuis Kwangchau (Canton) jusqu'à l'Euphrates. En 851, le marchand Sulayman atteste que l'on chargeait à Sirâf les marchandises sur les bateaux chinois qui allaient à la même époque à Aden; ils allaient probablement aussi sur les côtes de l'Afrique à la recherche d'ivoire et de cornes de rhinocéros.

Mais les troubles qui eurent lieu en Chine, à la fin du $\mathrm{Ix}^{\mathrm{e}}$ siècle, amènent une récession et, au XII ${ }^{\mathrm{e}}$ siècle, le port le plus à l'ouest que touchaient les jonques était Debal sur la côte du Sind, probablement près de Karachi; el-Edrisi (1154) décrit ce port comme un lieu d'échange entre les produits de la Chine et de l'Inde et ceux venant d'Oman. À partir de cette époque, c'est dans les îles de la Sonde qu'ils allèrent s'approvisionner en épices et aromates. 


\section{L'Antiquité occidentale connaît la mousson avec Alexandre} d'Alexandre lorsque ce dernier envoya le crétois Néarque conduire une flotte macédonienne de 800 bateaux transportant 1000 hommes, matelots et rameurs, pour reconnaître les côtes depuis l'embouchure de l'Indus jusqu'au golfe Persique (326-325 av. J.-C.). Arrien a laissé dans son Historia Indica, chap. XX, un résumé de la relation de ce voyage. L'expédition partit « quand se calmèrent les vents étésiens qui pendant tout l'été soufflent de la mer (c'est à dire du sud-ouest) et empêchent la navigation ». « Ils partirent le 20 du mois de Boèdromiôn, suivant la chronologie athénienne ", et donc avec la mousson du nord-est. Cette date correspond, selon Arrien, au 2 octobre 326 et, selon Chantraine qui rétablit la chronologie, au 21 septembre 325. Malgré cet exploit, les routes qui menaient vers les pays lointains des épices et des parfums (Ceylan, côte orientale de l'Inde, Malaisie, Indonésie) étaient, à cette date, contrôlées par les Indiens et les Persans surtout, puis les sud-Arabiques qui approvisionnaient le Moyen Orient et la Méditerranée depuis quelques siècles avant notre ère.

«Le contact établi entre le monde méditerranéen et l'Orient à la suite de la campagne d'Alexandre, la fondation de l'empire d'Açoka et plus tard de celui de Kanishka, la naissance de l'empire des Séleucides et de l'empire romain avaient donné au commerce des « denrées de luxe » un essor grandissant " (Cœdès 1948: 41-42). C'est dès le premier siècle de notre ère que les Grecs, notamment ceux d'Alexandrie, eurent des relations maritimes régulières avec l'Inde et mirent la main sur un commerce jusqu'alors détenu par les Indiens et les Persans. Ils y allaient chercher les perles, les animaux rares, l'acier, le coton et les épices qu'ils connaissaient déjà : le poivre, la cannelle de Ceylan que les Hébreux plaçaient au rang des meilleurs parfums, et un peu le gingembre ${ }^{23}$. Partant des ports égyptiens de la mer Rouge, on longeait les côtes jusque sur la rive occidentale de $\mathrm{l}^{\prime}$ Inde riche en épices. Au IV ${ }^{\mathrm{e}}$ siècle, les Romains atteignaient probablement régulièrement Ceylan où ils acquéraient la cannelle; c'est ce qu'attestent les très nombreuses pièces de monnaie de cette époque trouvées dans vingt sites différents de l'île (Miller $1969: 239)^{24}$. Depuis cette époque, l'île fut visitée par tous pour ses richesses (perles, parfums, épices), Persans, Arabes qui l'appelaient Sarandip, Sarandib. Plus tard, les Italiens et les Portugais la nomment Seyllan, Zeilam, Cillam, Ceylam. Aujourd'hui, c'est Sri Lanka.

Dès le $\mathrm{I}^{\text {er }}$ siècle de notre ère, le monde antique connaissait ces vents. Pline, l'un des premiers, mentionne l'existence de la mousson sous la forme de quatre noms de vents qui permettaient l'aller-retour en un an de l'Égypte aux pays de l'encens, Somalie et Yémen, et ceux des épices, Inde. C'est vraisemblablement des Égyptiens et Grecs d'Égypte qu'il a obtenu ses informations puisqu'il mentionne les noms égyptiens des mois.

« Du cap Syagros, en Arabie, ils vont à Patale [près de l'embouchure de l'Indus] avec le vent Favonius qu'ils appellent là Hippalus » (H. N. VI, 26, 100). L'hippale pourrait donc être la mousson du sud-ouest. Plus loin, dans le même chapitre, il ajoute « La navigation commence au début de l'été avant le lever du Chien [l'étoile Canopée] ou immédiatement après, et on arrive vers le trentième jour à Ocelis, en Arabie, ou à Cané, dans une région productrice d'encens...Pour aller en Inde, le mieux est de partir d'Ocelis; de là par le vent hippale, on gagne en quarante jours le premier entrepôt de l'Inde, Muziris [sud-ouest de l'Inde]... Le retour a lieu au début du mois égyptien de Tybis, qui est notre décembre, ou en tout cas avant le sixième jour du mois égyptien de Méchiris, c'est-à-dire avant nos Ides de janvier. Il se fait ainsi qu'on revient dans une même année. On fait voile de l'Inde par vent vulturne et une

Revue d'ethnoécologie, 5 | 2014 
fois rentré dans la mer Rouge, par l'africus ou par l'auster» (Pline l'Ancien ( ${ }^{\mathrm{er}}$ siècle)

1980, VI : 104-106).

1- De l'Égypte à Ptolemais et Adouli, les bateaux naviguent de janvier à septembre, c'està-dire de Tubi à Thôth; la meilleure époque étant septembre (Huntingford 1980 : chap. 4, $6)$.

2 - De l'Égypte vers le sud sur la côte africaine (ports de Avalitês, Malaô, Mosullon, à Opônê [et probablement Rhapta, bien qu'il ne la mentionne pas, au sud de Zanzibar] la meilleure époque est juillet (Huntingford 1980 : chap. 7 à 14).

3 - De l'Égypte à Mouza [sud-est mer Rouge], la meilleure époque est septembre, mais aussi auparavant (Huntingford 1980 : chap. 24).

4 - À propos de Barbarikê [ou Barbarikon, à l'embouchure de l'Indus, (Huntingford 1980 : 108], il dit »ceux qui naviguent avec les vents indiens prennent la mer en juillet « , c'est-àdire avec la mousson de sud-ouest (Huntingford 1980 : chap. 19).

5 - De l'Égypte à Barugaza (nord-ouest Inde), la navigation se fait vers juillet avec de grands bateaux [c'est-à-dire avec mousson du sud-ouest] (Huntingford 1980 : chap. 49). 6 - De l'Égypte à Limurikê [sur la côte tamoule, Huntingford 1980 : 113], via Kané [cf Shihr], et Aromata [ou Arômaton, à la pointe orientale de l'Afrique], la navigation se fait vers juillet, c'est-à-dire Epiphi, en faisant face au vent [c'est la mousson du sud-ouest ; ils ont donc des bateaux qui remontent au vent ou bien ce sont des bateaux à rames, type galère] (Huntingford 1980 : chap. 56 et 57 ).

7 - Les bateaux allant à Barugaza et Skuthia [pays à l'ouest de l'Indus, chap. 38], font face au vent pendant pas plus de trois jours puis s'éloignent des côtes et traversent l'océan avec le vent du sud-ouest appelé Hippalos, du nom de celui qui a découvert ce passage ${ }^{25}$ (Huntingford 1980 : chap. 57).

Bien que datant de 2000 ans, ces deux descriptions sont parfaitement d'actualité ce qui est un gage de la justesse de ces textes.

Il semble que Grecs et Latins aient acquis des Égyptiens leur savoir sur la navigation dans l'océan Indien. Ceux-ci connaissaient en effet depuis longtemps ces zones : la fameuse expédition de la Reine Hatshepsout (règne de 1504-1483 av. J.-C.) vers le pays de Punt, même si on ne s'accorde pas à situer cette région (est-ce la Somalie ou l'Hadramaout?) témoigne de l'ancienneté de ces navigations ${ }^{26}$. Un autre élément met peut-être en évidence les liens entre l'océan Indien et l'Égypte, c'est la construction navale à chants liés attestée clairement en Égypte par Hérodote au ve siècle av. J.-C. (Hérodote 1985, livre II : 96) ${ }^{27}$. De plus, les nombreux ports de la côte égyptienne de la mer Rouge attestent l'activité maritime des Égyptiens, Arsinoé, Myos Hormos, Mussel, Leucos Limen, Bérénice, Ptolemas, Adulis ...que les Grecs d'Alexandrie continuèrent d'utiliser.

Grecs et Romains commercèrent jusqu'à ce que se ressente la chute de l'empire romain, vers le $\mathrm{VI}^{\mathrm{e}}$ siècle. À ce moment-là, la marine persane prend le relais. 


\section{L'essor de la marine persane après la chute de Rome} serait peut-être la moderne Tâhira, selon Hornell. En tout cas, à cette époque, ce port était réputé pour les belles maisons des riches armateurs, construites en teck $d^{\prime} I n d e^{30}$ et divers bois d'Afrique, tels les palétuviers dont on faisait les poteaux. Il reste très fréquenté jusqu'aux $\mathrm{XI}^{\mathrm{e}}, \mathrm{xII}^{\mathrm{e}}$ siècles et est le lieu d'origine de plusieurs personnages tels Abû Zayd, l'auteur du Akhbar al-Sin wa-l Hind "Observations sur la Chine et l'Inde " (Reinaud (1946) 1982: XV ; al-Mas'ûdî, ( $x^{e}$ s.) 1962-1971, I : 130, n. 2) et l'hypothétique marchand Sulayman ${ }^{31}$. Le géographe al-Mas'ûdî connaît également bien ce port pour l'avoir souvent fréquenté. $\mathrm{Au} \mathrm{x}^{\mathrm{e}}$ siècle, les boutres de Sîrâf commerçaient régulièrement avec l'Afrique que l'on nommait globalement Zangî-bâr " pays des noirs "; plus tard, au $\mathrm{xv}^{\mathrm{e}}$ siècle, Zanzibar a désigné l'île qu'elle est aujourd'hui. Leurs bateaux s'aventuraient dans la mer Rouge jusqu'à Djeddah, centre important où transitaient les cargaisons en provenance d'Extrême-Orient et des Indes destinées à l'Égypte et aux pays riverains de la Méditerranée. Mais les Persans, craignant les récifs situés au nord de Djeddah, transbordaient leurs marchandises sur des boutres arabes dont les équipages connaissaient bien ces parages. Bandar Abbas, à l'entrée du golfe Persique, que les anciens documents européens appelaient Gombroon est encore aujourd'hui actif. Kung Bandar au nord du golfe Persique, est selon Tavernier (1925, I : 94), bien plus agréable à habiter qu'Ormuz qui est malsain. À Kongûn, on apporte, selon Hamilton au début du XVIII e siècle (I, $92 \mathrm{sq})$, les perles pêchées à Bahreïn et c'est de là qu'on embarque beaucoup de beaux chevaux pour l'Inde où ils se vendent bien. Il reçoit de bons navires jusque vers 1859. 
113 Aujourd'hui Abadan et Khoramshar sur le Chott el-Arab, Bandar Shapur dans la baie de Khor Musa, sur le littoral nord du golfe Arabique, Bushire, Bandar Lingeh et Bandar Abbas, proche de l'antique Hormuz sont les ports d'attache des boutres persans.

\section{Les marins d'Arabie du sud}

114 Le peu de chose que nous sachions sur l'ancienneté des connaissances en matière de navigation chez les Arabes nous vient des Grecs. Cependant, il convient de distinguer les Arabes du centre de la péninsule qui sont des bédouins ignorant des choses de la mer d'avec ceux qui vivent sur les côtes, Omanais, sud-Arabiques et Yéménites.

115 Agatharchide de Cnide, vers le milieu du IIe siècle avant notre ère, laisse l'une des premières descriptions assez précise. La société d'Arabie du sud se divise en "guerriers, cultivateurs et navigateurs-commerçants qui exportent surtout certains aromates employant souvent de grands radeaux et des bateaux en peaux » (Rodinson $1984: 59)^{32}$. Ce détail donne une idée de la navigation possible de ces populations sud-arabiques. Le radeau, de même que les embarcations en peaux ne permettaient guère qu'une navigation côtière. Cependant s'ils étaient voilés, on pouvait, en utilisant les vents alternatifs de la mousson, naviguer jusqu'en Afrique de l'est ou jusqu'à l'Inde occidentale. Le texte, en outre, oppose ces embarcations à celles des Indiens et des Persans de l'époque et permet de penser que la navigation de ces populations sud-arabiques n'est que côtière alors que les marchands de l'Inde et de la Perse pratiquent une navigation hauturière avec des embarcations plus conséquentes.

116 Trois siècles plus tard, le Périple de la mer Érythrée, à propos du commerce de l'encens que font les Yéménites de Kané (proche de la moderne Shihr) avec Omana, Skuthia et Barugaza (en Inde), parle encore de radeaux, de fabrication locale, fait d'outres gonflées [de chèvres ou de moutons] ou de peaux [de bovidés]; il mentionne aussi des bateaux (Huntingford 1980 : chap. 27) appelés madarate qui sont vraisemblablement des bateaux cousus dont il dit (Huntingford 1980 : chap. 36) que l'Oman les exporte en Arabie [Yémen], ce qui témoigne de l'importance, à cette époque déjà, des arsenaux omanais, qui pouvaient fonctionner grâce au bois que le pays possédait ou que l'on importait probablement d'Inde et d'Afrique.

117 Les Arabes bédouins n'ont pas une réputation de marins. L'historien maghrébin Ibn Khaldûn, au XIV siècle explique, dans sa Muqaddîma, Discours sur l'Histoire universelle, comment ils le sont devenus.

«Les Bédouins arabes [arrivant en Méditerranée après la conquête de l'Égypte] n'étaient pas, au début, exercés à la maîtrise de la mer et de la navigation...Mais par la suite, les Arabes devinrent puissants, avec un pouvoir royal et des états solides. Les nations étrangères passèrent à leur service et sous leur domination. Tout spécialiste vint alors leur proposer ses bons offices et ils utilisèrent les marins pour les besoins [de leur marine] » (ibn Khaldûn (xIve s.) 1967-1968, II : 518-519).

Quant aux Arabes du golfe Persique, leur navigation était bien développée dès au moins les $\mathrm{VI}^{\mathrm{e}}$ ou $\mathrm{VII}^{\mathrm{e}}$ siècles, "les choses de la mer, dit Abou Zeyd el-Hassan de Sirâf en 851, étaient parfaitement connues à cause des nombreux voyages que les marchands de l'Iraq faisaient dans les régions maritimes ».

119 Cependant les vents de moussons sont à peine mentionnés par les auteurs arabes. Seul alMas'ûdî, grand voyageur sur mer et sur terre au $x^{e}$ siècle, en parle d'une façon précise, à propos de marées, de courants et de vents. 

Persans jusqu'au XII ${ }^{e}$ siècle. Le premier est la relation, datée de 851, qui a été faite sur les récits du marchand Suleyman qui, s'embarquant à Sîrâf, fit plusieurs voyages dans l'Inde et la Chine. L'autre récit est le texte d'un amateur, Abou-Zeyd-Hassan, originaire de Sîrâf. Sans avoir lui-même voyagé, il a recueilli ses informations auprès des marins qui 
fréquentaient le port et avaient parcouru les mers orientales et extrême-orientales. Il semble que al-Mas'ûdî le rencontra à Basrah, en 916, et confirme ses dires (al-Mas'ûdî 1962-1971, I : 130).

L'importance des relations avec la Chine était marquée par l'existence d'une colonie musulmane importante et très active ${ }^{36}$ au $\mathrm{IX}^{\mathrm{e}}$ siècle, à Canton, ville qui regroupait de nombreux commerçants étrangers de diverses confessions. Les gens de l'Oman, de Sîrâf, de Bahrayn, d'al-Ubulla et de Bassora, faisaient le voyage de la Chine, et les navires chinois accostaient dans ces mêmes ports. Mais la situation changea totalement après les troubles de 878, où la colonie fut quasiment détruite entraînant la chute du commerce. Abû Zeyd rapporte comment, «l'état de tranquillité où se trouvait la Chine avait changé, et surtout comment la colonie de marchands étrangers de Canton avait été décimée par un chef chinois rebelle. La ville fut, en effet, prise en 879 par les rebelles chinois qui passèrent au fil de l'épée 120.000 musulmans, juifs, chrétiens, zoroastriens ». Il ajoute que «le chiffre des personnes de ces quatre religions est connu exactement parce que le gouvernement chinois prélevant sur eux un impôt de capitation, il en existait des registres " (Reinaud [1846] 1982: 63-64). Les relations commerciales se ralentissent, deviennent indirectes car « on ne peut plus compter sur la justice des gouvernants et sur la droiture de leurs intentions " (al-Mas'ûdî 1962-1971, I : 127). C'est alors que les navires chinois et ceux des divers musulmans se retrouvaient, à mi-distance entre la Chine et le golfe Persique, à Kedah, port sur la côte occidentale de la presqu'île de Malacca.

Voici comment se passait le voyage de Chine. Les navires arabes partaient de Mescate en décembre, descendaient la côte occidentale de l'Inde par la mousson du nord-est et arrivaient un mois après, en janvier, près de Ceylan. Laissant l'île sur leur gauche, ils atteignaient Sumatra vers le fin de février ou au début de mars, époque à laquelle souffle avec moins de violence la mousson de nord-ouest que l'on rencontre là ; ceux qui allaient en Chine, se rendaient de la pointe d'Achem à la presqu'île de Malacca, dans la rade de Kedah, par la mousson du sud-ouest, à partir d'avril-mai. Ils passaient au sud des Nicobar ou dans les canaux qui sont entre ces îles et la petite Andaman, ou bien encore entre Poulo Rondo et la Grande Nicobar. S'il ventait grand frais du sud-ouest au nord-sud-ouest, ils s'approchaient des îles Nias, qui sont en dehors de la pointe d'Achem. De Malacca, ils allaient à la côte du Cambodge qu'ils longeaient, puis celle de la Cochinchine jusqu'à Phu Yen d'où ils se dirigeaient directement sur la Chine avec la mousson du sud-ouest et arrivaient vers juin ou juillet. En naviguant à cette époque en mer de Chine, ils évitaient les typhons qui ne se déclaraient qu'au mois de mai (cf. Maury $1846: 236-7$ ). C'est cette route que suivirent, à partir du XVIe siècle, les bateaux portugais au départ de Goa pour le Japon, la Chine, l'Indochine, les hollandais pour le Japon et l'Indonésie, les espagnols allant aux Philippines, les anglais allant en Chine et les français en Indochine.

131 À l'extrême sud-est de l'Indochine existait, depuis le début de l'ère chrétienne, un puissant royaume hindou, le Champa, qui occupait et dominait cette région ainsi que la partie occidentale sur le golfe de Siam, avant l'arrivée des Khmers. Sanf ou Chanf est le nom que donnaient les Arabes à ces régions d'où au $\mathrm{IX}^{\mathrm{e}}$ siècle l'on exportait le bois d'aloès et où les bateaux, en route pour la Chine, mouillaient pour se procurer de l'eau fraîche (in Reinaud [1846] 1982). Aujourd'hui les Chams du sud-Viêtnam sont islamisés.

132 À Java et Sumatra, il y eut plusieurs royaumes dont la puissance, telle celle de Srivijaya aux $\mathrm{XI}^{\mathrm{e}}-\mathrm{XII}{ }^{\mathrm{e}}$ siècles, résultait de leur position de contrôle des passages maritimes entre l'océan Indien d'une part et les îles de la Sonde et la Chine d'autre part, ainsi que de l'exploitation des régions productrices d'épices ; la Malaisie fournissait le bois d'aloès, les 
cardamomes, le galanga, le zédoaire, Bornéo le camphre, les Moluques le clou de girofle et la noix muscade, tous produits qui étaient revendus aux Musulmans et aux Chinois.

\section{Les Arabes en Afrique de l'est}

C'est par la mousson d'hiver qui souffle du nord-est qu'Indiens, Persans et Arabes étaient et sont toujours portés par vent arrière sur les côtes de l'Afrique de l'est. C'est par la mousson d'été soufflant du sud-ouest qu'ils en reviennent. Cependant, même si aujourd'hui les bateaux sont tous motorisés, la violence de ces vents et la mer très forte de mi-mai à mi-août, ne permet en fait de naviguer qu'en avril ou en septembre, c'est à dire à la "montée » de la mousson ou à sa « descente ", avec une préférence pour avril, qui permet de rentrer au port d'attache pour les réparations et d'éviter les quatre mois d'hiver, de mai à août, sur la côte africaine (Datoo 1970). Hiver, car une bonne part de cette côte, Kilwa, Zanzibar, les Comores, Mombasa, Malindi, Lamu, se trouve dans l'hémisphère sud où les saisons sont inversées (Photographies 20, 21, 22). Ces variations de la mousson du sud-ouest déterminent un calendrier de retour; les bateaux iraniens quittent vers la mi-avril, les arabes naviguent pendant tout le mois d'avril alors que les indiens peuvent retarder jusqu'au mois de mai. Certes, le voyage prend plus de temps en avril qu'en mai, mais les Arabes veulent surtout éviter les orages et les tempêtes qui commencent en mai aux approches de la corne de l'Afrique.

Photographie 20 : Lamu , sortant du port. Françoise Le Guennec Coppens janv. 1983

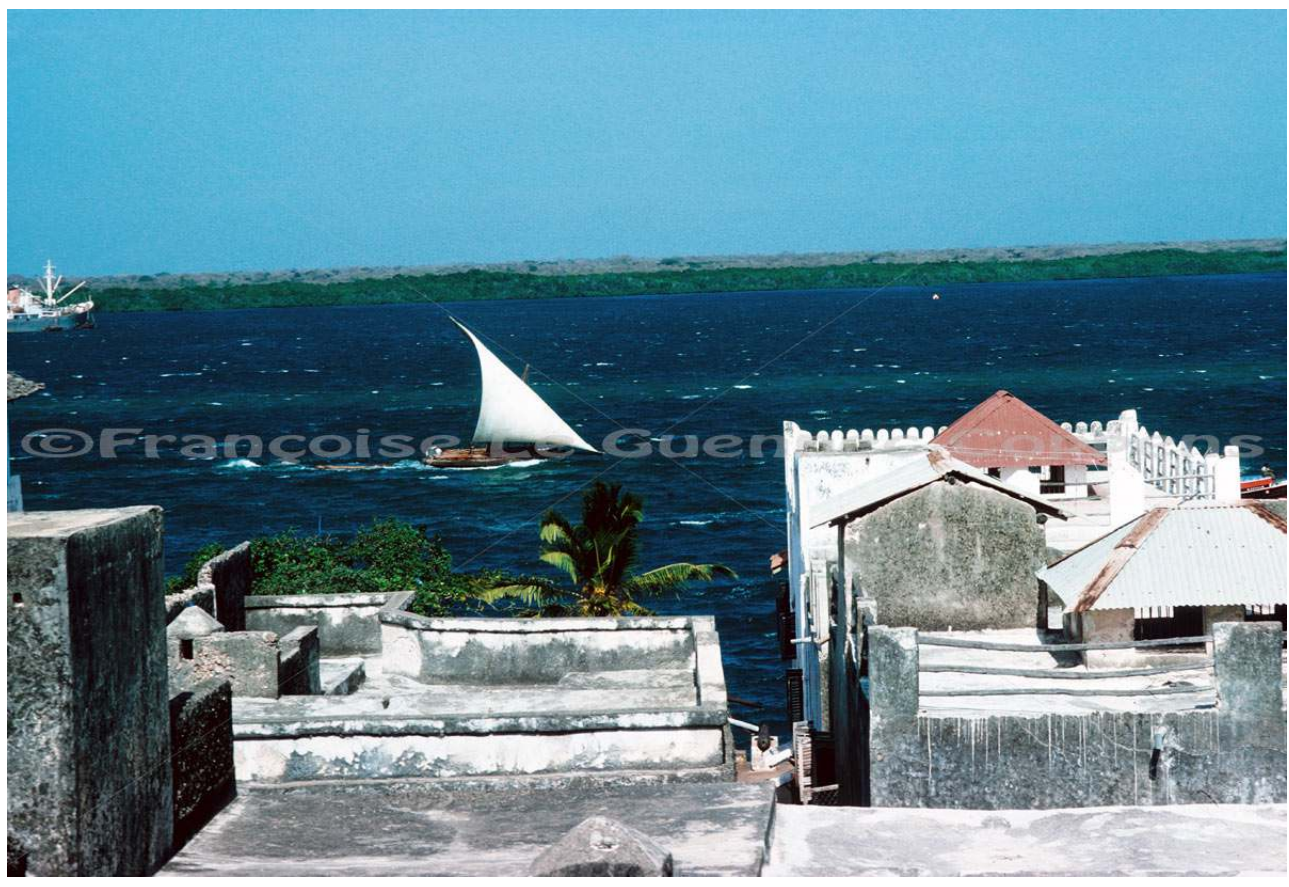

(c) F. Le Guennec Coppens 
Photographie 21 : Lamu sortie du port vent arrière; en fond les mangroves

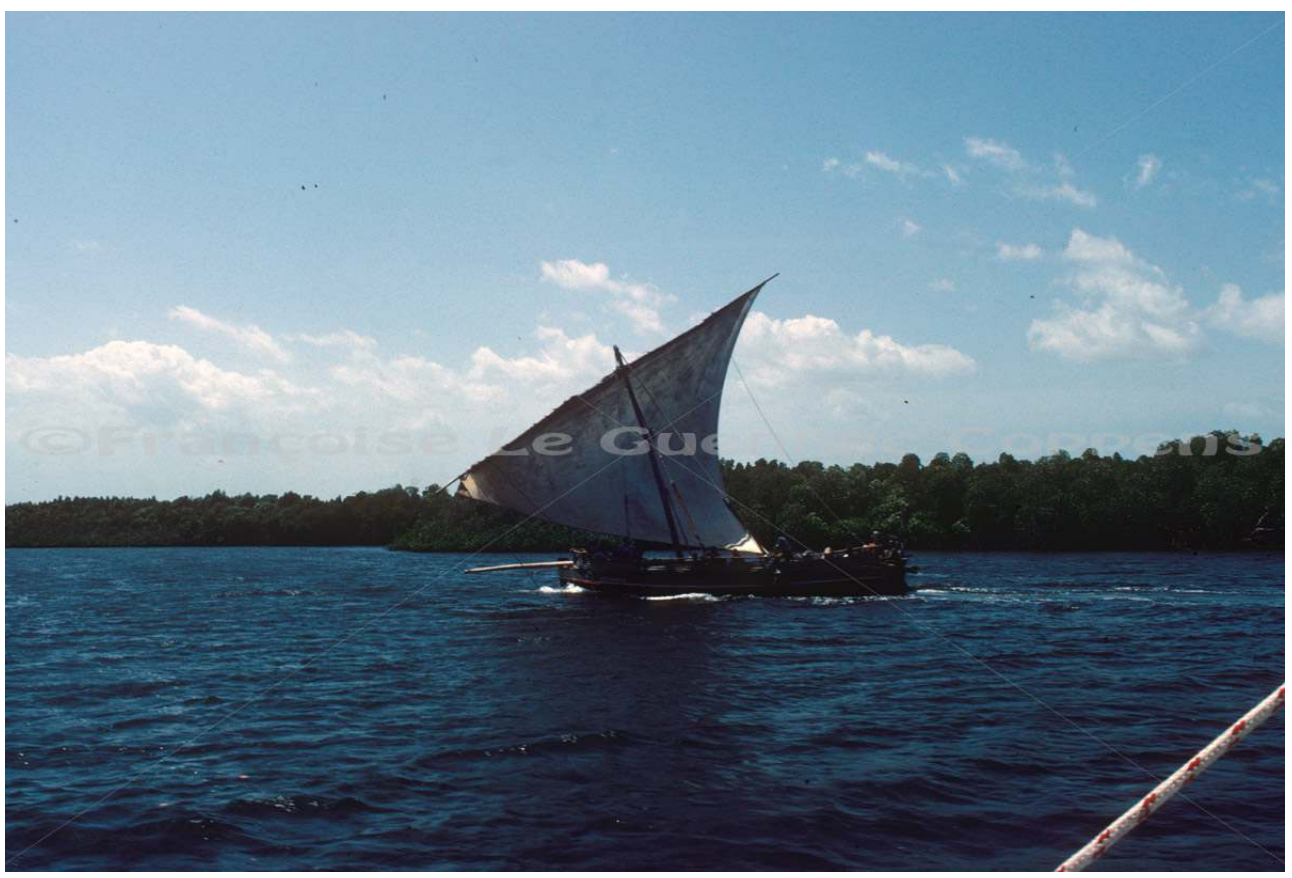

(C) F. Le Guennec Coppens 01-1983-6

Photographie 22 : Lamu 1 boutre sortant du port

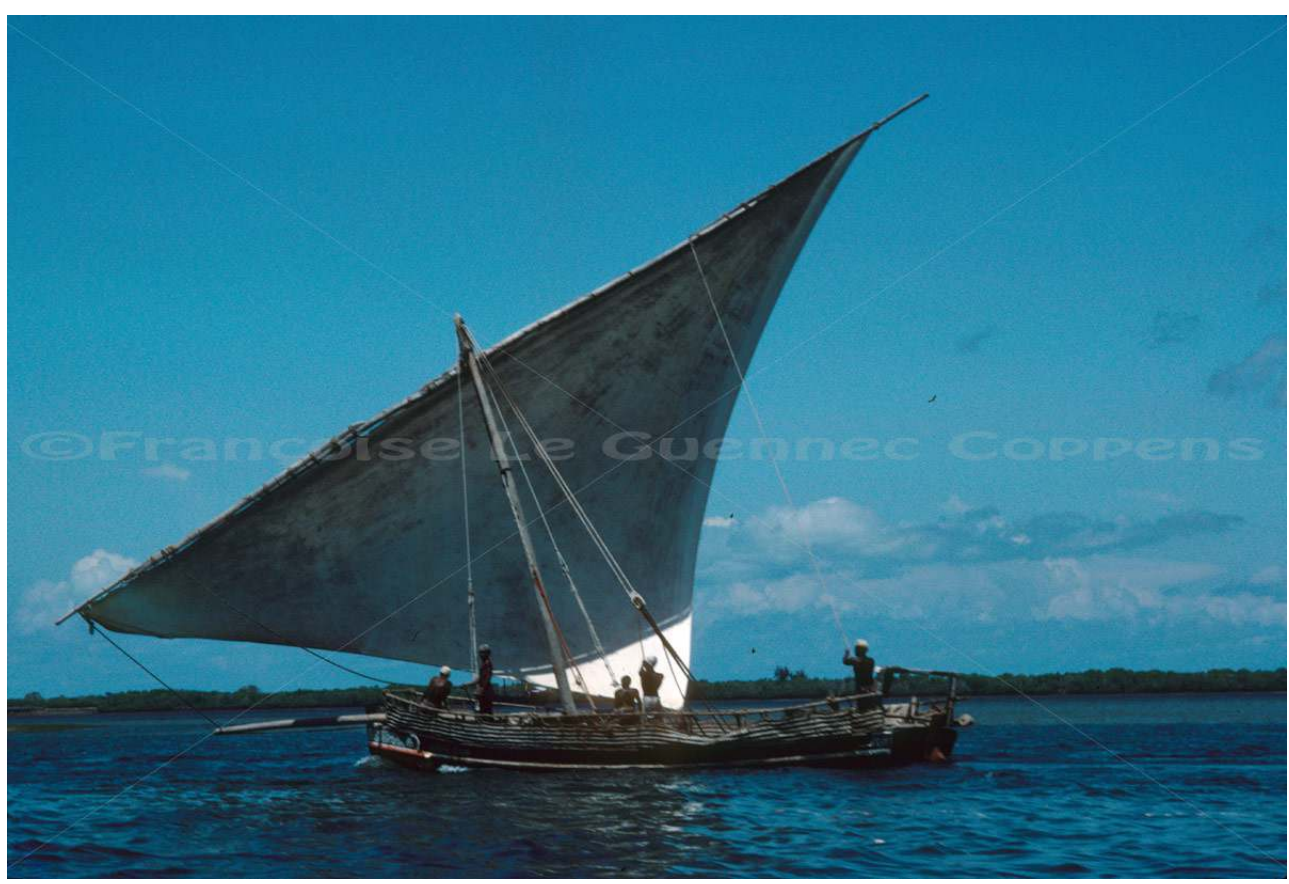

(C) F. Le Guennec Coppens janv. 1983

134 Cette "côte des Zandjs", comme on l'appelait, s'étend de la Somalie jusqu'au Mozambique incluant le nord de Madagascar. On en retirait les esclaves, la poudre d'or, l'ivoire, les cornes de rhinocéros, les gommes et résines de copal. À l'époque de la colonie 
portugaise, il y avait, à Bombay, une vente annuelle de l'ivoire que rapportaient les bateaux revenant du Mozambique en septembre, avec la dernière mousson de sud-ouest ${ }^{37}$.

Les trafics commerciaux ont créé des métissages de populations. Les Persans de Basrah et les Omanais ont épousé des femmes de Zanzibar, les Arabes du Yémen des Dankalies et des Somalies (Lesourd, 347). Cette longue association des Arabes du Golfe et de la côte sud avec les populations indigènes d'Afrique de l'est a permis la diffusion du swahili, devenue langue véhiculaire parlée aujourd'hui, non seulement sur la côte mais aussi à l'intérieur dans toute l'Afrique de l'est et jusqu'en Afrique centrale (Hawkins 1981 :5).

Des liens très forts se sont créés avec les populations d'Afrique de l'est. Zanzibar, île au large des côtes sud d'Afrique, fut très tôt visitée par les Persans avant de l'être par les Omanais ; ces derniers y installèrent un sultanat jusqu'au XIX ${ }^{e}$ siècle, elle fut même leur capitale et "la plaque tournante de l'esclavage ». Au $\mathrm{x}^{\mathrm{e}}$ siècle déjà, l'île de Qanbalû, comme ils la nommaient alors, était depuis longtemps colonisée par les Omanais et « habitée par une population mélangée de musulmans et de noirs (zandjs). Les marins de l'Oman qui fréquentent ces parages sont des Arabes de la tribu de Azd » (al-Mas'ûdî 1962-1971, I : 92). En 1858, l'île devient indépendante de l'imam de Mescat.

Mombasa, au Kenya, jouit d'un long passé maritime. Cette île formée par deux estuaires fut très tôt le fief des Arabes commerçant les bois précieux, les gommes parfumées et les esclaves -et ce jusqu'au début du $\mathrm{Xx}^{\mathrm{e}}$ siècle (Photographie 23). En 1498, Vasco de Gama essuie une défaite devant cette ville où les Arabes accueillent fort mal les Portugais. Aujourd'hui, la plupart des boutres qui y mouillent sont iraniens ou sud-arabiques. Leur cargaison est principalement constituée de poissons séchés parmi lesquels figurent en bonne place le requin, provenant d'Arabie du sud (Dhofâr, Mukalla et île de Socotra); vient ensuite le sel d'Aden. Graisse, café, charbon de bois, huile de coco et huile de coton constituent le fret de retour. Mombasa possède aujourd'hui un nouveau port, Kilindini Harbour, principal port de commerce du Kenya (Hawkins $1981: 29$ ).

\section{Photographie 23}

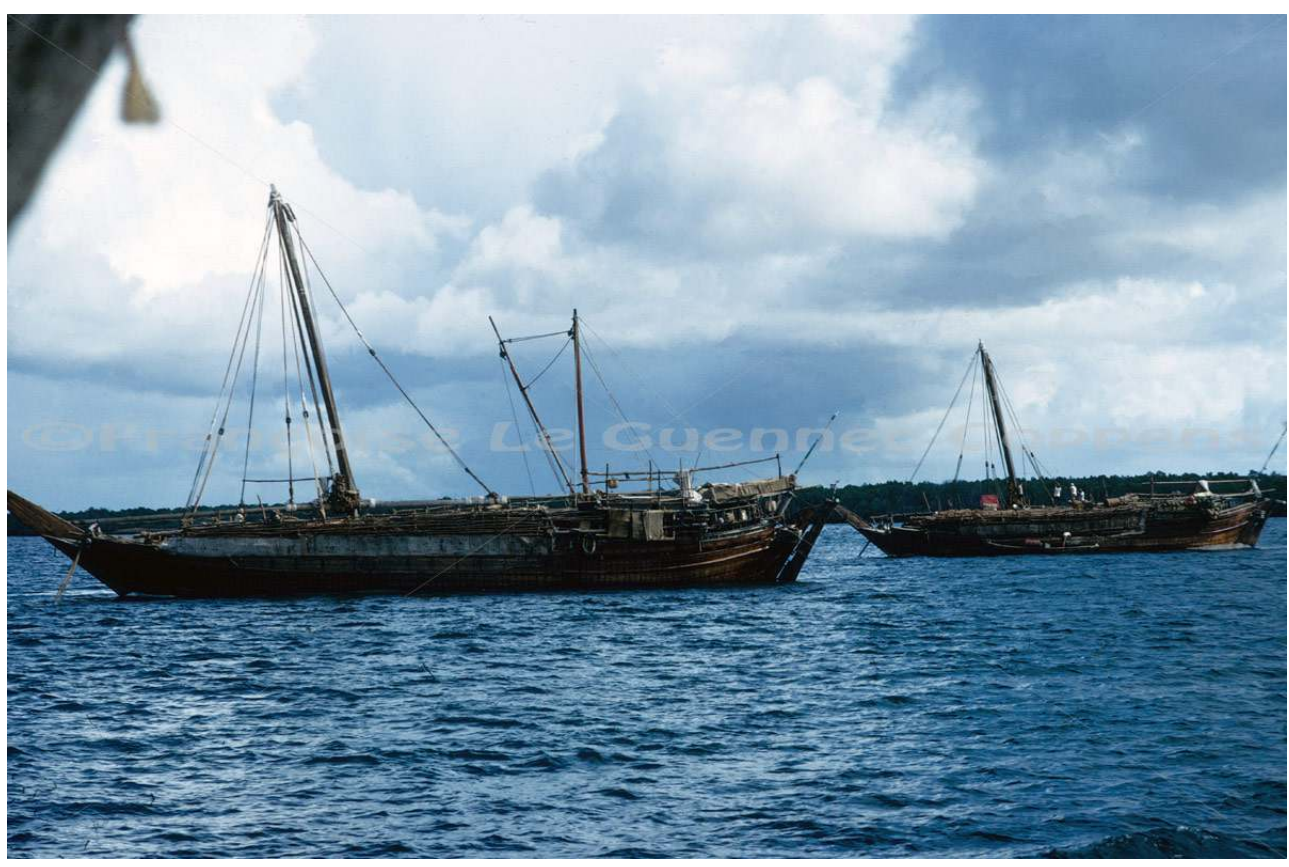

(c) F. Le Guennec Coppens 
Malgré la présence portugaise en Afrique orientale, les Sud-arabiques maintinrent leur suprématie commerciale; en 1729, lorsque les Européens furent chassés de leurs comptoirs et que Zanzibar devint la capitale des sultans de Mescat et d'Oman, ces Arabes, aussi à l'aise sur le littoral africain que sur celui du golfe d'Oman, trafiquaient esclaves, bétail, céréales, cornes de rhinocéros et dents d'hippopotames. Au XIX siècle, ils importaient en Arabie cotonnades, verrerie, porcelaine chinoise, quincaillerie et esclaves.

\section{Les premiers Européens connaissent une navigation difficile dans l'océan Indien}

\section{Un voyage exemplaire}

Malgré les difficultés, ce premier voyage d'un Européen dans l'océan Indien fut presque idéal. Bénéficiant de vents toujours portants, Vasco de Gama a ouvert l'Océan Indien aux Portugais certes mais à leur suite, à tous les Européens, Espagnols, Hollandais, Anglais et Français. En ce sens, l'hostilité des marins et marchands musulmans qu'il a rencontrés sur les côtes d'Afrique, était tout à fait fondée. Car c'est à partir de ce moment-là que ces derniers ont cessé d'être les uniques pourvoyeurs d'épices de l'Europe.

Carte 2 : Le voyage de Vasco de Gama

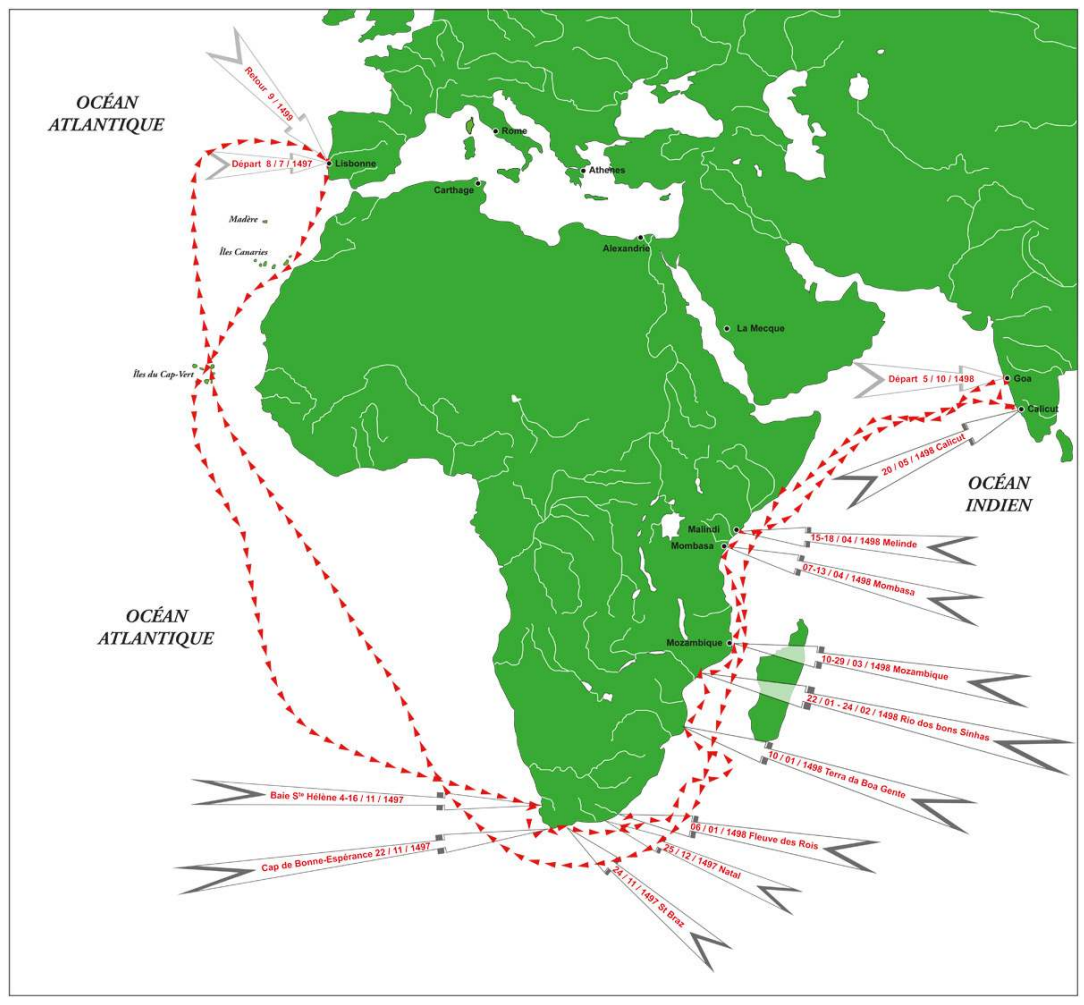

Carte établie par S. Bahuchet et L. Venot

Quatre bateaux appareillent de Lisbonne le 8 juillet 1497, embarquant quelques deux cents hommes d'équipage, après une nuit de prière. Ils arrivent heureusement à Santiago, l'île principale de l'archipel du Cap Vert, et reprennent leur route, après quelques jours, droit au sud, évitant ainsi les calmes du golfe de Guinée, pour atteindre le 4 novembre la baie de Sainte Hélène qu'ils quittent le 16 du même mois. Le 22 novembre, la petite flotte 
double le cap de Bonne Espérance et arrive le 24 à l'aiguade de Saint Braz où l'équipage se repose pendant 13 jours. Puis, dépassant le Rio Infante, limite extrême des terres qu'avait découvertes Bartolomé Diaz, la flotille arrive le 25 décembre devant un lieu qu'on appela Natal (portugais Noël) et le jour de l'Épiphanie, 6 janvier 1498, elle entre dans le fleuve des Rois. À ce moment-là il était urgent de gagner un lieu sûr pour réparer les navires ; le 10 janvier, les Portugais arrivent dans ce qu'ils nommèrent Terre des Bonnes Gens Terra da Boa Gente, ainsi nommée pour les rapports cordiaux qu'ils eurent avec les Cafres, chasseurs armés de longues sagaies à pointe de fer et à gaine d'ivoire. Ils poursuivent leur route en longeant la côte, doublent la nuit le cap des Courants Cabo dos Corrientes et prenant un peu le large pour éviter les dangers de la côte, ils dépassent Sofala sans s'en douter et abordent le 22 janvier près de l'embouchure d'un grand fleuve qu'ils nomment Río dos Bons Sinaes "fleuve des bons indices" parce qu'ils recueillent là d'utiles informations. Après plus de six mois de navigation, les équipages souffrent d'une terrible maladie, encore nouvelle pour eux, le scorbut, qui enlève plusieurs d'entre eux. Le 24 février, ils reprennent la mer et 14 jours plus tard, le 10 mars, jettent l'ancre près de Mozambique. C'est là qu'ils rencontrent les premiers bateaux arabes chargés de marchandises indiennes (Plattner 1954 : 16) et qu'ils éprouvent l'hostilité des Musulmans qui cherchèrent à s'emparer d'eux et à les tuer en entraînant leurs bateaux vers les écueils. Le 29 mars, la flotille quitte ce port, atteint le 7 avril Mombasa qu'elle quitte le 13 avril après avoir déjoué de nouvelles embûches des Musulmans. Rencontrant sur leur route deux sambuks richement chargés, les Portugais attaquent et en prennent un, puis toujours longeant la côte, ils entrent le 15 Avril, jour de Pâques, dans la rade de Melinde. L'accueil y est des plus confiants et des relations amicales se nouent entre les marins et les riches habitants du port. Pilotés par un marin gujerati, ils reprennent la mer le 18 avril et, malgré une saison contraire, le trajet jusqu'à la côte indienne est rapidement parcouru : ils entrent le 20 mai à Capocate mais s'en éloignent aussitôt, remorqués par de nombreuses almadies (al-mahdia, petites embarcations), pour aller mouiller près de Calicut, alors le plus riche entrepôt de l'Océan Indien. Là, Vasco de Gama se met en rapport avec le rajah de cette ville. C'est donc au terme d'un voyage de 10 mois et demi, avec très peu d'escales, que Vasco de Gama a rallié Calicut (cf. Poujade 1946: 112-3; Amsler 1960 : 94-95). Nous verrons que ce temps est un des plus courts que l'on puisse mettre et que ces voyages durent plus souvent un an à un an et demi, voire deux ans.

\section{La navigation dans l'océan Indien est une navigation difficile}

141 Tout de suite, un calendrier s'institue. Les bateaux partaient de Lisbonne une fois par an, en mars ou en avril, et tant que la colonisation des Indes fut dans sa période d'essor, quatre ou cinq navires prenaient chaque année la route de Goa. Par la suite, l'importance politique et commerciale du Brésil ne cessa de grandir au détriment de celle des Indes. Il n'y eut plus qu'un seul navire à destination des Indes tandis qu'une cinquantaine de voiliers au moins appareillait régulièrement pour Bahia (Plattner1954: 34 et 37). À ces raisons s'ajoutent les difficultés de la navigation dans l'océan Indien, les nombreux naufrages, l'érosion rapide des bateaux, le temps très long des voyages, la piraterie de tous bords. En outre, quatre mois sans escale étaient au mieux nécessaires pour arriver au Mozambique; le scorbut sévissait sur les équipages et les bateaux devaient hiverner là malgré l'insalubrité du lieu qui était considéré comme le cimetière de nombreux marins affaiblis. Si l'on arrivait un peu plus tard, la mousson s'était inversée et l'on devait se résigner à une escale de neuf à dix mois. En août de l'année suivante, les navires 
pouvaient enfin laisser ce lieu de fièvres et de mort...Le trajet de Mozambique aux Indes exigeait quelque quatre semaines grâce à la mousson d'été. Comme les navires mettaient le cap vers le nord, ils parvenaient souvent aux abords de Socotra et y abordaient pour s'approvisionner en vivres et eau fraîche. Ceux qui pénétraient dans l'océan Indien avec retard risquaient de ne pas pouvoir résister à la mousson du nord. Au lieu d'atteindre Goa, ils devaient aborder à Ceylan ou bien dans la presqu'île de Malacca (Plattner 1954 : 52-3). Point d'aboutissement du voyage des Indes, Goa servait de point de départ pour l'Extrême-Orient. De cette ville, on allait vers les lointaines îles aux épices des Moluques, vers la Chine et le Japon (Plattner 1954 : 59).

Les difficultés de la navigation restent les mêmes au cours des siècles. Le marchand Sulayman, en 851 , les évoque à propos des marchandises venant de Canton, qui était l'entrepôt des Arabes en Chine: «L'une des causes de la rareté de ces marchandises, ce sont les naufrages des navires, soit en revenant, soit en allant; ajoutez à cela que les navires sont exposés à être pillés ou bien forcés de faire un long séjour dans certains endroits [bloqués par un vent contraire, la mousson], ce qui oblige les voyageurs à se défaire de leurs marchandises hors des provinces arabes. D'autres fois, le vent [de mousson] pousse les navires dans le Yémen [au lieu du golfe Persique ] ou dans d'autres contrées...enfin on est quelquefois obligé de s'arrêter pour faire radouber le navire " (Reinaud [1846] $1982: 11-12$ ).

Ce texte reste d'actualité jusqu'au début $d u x^{e}$ siècle sur tous les points et préfigure les nombreux textes des Européens $\mathrm{du}_{\mathrm{XVI}}{ }^{\mathrm{e}}$ au $\mathrm{XIX}^{\mathrm{e}}$ siècle: tempêtes et typhons qui entraînent les naufrages en mer de Chine et golfe du Tonkin, piraterie, blocage dans un port pendant des mois par la mousson contraire, déviement de la route par une mousson trop forte, enfin radoubements fréquents des bateaux pour nettoyer les coques des crustacés et des tarets qui prolifèrent dans ces mers chaudes.

\section{Les marchandises transportées}

Nous n'avons jusque là mentionné que les produits prestigieux dont se chargeaient les bateaux, épices, aromates, poudre d'or ${ }^{38}$, ivoire à quoi s'ajoutent les porcelaines blanches et bleues de Chine qui, avant d'arriver en Europe, se retrouvaient dans les îles de la Sonde et jusqu'en Afrique de l'est. On estimait aussi l'acier d'Inde et l'étain de la presqu'île de Malacca, et surtout les esclaves dont le commerce, commencé vraisemblablement sous les Sassanides d'Iran (III ${ }^{e}-\mathrm{VII}^{\mathrm{e}}$ siècle), a terriblement saigné la population africaine jusqu'au $\mathrm{XIX}^{\mathrm{e}}$ siècle et de façon plus restreinte jusqu'à la deuxième guerre mondiale. On transportait aussi les bois, bois de construction, bois de chauffage pour des pays qui en sont démunis comme l'Arabie.

Les denrées alimentaires ont certainement été, depuis longtemps, l'un des principaux chargements, même si les textes ne les mentionnent que fort rarement. Nous avons vu plus haut que les sambouks du golfe Persique, construits en cocotier, étaient, au XVII siècle, chargés de noix de coco. Aujourd'hui, dans le commerce entre l'Arabie et l'Afrique, l'un des principaux chargement est celui des dattes que les boutres arabes transportent de Basrah, en Irak, vers les émirats arabes et même jusqu'à Cochin, sur la côte de Malabar. C'est que la récolte des fruits coïncide avec le moment où souffle le vent du nord (mousson du nord-est) permettant à ces bateaux de mettre à la voile vent arrière pour leur long voyage vers le sud alors que les bâtiments indiens doivent se rendre depuis leurs ports d'attache jusqu'au fond du Golfe par un vent contraire (Hawkins 1981 : 16). 
«La capacité de chargement d'un boutre se calcule au nombre de couffins de dattes qu'il est capable de transporter ; c'est la preuve du rôle déterminant que jouent les dattes dans cette partie du monde ...Le poids des couffins ou qalla (terme arabe irakien) varie, ainsi à Bombay, il est de $13 \mathrm{~kg}$. Comprimés, entassés, ces qalla arrivent parfois mal en point au lieu de destination mais on trouve toujours quelqu'un qui, flairant une bonne affaire, se portera acquéreur. Les marchands montent sur les boutres (à bord) pour vérifier l'état de la marchandise et achètent en petites ou grandes quantités, dans l'espoir de réaliser un bénéfice. Lorsqu'on remue un couffin de dattes ou qu'on l'ouvre pour vérifier le degré de conservation, invariablement des mouches s'en échappent; à Dubay par exemple, elles semblent se donner rendez-vous sur le front de mer quand arrivent les boutres chargés de dattes ; ces insectes se gorgent du jus sucré qui s'en échappe. Celui qui suinte pendant la traversée n'est d'ailleurs pas perdu; recueilli au fond de la cale, il est vendu aux pâtissiers et aux fabricants de boissons fermentées » (Hawkins 1981 : 27-29).

Sur le littoral méridional de l'Arabie, entre Sur et Aden, la pêche constitue la ressource principale et chaque année, de grands boutres chargés à ras bord de poissons séchés appareillent à al-Jazir, dans le Dhofâr et des ports du Yémen, pour rejoindre les navires transportant des cargaisons de dattes à destination de l'Afrique orientale. La plupart s'arrêtent à Mombasa (Hawkins 1981 : 74).

\section{Conclusion : influence de la mousson sur les sociétés et les civilisations}

La mousson a un caractère d'ambivalence pour tous, marins et paysans; elle est une contrainte non seulement pour la navigation à voile et ce depuis la nuit des temps, mais elle l'est également pour les bateaux à moteur, bien qu'à un degré moindre; de même, pour les «terriens » l'abondance des pluies de la mousson d'été est souvent difficile à "gérer» même si celle-ci est bénéfique pour les cultures, car ce sont ces pluies abondantes qui permettent les rizières à haut rendement agricole qui pourront nourrir des populations importantes. Mais, en retour, cette période chaude et humide apporte maladies, inondations et il n'est que de voir les nombreux rituels et croyances négatives des diverses populations de l'Asie des Moussons pour réaliser le coté néfaste de la mousson dont il faut se protéger.

Par ailleurs, les pluies de la mousson d'été opposent la vie active à une vie de repos et de retraite. C'est pendant cette période que le marin et le pêcheur restent chez eux, que le sage hindou se retirait du monde pour penser, comme nous l'enseigne Yuan chwang dans la relation de son voyage en Inde, de 629 à 645. Le sanscrit varchâ (pâli vassâ) désigne la période des pluies et la retraite et varshâm vas (pâli vassam vasati) signifie « faire retraite » (Watters 1943).

Mais il est un fait que les contraintes de la mousson n'ont pas empêché les hommes de circuler, d'échanger des marchandises, d'apporter des techniques nouvelles comme la boussole, de diffuser de nouvelles plantes tels le henné du monde musulman (AubaileSallenave 1982), le jasmin d'Inde en Chine, des fruits de Citrus d'Indonésie (AubaileSallenave 1992) et les oranges douces rapportées de Chine par les Portugais au XVI ${ }^{\mathrm{e}}$ siècle ; sans parler des influences culturelles, médicales, philosophiques que l'Inde puis la Chine eurent sur les populations de l'ouest asiatiques. 
151 L'hégémonie des Musulmans (Persans, Indiens, Omanais, sud-Arabiques) sur l'océan Indien dura du VIII ${ }^{\mathrm{e}}$ siècle jusqu'à la fin du $\mathrm{XV}^{\mathrm{e}}$ siècle (1498), quand Vasco de Gama commença à prendre en chasse et à piller les boutres arabo-persans et sud-arabiques. Ils contrôlaient en maîtres tout le commerce des produits arrivant en Méditerranée, où les Vénitiens prenaient le relais. Les échanges allaient de l'Extrême Orient au Maghreb: épices, aromates, perles d'Asie du sud-est, pierres précieuses d'Inde, soie, porcelaines de Chine, et à l'inverse le corail de Méditerranée occidentale et de la mer Rouge, l'ivoire d'Afrique centrale allaient en Inde, en Chine, au Tibet. Tout cela impliquait un "énorme mouvement d'hommes de marchandises, d'argent" selon Braudel (1993: 96). Ce mouvement s'est prolongé jusqu'à aujourd'hui avec d'autres acteurs, les Européens, qui ont fait se rejoindre l'océan Indien, avec le Pacifique et l'océan Atlantique dans une mondialisation de l'échange. Cependant, à l'échelle locale, les boutres arabes continuent leurs trajets triangulaires allant du golfe Persique en Inde et en Afrique de l'est, poursuivant des routes millénaires.

Enfin, preuve de l'utilité de la mousson ou de l'habileté des marins malais, l'origine indomalaise d'une partie du peuplement de Madagascar nous fait prendre conscience de la très grande ancienneté des mouvements marins dans cet immense océan Indien, que ce soit à bord de radeaux, de pirogues à balancier ou de bateaux de haut-bord et de la maîtrise par ces hommes des vents et des courants.

\section{BIBLIOGRAPHIE}

al-Mas'ûdî, ( $x^{\mathrm{e}}$ s.) 1962-1971 - Les prairies d'or. trad de Meynard et Pavet de Courteille, revue par Charles Pellat. Paris, Société Asiatique. 3 vol.

al-Mas'ûdî, (x s.) 1896 - Livre de l'avertissement et de la révision. B. Carra de Vaux, trad. Paris, Imprimerie Nationale.

Amsler J., 1960 - Histoire Universelle des Explorations. II : La Renaissance. Paris, Nouvelle Librairie de France.

Arrien, (IIe s.) 1927 - L'Inde. Éd. et trad. P. Chantraine. Paris, Les Belles Lettres.

Arveiller R., 1963 - Contribution à l'étude des termes de voyage en français (1505-1722). Paris, éd.

d'Artrey. $X$ à Serge

Aubaile-Sallenave F., 1982 - Les voyages du Henné. JATBA XXIX, 2 : 123-178.

Aubaile-Sallenave F., 1984 - "L'agriculture musulmane aux premiers temps de la conquête :

apports et emprunts". JATBA XXXI : 245-256.

Aubaile-Sallenave F., 1987 - Bois et bateaux du Viêtnam. Paris, SELAF. Préface de Lucien Bernot. $184 \mathrm{p}$ ., index, 39 fig., 50 cl., carte, tabl.

Aubaile-Sallenave F., 1992 - Zanbô‘a, un Citrus mystérieux chez les Arabes médiévaux d'alAndalûs. In Sanchez García Expiración (Ed.), Ciencias de la Naturaleza en al-Andalus. Granada, CSIC : 111-134. 
Bouillet M. N. (1842) 1896 - Dictionnaire universel d'Histoire et de Géographie. Paris, Hachette.

Braudel F., 1979 - Civilisation matérielle, Économie et capitalisme, $\mathrm{XV}^{\mathrm{e}}-\mathrm{XVII}{ }^{\mathrm{e}}$ s. Paris, Coin,

Braudel F., (1987) 1993 - Grammaire des civilisations. Paris, Flammarion, col. Champs.

Bray F., 1987 - Parfums et aromates dans la Chine ancienne. In Aubaile-Sallenave F. (Ed.), Parfums de plantes. Paris, Muséum National d'Histoire Naturelle : 193-196.

Bretschneider E., 1870-1871 - Botanicon Sinicum. Notes on the chinese Botany from natives and western sources. Journal of the north China branch of the Royal Asiatic Society : 18-230.

Chardin J., (1711) 1811 - Voyages du Chevalier Chardin en Perse et autres lieux de l'Orient. Éd de L. Langlès. Paris, Le Normant. 10 volumes.

Cœdès G., 1948 - Les états hindouïsés d'Indochine et d'Indonésie. Paris, de Boccard.

Condominas G., 1953 - L'Indochine. In Leroi-Gourhan A. et al., 1953 - L'ethnologie de l'Union

française, II : Asie, Océanie, Amérique, Paris, PUF : 514-680.

Cook J. M., 1993 - The Cambridge History of Iran, vol. 2. Cambridge at the University Press.

Cosmas Indicopleustes (écrit vers 550), 1868 - Topographie chrétienne. Wanda Wolska-Conus.

Datoo B.A., 1970 - Misconceptions about the use of monsoons by dhows in east african waters.

East African Greographical Review : 1-10.

Delvert J., 1968 - "Asie. Géographie physique". “L’Asie méridionale”. “L’Asie extrême-orientale”. Paris in Encyclopaedia Universalis.

Devic L M., 1878 - Les Merveilles de l'Inde. Paris, Cerf, 3 vol.

Dumont L., 1957 - Une sous-caste de l'Inde du sud, Paris, Mouton.

Durand F., 1995 - Mousson. Encyclopaedia Universalis. Paris.

Favre abbé P., 1885 - Dictionnaire malais-français. Vienne, 2 vol.

Ferrand G., 1913-1914 - Textes arabes relatifs à l'Extrême-Orient. Paris, Leroux. 2 vol.

Ferrand G., 1907 - Les géographes arabes et Madagascar : les îles Ramny, Lâmery, Wâqwâq, Qomor des géographes arabes et Madagascar. Journal asiatique 10 : 433-566.

Ferrand G., 1932 - Le Wâqwâq est-il le Japon. Journal asiatique 220 : 193-243.

Gaborieau Marc, 1982 - "Les fêtes, le temps et l'espace : structure du calendrier hindou dans sa version indo-népalaise". L'Homme XXII (3) : 11-29.

Ganji M.H., 1968 - Climate. In Fisher W.B. (Ed.) The land of Iran: The Cambridge History of Iran , vol. 1. Cambridge at the University Press.

Giles H.A., 1923 - The travels of Fa-Hsien. Cambridge at the University Press.

Hamilton A., 1727 - A new account of the East Indies. Edimburgh : J. Mosman, 2 vol.

Hammer J. von (Trad.), 1834 - Extracts from the Mohi't, that is the Ocean, a Turkish work on Navigation in the Indian Seas. Journal of the Asiatic Society of Bengal III (35) : 545-553.

Haudricourt A. G., 1953 - Recherches récentes sur l'histoire des plantes cultivées, Revue de Botanique Appliquée 33 (373-374) : 537-545.

Hawkins C. W., 1981 - Les Boutres, derniers voiliers de l'Océan Indien. Paris, Vilo.

Hérodote (v ve av. JC) 1985 - L'Enquête. Trad. A. Barguet. Paris, Gallimard, Folio, 2 vol. 
Hobson-Jobson, voir Yule

Hornell J., (1946) 1970 - Water Transport. Origins \& early evolution. Newton Abbot; David \& Charles.

Hui-Lin Li, 1979 - Nan-fang ts'ao-mu chuang. A fourth century flora of southeast Asia. (304 A. D.par

Chio Han) Hong Kong, The Chinese University press.

Huntingford G.W.B., 1980 - The Periplus of the Erythraean sea by an unknown author. London, The Hakluyt Society.

ibn Khaldūn (XIV s.) 1967-1968 - al-Muqqadima. Trad. Vincent Monteil, Discours sur l'Histoire universelle. Paris, Sindbad, 3 vol.

Jal A., (1848) 1970 - Nouveau glossaire nautique. Révision de l'édition de 1848. Paris, La Haye, Mouton.

Kabarity A.M. et al., 1988 - Botany \& microbiology Dictionary. Kuwait Foundation for the advancement of sciences : 231.

Kazimirski A. de Biberstein, (1860) 1980 - Dictionnaire arabe-français. Beyrout, Librairie du Liban. 2 vol.

Laufer B., (1919) 1967 - Sino-iranica. Chinese contributions to the History of Civilization in Ancient Iran. Tai Pei, Ch'eng-Wen Publishing Company, $630 \mathrm{p}$.

Leroi-Gourhan André et al., 1953 - L'ethnologie de l'Union française, II : Asie, Océanie, Amérique, Paris, PUF.

Lesourd, M., 1960 - Notes sur les Nawakhid, navigateurs de la Mer Rouge. Bull. de l'Inst., de l'Afr. Noire $22: 346-355$.

Martel Gabrielle, 1965 - La culture du riz chez les Santals du Bengale. BEFEO, 52 (2) : 313-356.

Maury A., 1846 - Examen de la route que suivaient au IXe siècle de notre ère, les Arabes et les Persans pour aller en Chine, d'après la relation arabe traduite successivement par Renaudot et $\mathrm{M}$. Reinaud. Bull. de la Société de Géographie 5 : 203-238.

Miller A.G. \& Miranda Morris, 1988 - Plants of Dhofâr. Sultanate of Oman, The office of the Adviser for Conservation of the Environment. Diwan of Royal Court.

Miller J.I., 1969 - The spice trade of the Roman Empire. Oxford, Clarendon Press.

Monfreid H. de, 1931 - Les secrets de la Mer rouge. Paris, Grasset

Monod T., 1979 - Les arbres à encens. Bulletin du Muséum national d'Histoire naturelle, série B Paris.

Mookerji Radha K.umud, (1912) 1957 - Indian shipping. Bombay, Calcutta, Madras. Orient

Longmans.

Needham Joseph, 1974 - La tradition scientifique chinoise. Paris, Hermann.

Ollone, Ct d', 1911 - Recherches sur les Musulmans chinois. Paris, Leroux.

Pelliot P., 1904 - Deux itinéraires de Chine en Inde à la fin du VIIIe siècle. BEFEO : 131-413.

Pelliot P., 1933 - Les grands voyages maritimes chinois au début $\mathrm{du} \mathrm{XV}^{\mathrm{e}}$ siècle. T'oung Pao 30 :

237-455.

Pfeiffer P., [s. d.] - L'Asie. Paris, Hachette.

Plattner F.A., 1954 - Quand l'Europe cherchait l'Asie. Tournai, Paris, Casterman.

Pline l'Ancien, ( $\left.\mathrm{I}^{\mathrm{er}} \mathrm{s}.\right) 1980$ - Histoire Naturelle, J. André et J. Filliozat (Ed.). Paris, Les Belles Lettres. 
Poujade J., 1946 - La route des Indes et ses navires. Paris, Payot.

Queney P., 1959 - Les mouvements de l'atmosphère. In Goguel J. (Ed.), La terre, Paris, La Pléiade : 243-314.

Reinaud J. T., (1846) 1982 - La Relation des voyages faits par les Arabes et les Persans dans l'Inde et la Chine dans le IX $X^{e}$ siècle de l'ère chrétienne. Osnabrück, O. Zeller Verlag, 2 vol.

Rodinson M., 1984 - L'Arabie du sud chez les auteurs classiques. In Chelhod J., Yemen. Paris, Maisonneuve et Larose : 55-89.

Ruhlen M., 1987 - A guide to the World's Languages. vol. 1: Classification. Stanford, Stanford University Press.

Sauvaget J., 1948 - Relation de la Chine et de l'Inde. éd. et trad. Paris, Les Belles Lettres.

Sion J., 1928 - L'Asie des moussons. Tome IX de la Géographie Universelle publiée sous la direction de P. Vidal de la Blache et L. Gallois. Paris, Armand Colin, 2 vol.

Soutif, M., 1992 - L'avance des technologies chinoises. In L'Etat du monde en 1492, G. de la Martinière \& C. Varela. Paris, La Découverte : 147-149.

Tavernier J. B., (1676) 1925, 2nd ed. - Travels in India. Transl. by C. B. Ball. London, Oxford Univ. Press, Humphrey Milford, 2 vol.

Termier H. \& G., 1959 - Histoire de la surface terrestre. In Goguel J. (Ed.), La terre, Paris, La Pléiade : 1331-1490.

Tibbets G.R., 1971 - Navigation in the Indian Ocean before the coming of the Portuguese. London, The Royal Asiatic Sty of Great Britain and Ireland. 614 p.

Van der Sleen - Ancient glass-beads with special reference to the beads of East and Central Africa and the Indian Ocea. The Journ. of the Royal Anthropological Inst. of Great Britain and Ireland, vol. 88, part II: 203-216, 1 pl., 7 fig.

Watters T., (1904-5) 1943 - On Yuan chwang's travels in India. New Delhi, Munshiram Manoharlal.

Yule H., 1915-19 - Cathay and the way thither. London, Hakluyt Society, new éd. 4 vol.

Yule H. \& Burnell A.C., (1903) 1984 - Hobson-Jobson. Glossary of colloquial anglo-indian words and phrases, and of kindred terms, etymological, historical, geographical and discursive. Nouvelle éd par W. Crooke. New Delhi, Munshiram Manoharlal.

\section{NOTES}

1. Dans les premiers temps, le terme a légèrement fluctué. En 1598, on disait monson, monsson, muesson qui était un emprunt au néerlandais, lui-même l'ayant emprunté au portugais; cette forme subsiste jusqu'au XVIII ${ }^{\mathrm{e}}$ siècle à coté de mousson (in Arveiller). "Vent qu'ils appellent moussons ou muessons » (Vinc. Le Blanc, 1649 in Hartfeld \& Darmesteter), Furetière, 1690, monson. L'espagnol monzon, vient lui-même du portugais monção, saison, quant à l'anglais monsoon , il est probablement un emprunt au hollandais (Hobson-Jobson, 577). Le français et le portugais sont des mots féminins.

2. Maûsim, mûsim sont deux prononciations du même mot. En arabe parlé, le $u$ [ou] diphtongue souvent en â̂ [aou]. Ce mot est la $3^{\text {ème }}$ forme du verbe wasama «marquer quelque chose d'une impression au fer chaud ».

3. Cette fête correspond à celle du $5^{\text {ème }}$ jour du $5^{\text {ème }}$ mois des Bouddhistes, vue plus haut. 
4. Ghâba: terrain bas, encaissé, bas-fond endroit planté de roseaux, de buisson (qui servait de retraite aux lions) (Kazimirski II : 521).

5. Tous ces noms de bateaux sauf sambûq, qui est un terme arabe, sont des noms indiens.

6. Warmington 1928, The commerce between the Roman Empire and India, Cambridge Univ. Press, Cambridge, in Miller $1969: 240$.

7. Ce port se trouve, selon Pelliot (1904: 215), dans la préfecture de Canton et pourrait s'identifier à Canton. Cependant, pour Yule $(1915: 89$, n. 3), le nom désigne le port de Hang chau ou Khansa, chinois Kan P'hu, qui est celui d'une ville située à un demi-mille au nord de l'ancien site.

8. La carvelle est un procédé de bordage caractérisé par le fait que les bordages s'ajustent à joints vifs, l'un à la suite de l'autre, le bordé ayant de ce fait un aspect lisse. Le clou-carvelle est le type de clou utilisé dans le bordage du même nom (Jal, s. v.)

9. Information orale de O. Herrenschmidt, professeur d'ethnologie à Nanterre (2. 7. 1996).

10. Le gouvernail axial est attesté dans une splendide collection de modèles de navires en céramique trouvés dans des tombes d'époque Hou Han des $1^{\text {er }}$ et $2^{\text {ème }}$ siècles de notre ère qui furent fouillées dans la ville de Canton, en 1958 (Needham 1974 : 165-166).

11. L'auteur des Merveilles de l'Inde, trad. Devic, connaît au VIII ${ }^{\mathrm{e}}$ siècle les bateaux à deux mâts (Tibbets $1971: 52$, note 34 ).

12. Id. p. 52

13. Enduit qui empêche l'implantation des tarets, par la propriété de la chaux. Ce type d'enduit est utilisé sur toutes les embarcations de Chine où le mélange huile (acide)-chaux (basique) produit un mastic dur. Cf. notre étude sur les embarcations viêtnamiennes (Aubaile-Sallenave 1987 : 27-28).

14. Il a été probablement lui aussi introduit par les missionnaires bouddhistes et se trouve encore dans les jardins des temples comme celui que j'ai vu dans un temple de Luang Prabang en avril 2011.

15. En effet il faut abattre l'arbre pour prendre à l'intérieur du tronc.

16. Cette ville de Carie, au sud-ouest de l'Asie Mineure, colonie de Lacédémone, bâtie moitié sur le continent moitié sur une île reliée à la terre par une chaussée, faisait un commerce considérable et possédait une flotte importante.

17. Le texte d'Agatharchide est connu par les extraits qu'en donnent Diodore de Sicile (III 46-47) et Photios qui concordent sur ce point, comme le fait remarquer M. Rodinson dans une note savante et claire de son excellent article (1984: 60 et $n$. 18).

18. Ce sont les commerçants hindous originaires du Gujerat (cf. le terme gujerati vâniya " homme de la caste des commerçants»). Nombre d'entre eux se sont installés dans les ports d'Arabie (Hobson Jobson, s. v.).

19. Cela semble être des navires à rames qui remorquaient les bateaux étrangers.

20. Je n'ai trouvé chez aucun historien confirmation de cet épisode.

21. Selon Bruce 1907, in Hornell (1946) $1970: 231$.

22. Needham \& Lu Gwei-Djen 1974, Science and civilization in China. V.2, Spagyrical Discovery and Invention: Magisteries of gold and immortality. Cambridge University Press, p. 143, in Bray 1987 : 194.

23. Exode 30, 23, Proverbes 7, 17, Cantique des Cantiques 4, 14.

24. Ceylan est mentionnée dès l'Antiquité ; le Périple de la mer Erythrée parle de Taprobanê, mais Ammien Marcelin (c. 362) cite Serendivia et Cosmas Indicopleustes (ca 545) écrit le nom de Siélédiba (qui viendrait du pâli Sihala dvîpa) que lui donnent les indigènes et Taprobane que lui donnent les Grecs (Hobson-Jobson s. v.).

25. Du vent hippalus, l'auteur du Périple de la mer Érythrée, ( $\mathrm{I}^{\mathrm{e}}-\mathrm{II}^{\mathrm{e}}$ siècle de notre ère), a fait un marin Hippalos, qui aurait découvert l'utilisation de la mousson. Ce que Grecs et Latins 
appelaient mer Erythrée était la partie occidentale de l'océan Indien à laquelle se rattachaient la mer Rouge et le golfe Persique.

26. Cette reine, soucieuse d'indépendance, envoya chercher des arbres à encens et à myrrhe qu'elle voulut acclimater en Égypte, sans succès semble-t-il. Cet épisode est relaté par les peintures et gravures sur son tombeau à Deir el Bahari, près de Louqsor.

27. Ce n'est pas la Perse qui a pu exercer une influence, car à cette époque, elle n'avait pas de marine, non plus que l'Arabie du sud qui ne connaissait que les radeaux et les bateaux en peaux, selon Agatharchide, comme nous l'avons vu plus haut. Mais une invention indépendante reste toujours possible.

28. La Carie, au sud-ouest de l'Asie Mineure, avait été colonisée par les Phéniciens, puis par les Grecs, et enfin par les Perses quand Cyrus conquit le pays entre 554 et 539 (Bouillet 1896). C'était une région encore couverte de forêts qui pouvaient fournir les arsenaux des Cariens. Agarthachide était aussi de cette région.

29. Cette ville de Carie, au sud-ouest de l'Asie Mineure, colonie de Lacédémone, bâtie moitié sur le continent moitié sur une île reliée à la terre par une chaussée, faisait un commerce considérable et possédait une flotte importante.

30. Abû-l-Fidâ, II, $2^{\text {ème }}$ partie : 96 in Ferrand 1913-1914.

31. Il y a de grands doutes sur ce personnage qui aurait raconté son voyage en Chine vers 851 et dont le texte s'intitule La relation de la Chine et de l'Inde que nous évoquerons à plusieurs reprises. S'il a existé, il ne fut peut-être qu'un des informateurs du rédacteur de La Relation.

32. Ce sont vraisemblablement des embarcations type coracle qufa de l'Iraq. Et sachant que ces populations étaient des éleveurs, l'on peut penser qu'ils utilisaient les peaux de leurs bovins pour fabriquer leurs bateaux.

33. Ce vent du nord en été s'explique par la situation particulière du golfe Persique dont nous avons parlé plus haut. En effet, dans la partie nord du Golfe, soufflent en été les vents du nord nord-est et ce n'est que dans la partie sud sud-ouest que se ressent la mousson du sud-ouest.

34. Sur l'origine et les sens du nom de Java. Marco Polo désignait par ce nom tout l'archipel indien et indonésien. Dans plusieurs langues de l'archipel, ce mot désigne l'île et le millet, et certains prétendent que l'île a reçu son nom de cette graine qu'y ont trouvé les premiers indiens qui y sont arrivés et que l'on suppose avoir été à la base de la nourriture des aborigènes. Dans ce cas, l'origine du mot serait persane et viendrait de jaw, une sorte de millet, orge mondée (Père Favre 1885, I : 530).

35. C'est aussi un lieu que l'on a pu identifier avec le Japon, les côtes de l'Afrique de l'est ou Madagascar. Voir la savante étude de G. Ferrand in Journal Asiatique 1907 (pp 433- 566) et 1932 (193-243)

36. Il y avait à Canton, au début du siècle, la mosquée du Saint Souvenir (Houei-chen-sseu) qui est un des monuments les plus anciens de la Chine et de loin le plus ancien que les Musulmans aient élevés en Chine (Ollone $1911: 383$ ).

37. Jackson 1967 - European power and south-east Africa. London, Routledge \& Kegan. In Datoo $1970: 6$.

38. D'Afrique surtout; on trouve de l'or natif dans les terrains cristallins anciens, alors que les terrains tertiaires n'en contiennent que peu ou pas. 


\section{RÉSUMÉS}

La mousson, c'est un mot arabe ayant une origine et une histoire propre. Ce sont aussi des vents et des courants marins qui vont de l'océan Indien aux mers de Chine et du Japon. C'est une zone de mouvements intenses mettant en contact des populations très diverses.

La mousson a facilité depuis fort longtemps les voyages est - ouest (Chine vers Asie du sud-est et Inde) et ouest-est (Arabie vers Inde, Asie du sud-est et Chine), voyages qui donnent accès aux îles et presqu'îles de l'Asie du sud-est riches en épices. Par contre, la mousson contraint les marins à s'accommoder de son calendrier très particulier, car elle pousse alternativement et annuellement les bateaux d'ouest en est et d'est en ouest.

Le cadre culturel de l'article est centré sur le monde arabo-musulman des $\mathrm{IX}^{\mathrm{e}}-\mathrm{XVII}{ }^{\mathrm{e}}, \mathrm{XVIII}^{\mathrm{e}}$ siècles avec des regards sur les autres cultures (bateaux, voyages, voyageurs, produits).

On évoquera l'action de la mousson sur les terres et l'adaptation des agriculteurs aux pluies, mais aussi les bonnes et mauvaises conséquences de ces pluies dans les sociétés.

On évoquera aussi les grandes étapes du commerce (chinois, indien, arabe, persan, puis portugais, anglais et français), quelques grands voyageurs orientaux et occidentaux et ce qu'ils visaient.

Cette route des moussons a été certes pour les Européens une alternative à la route intérieure dite de la soie. Mais cette zone, liée à a quête des épices, a été en même temps le point de départ des grandes explorations et donc de la conquête du monde.

The monsoon is an arabic word (with its proper origin and history), which designates as well as winds, as marine streams, which go from indian Ocean to the china and japanese sea. That large zone of intense movements putt in contacts very diverse populations.

The monsoon facilitated since a very long time the travels from east to west (China to India and persian gulf) and from west to east (South Arabia to Indonesia and China), travels which gave access to the islands and peninsulas of India and southeast Asia, rich in spices and fine products. But monsoon obliges the travelers to accomodate to its very particular annual calendars: it directs the boats alternatively from west to east and from east to west.

The cultural frame of the paper focalizes the arabo-muslim world of the 8th-16th, 18th centuries, with glimpses on the other cultures (in term of boats, travels, travelers, products).

We shall evocate the action of the monsoon on the land and the adaptation of the small farmers to those rains, but also the good and bad consequences of those rains for the societies.

We also shall evocate the steps of the trade (chinese, indian, arabic, persian, then portuguese, english and french), some great oriental and occidental travelers, their aims.

For the Europeans in the Indian Ocean, that monsoon route has been first the alternative to the inside asiatic route, the silk route. But overall, the monsoon route merges into the discovery of the world. That large zone, linked to the search of the spices, is the starting point of great explorations, and world tours, therefore of the world conquest. 